\title{
Engaging parents to promote girls' transition to secondary education: Evidence from a cluster randomised trial in rural Gujarat, India
}

K.G. Santhya

Population Council

A.J. Francis Zavier

Population Council

Pallavi Patel

Neeta Shah

Follow this and additional works at: https://knowledgecommons.popcouncil.org/departments_sbsr-pgy

Part of the Demography, Population, and Ecology Commons, Family, Life Course, and Society Commons, Gender and Sexuality Commons, Gender Equity in Education Commons, and the International Public Health Commons

How does access to this work benefit you? Let us know!

\section{Recommended Citation}

Santhya, K.G., A.J. Francis Zavier, Pallavi Patel, and Neeta Shah. 2016. "Engaging parents to promote girls' transition to secondary education: Evidence from a cluster randomised trial in rural Gujarat, India." New Delhi: Population Council. 

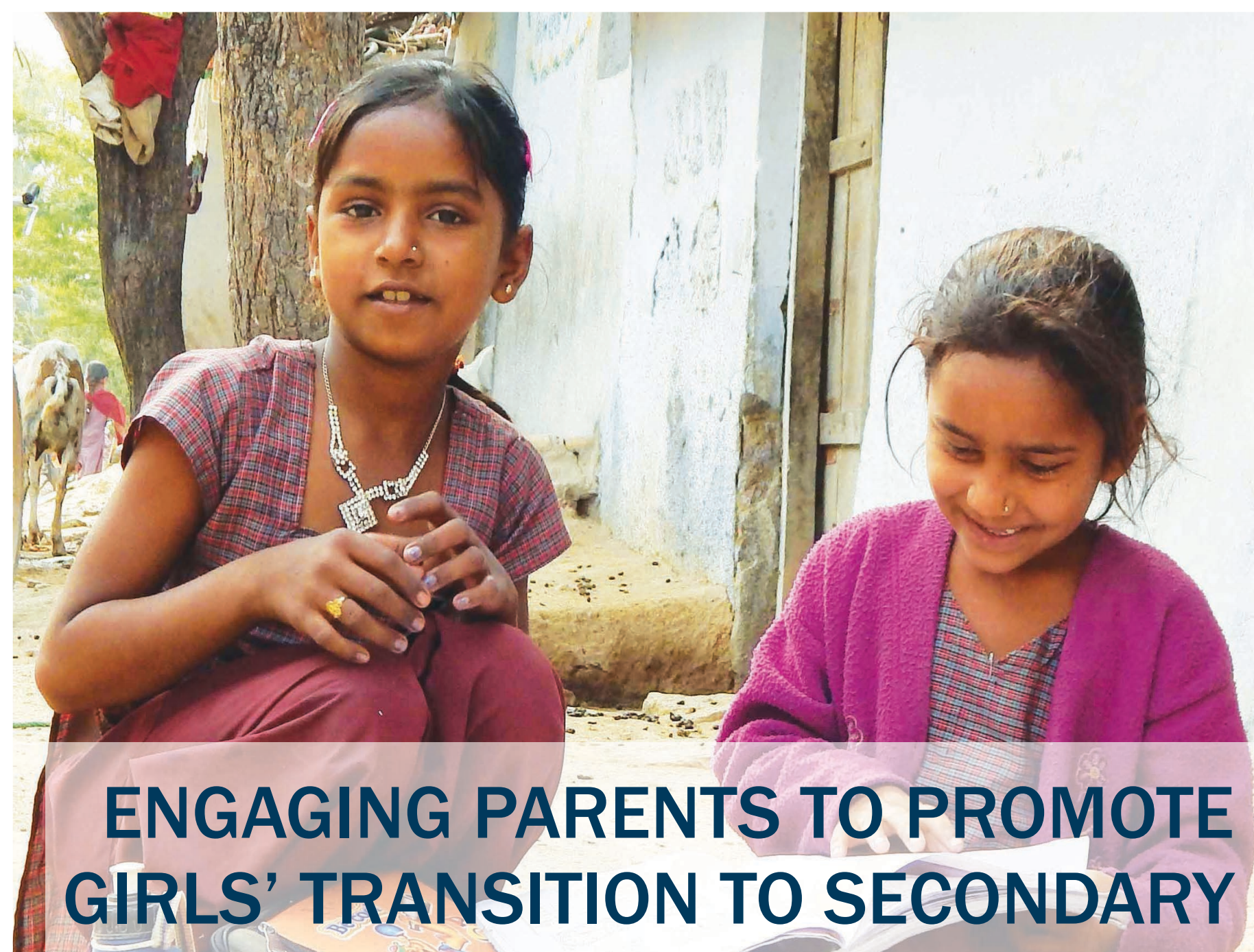
EDUCATION: EVIDENCE FROM A CLUSTER RANDOMISED TRIAL IN RURAL GUJARAT, INDIA

$\stackrel{0}{1}$
$\stackrel{N}{0}$
$\stackrel{\Xi}{\Xi}$

KG Santhya AJ Francis Zavier Pallavi Patel Neeta Shah

\section{POPULATION} COUNCIL

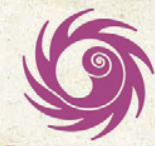

CHETNA

4. For Women Young people Children 


\section{P Population COUNCIL \\ Ideas. Evidence. Impact.}

The Population Council confronts critical health and development issues-from stopping the spread of HIV to improving reproductive health and ensuring that young people lead full and productive lives. Through biomedical, social science, and public health research in 50 countries, we work with our partners to deliver solutions that lead to more effective policies, programs, and technologies that improve lives around the world. Established in 1952 and headquartered in New York, the Council is a nongovernmental, nonprofit organization governed by an international board of trustees.

\section{Population Council}

Zone 5A, Ground Floor

India Habitat Centre, Lodi Road

New Delhi, India 110003

Phone: +91-11-2464 2901

Email: info.india@popcouncil.org

Website: www.popcouncil.org

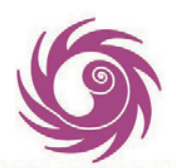

CHETNA

For Women Young people Children

Center for Health, Education, Training and Nutrition (CHETNA) as a resource organisation contributes towards empowering children young people and women especially from marginalized social groups to take control of their own their families' and communities' health.

\section{CHETNA}

Supath-II, B-Block, 3rd Floor, Opp. Vadaj Bus Terminus

Ashram Road, Vadaj

Ahmedabad-380013.

Phone: 91-079-27559976/77

Email: chetna456@gmail.com

Website: www.chetnaindia.org

Suggested Citation: Santhya, K. G., A. J. Francis Zavier, P. Patel et al. 2016. Engaging parents to promote girls' transition to secondary education: Evidence from a cluster randomised trial in Rural Gujarat, India. New Delhi: Population Council. 


\section{ENGAGING PARENTS TO PROMOTE GIRLS' TRANSITION TO SECONDARY EDUCATION: EVIDENCE FROM A CLUSTER RANDOMISED TRIAL IN RURAL GUJARAT, INDIA}

KG Santhya AJ Francis Zavier Pallavi Patel Neeta Shah 


\section{Table of Contents}

List of Tables

List of Figures $\quad$ vii

Acknowledgements

Executive summary

Chapter 1 Introduction 1

Chapter 2 Profile of girls' school experiences at baseline 12

Chapter 3 Project Sankalp 21

Chapter 4 Girls' awareness and experiences of Project Sankalp 34

Chapter 5 Effect of Project Sankalp on creating an enabling environment for girls to pursue secondary education

Chapter 6 Effect of Project Sankalp on girls' transition to secondary education, school attendance, and competency

Chapter 7 Summary and conclusions 47

$\begin{array}{ll}\text { References } & 49\end{array}$

Appendix 1: Selected characteristics of clusters in the intervention and control arms 51

Appendix 2: Details of the household wealth index 52

Appendix 3: Indicators of community engagement by treatment arms, endline survey 53

\begin{tabular}{ll} 
Authors & 54 \\
\hline
\end{tabular}

List of Investigators $\quad 55$ 


\section{List of Tables}

Table 1.1: Selected characteristics of the study district and state

Table 1.2: Follow-up rate of study participants and reasons for loss to follow up at endline by treatment arms

Table 2.1: Selected background characteristics of girls who participated in the baseline survey by treatment arms, 2013

Table 3.1: Stakeholders targeted by Project Sankalp and the strategies used to reach out to them

Table 3.2: Activities carried out by project staff for capacity building of SMCs and by SMC members to reach out to selected target groups, project monitoring data

Table 3.3: Activities carried out by project staff for capacity building of AGGs and by AGG members to reach out to selected target groups, project monitoring data

Table 3.4: Percent distribution of calls made to relay generic messages by the status of the recipient and the audibility of the message received, project monitoring data

Table 3.5: Percent distribution of calls received by the IVRS host system by the status of the caller and the action taken by the caller, project monitoring data

Table 3.6: Percent distribution of calls made to relay feedback messages by the status of the recipient and the audibility of the message received, project monitoring data

Table 3.7: Percentage of parents, SMC members and teachers who were reached through the IVRS, project monitoring data

Table 3.8: Average number of adolescent girls, their parents, SMC members and teachers with whom project staff interacted in a month, project monitoring data

Table 4.1: Percentage of girls reporting awareness of and participation in AGG activities, intervention arm, endline survey, 2014-15

Table 4.2: Percentage of girls reporting awareness of and experiences with the IVRS, intervention arm, endline survey, 2014-15

Table 4.3: Percentage of girls reporting awareness of and participation in project activities to promote girls' secondary education, intervention arm, endline survey, 2014-15

Table 4.4: Percentage of girls reporting their own and their parents' interactions with Project Sankalp staff in the year preceding the interview, intervention arm, endline survey, 2014-15

Table 4.5: Percentage of girls reporting changes perceived in teachers' and parents' practices with regard to their schooling during the inter-survey period, by treatment arms, endline survey, 2014-15 
Table 6.1: Comparison of cluster summaries with overall means for selected outcome indicators by treatment arms, endline survey, 2014-15

Table 6.2: Estimated intervention effect on transition rates, endline survey, 2014-15

Table 6.3: Estimated intervention effect on attendance at school, endline survey, 2014-15

Table 6.4: Estimated intervention effect on learning outcomes, endline survey, 2014-15 


\section{List of Figures}

Figure 1.1: Theoretical framework underpinning project Sankalp

Figure 1.2: Flow diagram showing the number of girls interviewed, number of girls assigned to treatment arms and number of girls lost to follow up

Figure 2.1: Transition rates of girls to Class 9 and Class 10 by treatment arms, baseline survey, 2013

Figure 2.2: Percentage of girls reporting attendance at school by treatment arms, baseline survey, 2013

Figure 2.3: Standardised scores obtained by girls in competency tests by treatment arms, baseline survey, 2013

Figure 2.4: Percentage of girls reporting their educational aspirations and agency in matters related to their schooling by treatment arms, baseline survey, 2013

Figure 2.5: Percentage of girls reporting in-depth awareness and utilisation of scholarships from school by treatment arms, baseline survey, 2013

Figure 2.6: Average number of hours spent on school-related activities on the last school day by treatment arms, baseline survey, 2013

Figure 2.7: Percentage of girls reporting teacher attendance, attitudes and practices during the week preceding the interview by treatment arms, baseline survey, 2013

Figure 2.8: Percentage of girls reporting parental aspirations for their secondary education, and discussion with and time spent by parents in supporting their education during the week preceding the interview, by treatment arms, baseline survey, 2013

Figure 2.9: Percentage of girls reporting parental interaction with school authorities in the month preceding the interview by treatment arms, baseline survey, 2013

Figure 2.10: Percentage of girls reporting awareness of SMCs and perceptions about engagement of Panchayat members in promoting girls' education by treatment arms, baseline survey, 2013

Figure 3.1: Percent distribution of calls generated by the IVRS by the type of call, project monitoring data

Figure 5.1: Percentage of girls reporting their educational aspirations and agency in matters related to their schooling by treatment arms, endline survey, 2014-15

Figure 5.2: Percentage of girls reporting in-depth awareness and utilisation of scholarships, by treatment arms endline survey, 2014-15

Figure 5.3: Average number of hours spent on school-related activities by treatment arms, endline survey, 2014-15 
Figure 5.4: Percentage of girls reporting teacher attendance, and teachers' attitudes and practices in the week preceding the interview by treatment arms, endline survey, 2014-15

Figure 5.5: Percentage of girls reporting parental support for their studies in the week preceding the interview by treatment arms, endline survey, 2014-15

Figure 5.6: Percentage of girls reporting parental interaction with school authorities in the month preceding the interview by treatment arms, endline survey, 2014-15

Figure 5.7: Percentage of girls reporting awareness and engagement of SMCs in their schooling by treatment arms, endline survey, 2014-15

Figure 5.8: Percentage of girls reporting their perceptions about the involvement of Panchayat members in matters concerning girls' schooling by treatment arms, endline survey, 2014-15 


\title{
Acknowledgements
}

This study has benefitted immeasurably from the inputs of many. We are extremely grateful to the John D. and Catherine T. MacArthur Foundation and the Human Dignity Foundation for their financial support which made this study possible. In particular, we are grateful to Dipa Nag Chowdhury, John D. and Catherine T. MacArthur Foundation, and Kasia Pilat, Human Dignity Foundation, for their support, guidance and inputs throughout the course of this study.

We could not have successfully completed this study without the support of the Education Department, Government of Gujarat. We would like to acknowledge with gratitude the support that we received from Shri J. G. Pandya, former District Education Officer, and Shri P. S. Parghi, former District Primary Education Officer, Surendranagar District, Gujarat. We would also like to acknowledge the contribution of various officials of the Education Department at the block level in Surendranagar District, and the principals and teachers of the primary and secondary schools in the villages in which the study was conducted.

We are grateful to Leela Visaria, Honorary Professor, Gujarat Institute of Development Research, Ahmedabad, for her support and guidance throughout the course of this study. We are also grateful to the staff of Navjeevan Trust who partnered with CHETNA in implementing intervention activities; Ravindra Pawar, Chandrakant Solanki, Manishaben Pancholi, Rahulbhai Vala, Pravinbhai Talavdia, Khodabhai Rangpara, Vidhyadhar Solanki, Ranjitbhai Parmar, Virendrabhai Solanki, Usha Solanki, Bhageshree Rathod and Manisha Solanki contributed immensely to the successful completion of this study. Our sincere thanks goes to R.Venkat Reddy and other colleagues at the MV Foundation for their guidance in designing the intervention and support in conducting training workshops for the project team and for members of the school management committees as part of the study, and to Bhaumik Shah and other colleagues at Awaaz.De for their support in designing and managing the interactive voice response system utilised for the study. The contributions of Sapna Desai in analysing the evaluation data are greatly appreciated.

At the Population Council, several colleagues have supported us in both the technical and administrative aspects of this study. A special thanks goes to Shireen Jejeebhoy for her collegial support, mentoring and guidance at every stage of this study. We are grateful to Barbara Mensch, Cynthia B. Lloyd and Rajib Acharya for their contributions in designing the intervention and the study protocol, and to Barbara Mensch, Cynthia B. Lloyd and Shireen Jejeebhoy for reviewing an earlier draft of this report and giving valuable comments and suggestions. We would also like to thank M.A. Jose for ably managing the administrative aspects of the project, Shilpi Rampal for her support with data management and Komal Saxena for efficiently coordinating the printing of the report. We would like to thank Jyoti Moodbidri and Komal Saxena for their editorial contributions. We also appreciate the efforts of our investigators who painstakingly collected the data.

At CHETNA too, several colleagues have supported the study; we are grateful to Bhanu Makwana and Antara Trivedi for the support provided to us.

Finally, and most importantly, we would like to thank the adolescent girls who generously gave us their time and shared their views and experiences with us.

\author{
K G Santhya \\ A J Francis Zavier \\ Population Council, New Delhi \\ Pallavi Patel \\ Neeta Shah \\ CHETNA, Ahmedabad
}




\section{Executive summary}

In India, just 42 percent of women aged 18-24 had completed Class 10, the final year of (lower) secondary school, in 2011. Moreover, learning levels among those who had transitioned to secondary education continued to be poor. Although attention has increasingly been paid towards enabling adolescents to transition to and successfully complete secondary education (for example, the launching of Rashtriya Madhyamik Shiksha Abhiyan, a scheme for the universalisation of secondary education in 2009, and Beti Bachao Beti Padhao, a nation wide campaign encouraging people to celebrate and educate the girl child, in 2015, there is an imperative need to build evidence about innovative interventions to promote secondary education among adolescent girls, including models that engage parents and communities in girls' secondary education.

The Population Council, in partnership with CHETNA, MV Foundation, Awaaz.De and Navjeevan Trust, and with the support of the Human Dignity Foundation and the John D. and Catherine T. MacArthur Foundation, implemented a pilot intervention-Project Sankalp-to assess the acceptability and feasibility of engaging parents and communities to promote girls' secondary education, and measure its effectiveness in improving adolescent girls' transition to secondary education, their attendance at school and learning outcomes in Mathematics, and the English and Gujarati languages. Project Sankalp was implemented over a period of 15 months among girls attending Class 8 and Class 9, their parents, School Management Committee (SMC) members and teachers of primary and secondary schools in 45 villages of Surendranagar district, in the state of Gujarat. The key strategies adopted by Project Sankalp included: revitalising SMCs and supporting them to implement villagewide campaigns advocating secondary education for girls; forming Adolescent Girls' Groups (AGGs) and supporting them to undertake girl-to-girl campaigns, girl-to-parents campaigns and villagewide campaigns on girls' secondary education; launching an Interactive Voice Response System (IVRS) for relaying messages on the importance of secondary education for girls as also for providing parents, other community members and teachers an opportunity to voice their concerns about the subject; and disseminating informational materials related to girls' secondary education. In addition, over the course of Project Sankalp, its staff made continuous efforts to reach out to its target groups through opportunistic individual interactions and two villagewide campaigns.

We used a cluster randomised trial, with nine clusters each in the intervention and control arms, to evaluate Project Sankalp. The baseline assessment comprised a household census and a survey of all the girls attending Class 8 and Class 9 , in the 90 villages comprising the 18 clusters. A total of 1,568 girls were identified and invited for an interview conducted at baseline, and 99 percent of them were successfully interviewed. We held the endline assessment, comprising a household census and a follow-up survey of the girls who had participated in the baseline survey, one to two months after concluding the activities of our 15-month-long pilot intervention. At endline, 97 percent of the baseline respondents were successfully interviewed. Statistical analyses of the intervention effect were performed using Stata 11. Effect estimates were computed as the difference in cluster-level proportions or means, as appropriate. Analysis was by intention to treat. We compared unadjusted cluster-level summary measures across treatment arms using an unpaired $t$-test for the main outcomes. For outcomes that showed evidence of an intervention effect, we applied a t-test with unequal variances to check whether precision had improved.

Findings indicate that girls in the intervention arm were well aware of the activities of Project Sankalp: almost all the girls had heard about the project in general, four-fifths had heard about the AGGs and IVRS, and two-thirds had heard about the villagewide campaigns to promote girls' secondary education. Girls enrolled in the intervention arm also showed appreciable engagement in the activities of Project Sankalp. About one-half of the girls were members of an AGG and, of them, almost two-fifths had retained their membership at the time of the endline survey. Three-fifths had encouraged their parents and others to use the IVRS and one-eighth had used it, through their parents or others in the family, to report a problem. Besides, between one-third and two-fifths of the girls had joined girl-to-girl campaigns and girl-to-parents campaigns, and no less than one-half had participated in a villagewide campaign to promote girls' secondary education. Finally, a majority of the girls recalled their own as well as their parents' interactions with project staff.

The effect of Project Sankalp on creating an enabling environment for girls to pursue secondary education was mixed. On the positive side, the project had showed success in raising girls' educational aspirations; in improving parental support for their secondary education as measured by parental discussion with the daughter on her studies 
and parental interaction with her school authorities; and raising girls' awareness of SMCs. When we restricted the analysis to girls who were enrolled in school at the time of the endline survey, findings showed that the project was successful in increasing SMC members' interaction with school authorities and their involvement in resolving barriers to girls' secondary education; for example, those related to transportation. Girls' perceptions about the involvement of the Panchayat in matters concerning their education also improved. However, there was no evidence of any effect on their agency in matters related to their schooling, their awareness and utilisation of the entitlements obtainable from school, the time devoted by them to school-related activities, the time spent by parents in supporting their education, teacher absenteeism and classroom dynamics.

Findings also show that Project Sankalp did not produce any positive and significant effect on girls' transition to secondary education and their learning outcomes in Mathematics and English. At the same time, there was evidence of some effect on improving girls' attendance at school and learning outcomes in Gujarati, although the effect was statistically mildly significant.

Some key lessons are evident. Findings that there was no evidence of any effect on girls' agency in matters concerning their schooling, their awareness and utilisation of the benefits available from school, and the time committed to school-related activities as well as on the time spent by their parents in supporting their daughter's education underscore the need for a longer-term engagement with girls and their parents than was possible in Project Sankalp, or for more intensive efforts that will enable girls to make effective use of the knowledge and skills they gain through a pilot intervention such as Project Sankalp and, at the same time, give parents more time to translate the messages they receive from the project into real life practices.

The absence of an effect on transition rates and learning outcomes in Mathematics and English (two of the three subjects tested), suggests that pursuing and successfully completing their secondary education with the basic competencies expected of a secondary school graduate, call for an enabling environment at the school level as well. Given that the project had no effect on teacher absenteeism and classroom dynamics, factors that are more likely to influence girls' transition to secondary education and learning outcomes, our findings further underscore the need for complementing a demand-side model like protect Sankalp with supply-side interventions that focus more directly on teachers and school infrastructure. 


\section{Chapter 1 Introduction}

In India, attention has increasingly been paid to enable adolescent girls to transition to and successfully complete secondary education. For example, the Rashtriya Madhyamik Shiksha Abhiyan (a scheme for the universalisation of secondary education), launched in 2009, seeks to provide universal access to secondary education by 2017 , enhance and universalise retention by 2020 and improve the quality of education imparted at the secondary level by making all secondary schools conform to prescribed guidelines (Ministry of Human Resource Development, 2009). Likewise, the recently launched Beti Bachao Beti Padhao campaign (a nationwide campaign exhorting people to celebrate the girl child and educate her) has set the increase in girls' enrollment in secondary classes as one of the targets to monitor the success of the campaign (Ministry of Women and Child Development, 2015). While these initiatives are commendable, it is too early to observe their impact. Moreover, with a net enrollment ratio of 46 in Class 9 to Class 10 for girls in 2013-14 (National University of Educational Planning and Administration, Ministry of Human Resource Development, 2014), the country has a long way to go to achieve universal secondary education for its girls. Therefore, testing innovative practices to promote secondary education among girls is clearly needed.

With this background, the Population Council, in partnership with CHETNA, MV Foundation, Awaaz.De and Navjeevan Trust, and with the support of the Human Dignity Foundation and the John D. and Catherine T. MacArthur Foundation, initiated a pilot intervention-Project Sankalp to promote girls' secondary education. Project Sankalp aimed to support adolescent girls' transition to and retention in secondary school, and to improve their learning outcomes by building parental and community engagement in and accountability for secondary education. It was designed to respond to key gaps in programmes for achieving universal secondary education in the country namely, the lack of evidence on best and innovative practices to promote secondary education as well as of effective models for community mobilisation to support adolescent girls' secondary education. This report describes Project Sankalp and its implementation, and examines the extent to which this pilot intervention improved adolescent girls' transition to secondary education, their school attendance and their learning outcomes.

\section{Background and rationale}

In India, the most recent official educational statistics (2013-14) indicate a Net Enrollment Ratio (NER) of 73 for girls in Class 6 to Class 8, but a much lower NER (46) in Class 9 to Class 10 (National University of Educational Planning and Administration, Ministry of Human Resource Development, 2014). Moreover, 2011 census data show that 42 percent of women aged 18-24 had completed Class 10, the final year of (lower) secondary school, compared to 49 percent of similarly-aged men (Office of the Registrar General and Census Commissioner, India, 2015). These data underscore the sluggish progress in enabling adolescent girls to successfully complete secondary education.

Equally concerning is evidence from recent studies in India which highlights the poor learning levels among both girls and boys transitioning to secondary education (ASER Centre, 2015; Educational Initiatives, 2010; National Council of Educational Research and Training, 2012). For example, a nationwide study of students in rural areas, conducted in 2014, shows that 25 percent of Class 8 students could not read Class 2 text in their local language, 66 percent could not correctly do a three-digit by one-digit division problem, and 53 percent could not read simple sentences in English (ASER Centre, 2015). Yet another pan-India study, conducted among students in rural and urban schools across 18 states in 2009, notes that although performance in languages and Mathematics improved as students moved from Class 4 to Class 6 to Class 8, the extent of improvement was often not as large as one would expect, and most Class 8 students lacked the competencies that they should have acquired in lower classes (Educational Initiatives, 2010).

There are many reasons for the low levels of progression to and completion of secondary education as well as poor learning outcomes among adolescents. Data from the 2005-06 National Fertility and Health Survey-3 indicate that, of adolescents aged 14-17 who had discontinued schooling after completing Class 8, 15 percent of girls and seven percent of boys were withdrawn from school to take care of household responsibilities and six percent of girls and 18 
percent of boys were withdrawn to work on the family farm or business or to work for pay. ${ }^{1}$ Although primary education is free and secondary education is almost free ${ }^{2}$ in government and government-aided schools in India, some 18-19 percent of both girls and boys were withdrawn from school because their families were unable to afford the cost of schooling. Studies have noted that parental perceptions of the returns to education differ for sons and daughters and may be major drivers behind gender disparities in parental investment in their children's education. A study of parents of youth in six states in India indicates that parents recognised the need for a secondary or college education to enhance their son's earning prospects, but perceived that sociocultural factors would inhibit their daughters, if equally educated, from enhancing their earning prospects (Santhya and Jejeebhoy, 2012).

The fact that a sizeable proportion of students may be first-generation learners compounds their risk of discontinuation. Findings from a study of youth in six Indian states show that 25-26 percent of girls and boys aged 14-17 were firstgeneration learners and discontinuation after Class 8 was four times as high among girls whose mother and father had never attended school as among those whose parents had attended school (79\% versus 21\%); the corresponding percentages among boys were 70 and 31 (International Institute for Population Sciences and Population Council, 2010). Illiterate parents may not be able to negotiate the educational system to enrol their children in secondary schools or to ensure that their children receive quality education once enrolled; at the same time, the conditions prevailing in their home may not instil the importance of regular school attendance or the need for attentiveness in the classroom.

School- and curriculum-related factors such as lack of interest in studies, unfriendly atmosphere in schools, doubts about the usefulness of schooling, inability to cope with studies and academic failure are equally important reasons for discontinuation, and such reasons as lack of perceived relevance and lack of interest may also reflect the limited value placed on education in many households. In India, among adolescents aged 14-17 who had discontinued schooling after completing Class 8, 32 percent and 47 percent of girls and boys, respectively, had done so due to academic failure, lack of interest in studies and perceived irrelevance of further education. Concerns related to physical access have also been found to compromise the transition to secondary school, particularly among girls, because only two percent of primary school facilities in the country offer post-primary grades. As a result, almost all children have to transfer to a different school facility, most likely at a distance from home, to attend Class 9 and Class 10 (Mehta, 2014).

These findings clearly emphasise the importance of mobilising communities, especially parents, to encourage girls to transition to and successfully complete secondary education. Theories of educational change based on research conducted in both developed and developing countries have identified increased access to schools; effective accountability mechanisms; improved learning environment; curricular relevance and creation of facilitating conditions, including parental and community engagement, as critical for enabling educational transitions and improving academic performance, particularly among girls (Barrera-Osorio et al., 2009; Bruns, Filmer and Patrinos, 2011; Connell and Klem, 2000; Dhaliwal et al., 2011; Haynes, Comer and Hamilton-Lee, 1989a; 1989b; Jensen, 2010; Lloyd and Young, 2009; Nguyen, 2008). For example, a study conducted in the Dominican Republic found that providing Class 8 students with information on differences in earnings by years of schooling led to reduced dropout rates in the subsequent year and increased school completion four years later (Jensen, 2010). Another study in Madagascar found that providing information to Class 4 students and their parents about differences in earnings by educational level increased average attendance and test scores (Nguyen, 2008). Moreover, recent evidence from a comparative cost-effectiveness analysis of eleven programmes to improve school attendance in developing countries found that raising awareness among parents on returns to education was more cost-effective in terms of additional years of student participation per dollar spent than other interventions such as de-worming, free uniforms, monitoring of teachers' attendance, computer-assisted learning curriculum, remedial tutoring and conditional cash transfers (Dhaliwal et al., 2011). A review of the evidence on intervention strategies supporting the education of adolescent girls in developing countries observes that various demand-side strategies such as school transportation, the provision of boarding facilities, safety policies, training and advocacy, and the promotion of community engagement hold promise but are unproven; scholarships and stipends though have been proved to be successful (Lloyd and Young, 2009).

\footnotetext{
${ }_{1}^{1}$ Calculated using NFHS-3 survey data available at www.measuredhs.com

2 Students are expected to pay only a negligible amount as the school fee; schemes to provide text books and uniforms free of cost are implemented in several states.
} 
Yet, relatively little is known about how existing theoretical frameworks translate into action that improves the transition to and completion of secondary education, particularly for vulnerable groups. In India, while interventions incorporating one or more of the promising demand-side approaches mentioned above have been implemented to facilitate the completion of primary education, theoretically-grounded interventions focusing on the transition to secondary education are limited. Indeed, the Working Group on Secondary and Vocational Education for the XIIth Five Year Plan in India observed that an underlying issue for the inadequate progress in enabling adolescents to complete secondary school was the limited evidence on best and innovative practices to promote secondary education (Ministry of Human Resource Development, 2011).

Moreover, while a number of intervention models have attempted to engage parents and communities to promote primary education in India (Banerjee et al., 2006; 2010; Pandey, Goyal and Sundararaman, 2009), efforts to engage them in enabling adolescent girls to transition to secondary education are lacking. Indeed, the Working Group on Secondary and Vocational Education for the XIIth Five Year Plan reported that the lack of adequate community mobilisation activities has been a major impediment to the success of schemes intended to promote girls' secondary education (Ministry of Human Resource Development, 2011).

At the same time, the policy and programme environment is conducive for testing models to promote parental and community engagement and accountability in secondary education of girls. For example, as noted earlier, the Government of India has placed considerable emphasis on achieving universal secondary education (see the Rashtriya Madhyamik Shiksha Abhiyan, Beti Bachao Beti Padhao campaign etc.). The Rashtriya Madhyamik Shiksha Abhiyan, moreover, has called for the involvement of local self-government bodies, communities, teachers, parents and other stakeholders in the management of secondary education, through bodies such as School Management Committees (SMCs) and parent-teacher associations (Ministry of Human Resource Development, 2009). The First Joint Review Mission of the Rashtriya Madhyamik Shiksha Abhiyan also observed that strategies were needed to help students to significantly improve their basic skills, especially in Class 9, and these may include additional or remedial classes, specific learning materials, and parental engagement (Ministry of Human Resource Development, 2013). Therefore, it is imperative that evidence is generated about models that can engage parents and communities in girls' secondary education and the extent to which such models are effective and feasible.

\section{Objective}

The objective of this study was to assess the feasibility and acceptability of the pilot intervention, Project Sankalp, and its impact on increasing girls' transition to secondary school, improving the regularity of their attendance at school, and enhancing learning outcomes in Mathematics, and the English and Gujarati languages.

\section{Theory of change underpinning Project Sankalp}

Project Sankalp primarily targeted girls attending Class 8 and Class 9, their parents, the members of School Management Committees (SMCs) and community members in general and, in a limited way, teachers of primary and secondary schools in the intervention villages. A number of strategies were adopted to reach out to these groups. The main strategies through which the project sought to engage parents and communities in promoting girls' secondary education comprised: (1) the revitalisation of SMCs by organising training workshops for SMC members, and by project staff meeting them on a monthly basis, and supporting them to take up campaigns advocating girls' secondary education; (2) the formation of Adolescent Girls' Groups (AGGs) in each intervention village, training them to act as change agents by organising training workshops for them, and by project staff meeting them on a fortnightly to monthly basis, and supporting them to undertake girl-to-girl campaigns, girl-to-parents campaigns and villagewide campaigns to promote girls' secondary education; (3) the launching of an Interactive Voice Response System (IVRS) to relay messages on the importance of secondary education for girls as well as to provide a platform to parents, other community members and teachers a platform to voice their concerns regarding the subject; (4) the dissemination of informational materials related to girls' secondary education; and (5) opportunistic individual interactions between project staff and target groups, and villagewide campaigns organised by project staff twice over the course of the project.

Figure 1.1 describes the theory of change underpinning Project Sankalp. It describes the ways in which the strategies adopted by the project (Block D) were envisaged to lead to the key outcomes that it sought to achieve 
namely, increased transition of adolescent girls to secondary school, their regular school attendance and improved learning outcomes (Block A). We hypothesise that in the intervention villages, the strategies will lead to informed and empowered parents, and empowered SMCs and communities in general; increased interaction among the girls, their parents, SMC members, communities and schools; and greater participation of parents and SMC members in ensuring accountability for girls' education (Block C).

These processes will contribute to the critical success factors, described in Block B, for achieving the key outcomes (Block A). Specifically, we hypothesise that change in these key educational outcomes for girls requires changes at three levels-at the individual girl level, parent level and school level. At the individual girl level, the factors that will lead to the key outcomes may include increased appreciation of secondary schooling, improved awareness of the entitlements obtainable from school, increased sense of agency in matters related to schooling and increased time devoted to school-related activities. At the parental level, these factors will include increased appreciation of secondary schooling and academic achievements of daughters, increased attention to the daughter's studies, and increased awareness of the entitlements that can be accessed from school and their utilisation, thereby, lessening the cost of education. Finally, at the school level, the success factors will include an improved learning atmosphere; reduced social distance between parents and students, on the one hand, and teachers on the other; increased utilisation of available funds for school improvement; and a hassle-free transfer to a secondary school.

We hypothesise that the intervention can make an impact on improving learning outcomes among girls through several pathways. First, we hypothesise that increased appreciation of secondary schooling by girls as a result of project activities will lead to regular school attendance and increased efforts to perform well in class which, in turn, will improve learning outcomes. Second, empowered parents will create an improved atmosphere for learning at home, including encouraging their children to do their homework, freeing them from household chores to engage in schoolwork, and demonstrating that the family values schooling and academic achievement, all of which can contribute to improved learning outcomes. Third, greater parental and community engagement in school activities will lead to responses at the school level, including an improved atmosphere for learning in the school, reduced teacher absenteeism, better classroom dynamics and greater interaction between teachers and adolescent girls, which again can contribute to improved learning outcomes. We note that Project Sankalp is a demand-side model and recognise that supply-side factors will also affect project outcomes.

\section{Study setting}

The study was conducted in the rural areas of Surendranagar district in Gujarat state. Gujarat, the tenth largest among the 30 states of India, has a population of 60 million of which 20 percent are adolescents aged 10-19 years (Office of the Registrar General and Census Commissioner, India, 2013; 2014a). Its population continues to be characterised by population and child sex ratios unfavourable to females (overall sex ratio of 919 and child sex ratio of 890 in 2011; Office of the Registrar General and Census Commissioner, India, 2013). A substantial proportion of households in the state belong to socially excluded castes, namely, scheduled castes and tribes (22\%; Office of the Registrar General and Census Commissioner, India, 2013). Gujarat is among the most economically progressive states in the country. It ranked fifth among the states of India in terms of gross state domestic product and in 2012-13, it accounted for eight percent of the national GDP (Planning Commission, 2014); even so, 17 percent of its population was estimated to live below the poverty line in 2011-12 (Planning Commission, 2013). In 2011, the overall literacy rate was 78 percent in Gujarat, compared to 73 percent nationally (Office of the Registrar General and Census Commissioner, India, 2013); gender differences were, however, considerable: 86 percent of males, compared to 70 percent of females, were literate. Two-thirds (69\%) of the state's households had access to a mobile or landline phone (Office of the Registrar General and Census Commissioner, India, 2012).

Access to primary education (Class 1 to Class 8) is more or less universal and most children aged 6-14 years are enrolled in school in Gujarat as elsewhere in India. A 2014 survey reports that in rural Gujarat, only three percent of girls and boys aged 6-14 years were not enrolled in school (ASER Centre, 2015). However, a substantial proportion of adolescents, considerably more girls than boys, do not progress to secondary school: 65 percent and 53 percent of adolescent boys and girls, respectively, were enrolled in secondary school (Class 9-Class 10) in 2011-12. The state has a gender parity index of 0.82 in Class 9-Class10, compared to 0.93 nationally (Ministry of Human Resource Development, 2014). 

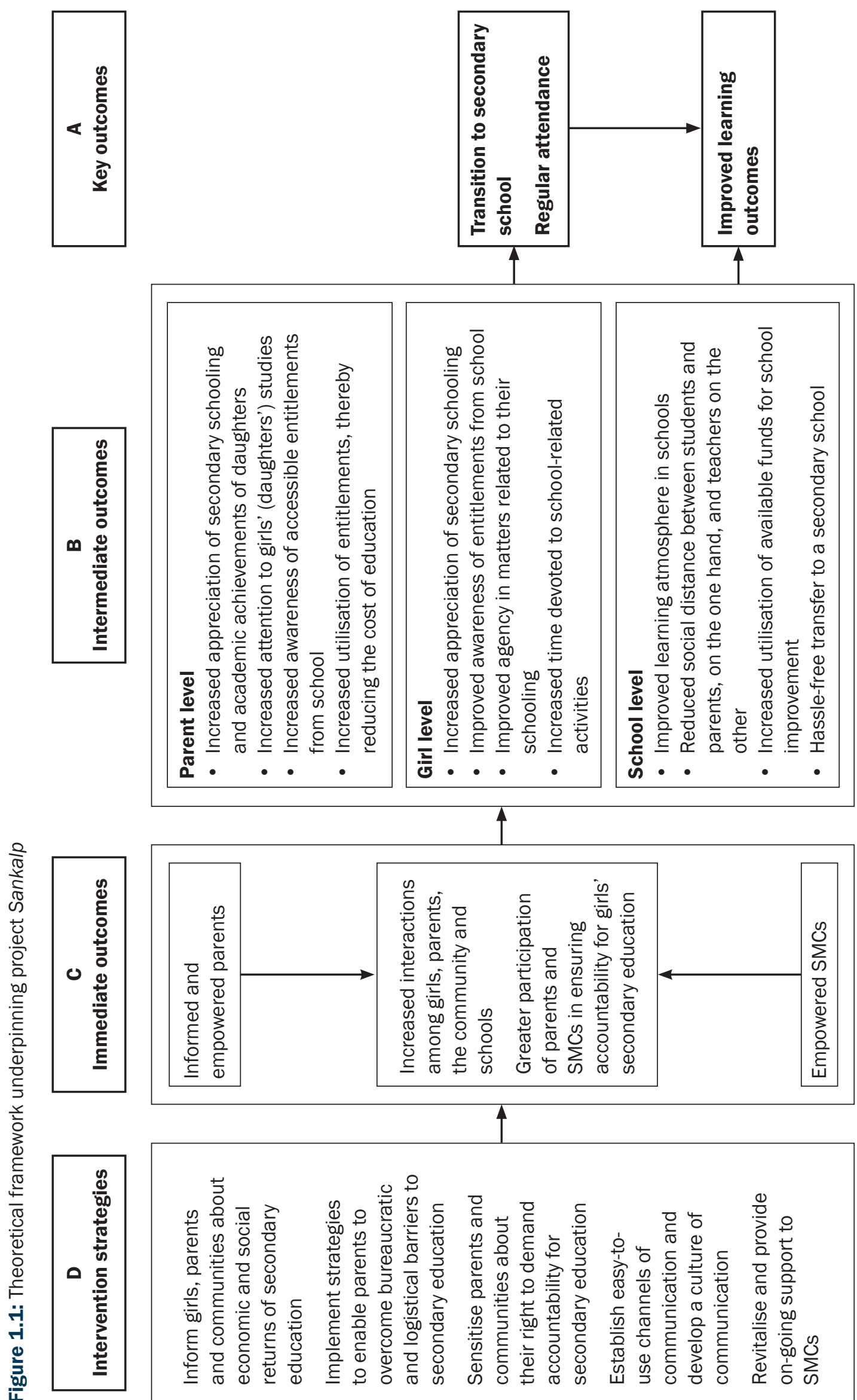

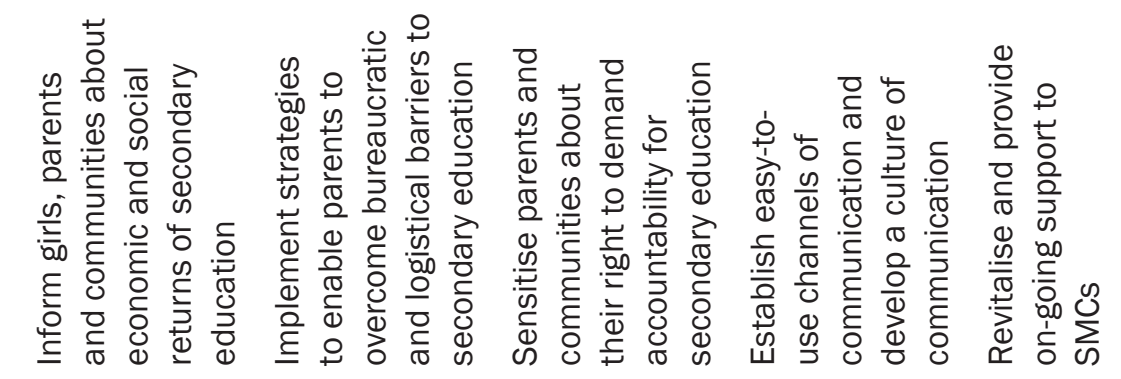


Surendrangar is among the districts of Gujarat that are characterised by high levels of school discontinuation among girls who complete their primary education. Data from a District Level Household Survey conducted in 2007-08 show that the transition rate from Class 8 to Class 9 among girls aged 14-17 years was only 59 percent (International Institute for Population Sciences, 2010). Sizeable proportions of the district's rural population are poor, educationally disadvantaged and socially excluded: in 2007-08, 18 percent of households were economically poor and 24 percent did not have a single literate adult member (International Institute for Population Sciences, 2010); moreover, in 2011, 11 percent belonged to socially disadvantaged caste groups (Office of the Registrar General and Census Commissioner, 2014b). At the same time, district data show that 69 percent of rural households had access to a mobile (67\%) or landline phone (2\%) in 2011 (Office of the Registrar General and Census Commissioner, 2012). A few key indicators of the study district and state are presented in Table 1.1.

Table 1.1: Selected characteristics of the study district and state

\begin{tabular}{|c|c|c|c|c|}
\hline \multirow[t]{2}{*}{ Characteristics } & \multicolumn{2}{|c|}{ Surendranagar district } & \multicolumn{2}{|c|}{ Gujarat state } \\
\hline & Total & Rural & Total & Rural \\
\hline Total population ${ }^{a}$ & $1,756,268$ & $1,259,352$ & $60,439,692$ & $34,694,609$ \\
\hline Percentage of rural population ${ }^{a}$ & 71.7 & - & 57.4 & - \\
\hline $\begin{array}{l}\text { Percentage of population in the adolescent age group } \\
(10-19 \text { years })^{b}\end{array}$ & 21.5 & 22.1 & 19.9 & 20.7 \\
\hline Child sex ratio (females/1,000 males $0-6$ years) ${ }^{a}$ & 896 & 906 & 890 & 914 \\
\hline Female literacy rate (population aged $7+$ years) $^{a}$ & 61.5 & 56.1 & 69.7 & 61.4 \\
\hline $\begin{array}{l}\text { Percentage of population belonging to socially } \\
\text { disadvantaged castes or tribes }{ }^{a}\end{array}$ & 11.4 & 11.7 & 21.5 & 29.7 \\
\hline $\begin{array}{l}\text { Percentage of population engaged in non-agricultural } \\
\text { activities }^{a}\end{array}$ & 17.6 & 10.6 & 23.7 & 12.8 \\
\hline
\end{tabular}

Sources: ${ }^{a}$ Office of the Registrar General and Census Commissioner, 2014b; ${ }^{b}$ Office of the Registrar General and Census Commissioner, 2014c.

Four of the ten blocks of Surendrangar district were selected for Project Sankalp. These blocks reflected sociodemographic indicators (namely, female literacy rate, the proportion of population belonging to socially disadvantaged groups, that is, scheduled castes and tribes, and the proportion of population engaged in nonagricultural activities) that were similar to the corresponding district averages.

\section{Study design}

We used a cluster randomised trial to evaluate Project Sankalp. We used this design because the intervention was implemented at the village level, targeting adolescent girls attending the last year of primary school (Class 8 ) and the first year of secondary school (Class 9 ), ${ }^{3}$ their parents, members of the SMCs and other influential adults in the village and, to a lesser extent, teachers of primary and secondary schools. As such, the chances of contamination were likely to be less with a cluster randomised trial than an individually randomised trial. Moreover, we were interested in measuring the effect of the intervention on the transition to secondary school among all girls at the village level.

We created geographical clusters, using maps of the four selected blocks and data collected during the preparatory phase of this study on the locations of secondary schools in these blocks. Each cluster contained five geographically contiguous villages and at least one secondary school. ${ }^{4}$ We excluded villages that shared a common boundary with any of the clusters to minimise contamination between intervention and control arms. Thus, we created 18 clusters,

\footnotetext{
${ }^{3}$ We note that although the intervention primarily focused on girls attending Class 8 and Class 9 and their parents, the project staff had focused on girls attending Class 7 as well.

${ }^{4}$ Of the 18 clusters created, 15 clusters contained one secondary school each, and the remaining three clusters contained two secondary schools each.
} 
consisting of 90 villages, within the four blocks. ${ }^{5}$ We randomised these 18 clusters into intervention and control arms, with nine clusters in each arm, using a restricted randomisation scheme. This scheme involves selecting randomly from a small set of allocations fulfilling certain predetermined criteria, using baseline or pre-existing data on each cluster. It thus seeks to ensure an acceptable level of overall balance between treatment arms and overcomes the limitation of not achieving adequate balance when simple unrestricted randomisation is used in cluster randomised trials involving a relatively small number of clusters (Hayes and Moulton, 2009). Specifically, for each cluster, we used pre-existing data on the percentage of population belonging to socially disadvantaged castes or tribes, the female literacy rate, the student-teacher ratio in the secondary school and the distance to a secondary school to achieve overall balance between treatment arms; data for the first two indicators were drawn from the 2001 census and that for the remaining two indicators were drawn from data collected from schools during the preparatory phase of this study. We used the following pre-determined criteria:

- the difference between the intervention and control arms should not exceed five percentage points in respect of the percentage of population belonging to scheduled castes or tribes;

- the difference between the intervention and control arms should not exceed five percentage points in respect of the female literacy rate;

- the difference between the intervention and control arms should not exceed 10 in respect of the number of students per teacher (student-teacher ratio) in secondary schools; and

- the difference between the intervention and control arms should not exceed five kilometers in respect of the average distance to a secondary school.

A computer programme was used to assess each of the 48,620 ways of allocating the 18 clusters to the two treatment arms, ${ }^{6}$ against these criteria. We excluded 32,232 combinations that did not meet the above-mentioned criteria. From the remaining 16,388 combinations, we then selected one using a random number. We checked the validity of the design and found that none of the pairs of clusters were allocated always to a different or same treatment group, confirming the acceptability of the randomisation scheme. As seen in Appendix 1, the clusters in the intervention and control arms were similar in terms of such contextual factors as the number of primary and secondary schools, the average distance between a primary and secondary school in the cluster, the percentage of households with a landline or mobile phone, and the percentage of households containing adolescent girls who were first-generation learners. Moreover, as shown in Chapter 2, the randomisation scheme that we used was able to achieve good overall balance between the treatment arms in terms of sociodemographic covariates and outcomes of interest to our study. Of the two arms of the selected combination, we randomly assigned one to serve as the intervention arm and the other to serve as the control arm.

Given that the steepest decline in school completion among girls occurs between Class 8 (the last year of primary education) and Class 9 (the first year of secondary education), and given our objective of increasing transition to secondary education, our intervention focused on adolescent girls who were in Class 8 and Class 9 , and their parents and the wider community, notably SMC members and, to a lesser extent, teachers of primary and secondary schools (see Chapter 3 for more details of the intervention design and its implementation). Correspondingly, our evaluation focused on girls who were attending Class 8 and Class 9 at the time of rolling out the intervention.

We based our calculation of the number of clusters per treatment arm on the following assumptions. First, we assumed that by the end of its duration, the project would generate at least a 15 percent increase (absolute terms) in the transition rate from Class 8 to Class 9-one of the main outcomes that it sought to influence. Second, we assumed that the transition rate from Class 8 to Class 9 would be 59 percent at baseline, drawing on data from the District Level Household Survey in 2007-08. Third, we assumed an intra-cluster correlation of 1.8 percent (required to calculate the value of the between-cluster coefficient of variation, $k$ ) and an average cluster size of 55 adolescent girls attending Class 8 . Based on these assumptions, the number of clusters per arm was calculated using the following formula:

$$
c=1+\left(z_{\alpha / 2}+z_{\beta}\right)^{2} \frac{\pi_{0}\left(1-\pi_{0}\right) / m+\pi_{1}\left(1-\pi_{1}\right) / m+k^{2}\left(\pi_{0}^{2}+\pi_{1}^{2}\right)}{\left(\pi_{0}-\pi_{1}\right)^{2}}
$$

\footnotetext{
${ }^{5}$ Each of the four blocks contained 4-5 clusters.

${ }^{6}$ The number of allocations that were available for selection, using a simple unrestricted randomisation scheme.
} 
where ' $c$ ' is the required number of clusters per arm; ' $\Pi_{0}$ ' and ' $\Pi_{1}$ ' are the levels of outcome-the transition rates from Class 8 to Class 9, before and after the intervention, respectively; ' $m$ ' is the average cluster size and ' $k$ ' is the between-cluster coefficient of variation. We, thus, estimated that we would require a minimum of nine clusters and a sample of 546 girls studying in Class 8 in each treatment arm. We note that we did not calculate the required sample of girls studying in Class 9 separately because the transition rate, the outcome indicator that we used for sample size calculation from Class 9 to Class 10, was higher than the transition rate from Class 8 to Class 9 , and we based our sample size calculation on the group that experienced a lower transition rate.

Following the randomisation of clusters, we conducted a baseline assessment, comprising a household census and a survey of all the girls attending Class 8 and Class 9 , in the 90 villages comprising the 18 clusters. We conducted the baseline assessment in August-September 2013, which corresponded with the second and third months of the academic year 2013-14.

In the household census, the field team enumerated all the households in the study villages. They first enquired about girls aged 10 to 18 years residing in the household from an adult member of the household. For each of these girls thus listed, the team collected information about her name, age, marital status, highest class successfully completed, the year in which she completed the last class successfully, whether she was currently studying and if yes, the class she was currently attending, the name of the school she was attending and the name of the village in which the school is located. A total of 26,868 households were enumerated. We used data obtained through the household census to calculate the transition rates to Class 9 and Class 10 at baseline as well as to identify eligible girls for the baseline survey. The transition rates obtained through the household census were cross-checked against the records maintained in the primary and secondary schools located within the study villages. We note that although we had assumed an average cluster size of about 60 girls attending Class 8 in our sample size calculation, we invited all the eligible girls-girls who were studying in Class 8 and Class 9 identified through the household census-to participate in the baseline survey as the cluster size was likely to vary. Thus, 1,568 girls were invited and interviewed: 492 and 516 Class 8 girls, and 251 and 309 Class 9 girls, in the intervention and control arms, respectively. We note that the number of eligible girls identified for the interview was smaller than the estimated number; for example, 1008 Class 8 girls were identified instead of an estimated 1092. Field teams suggested a range of reasons for the smaller than estimated number of girls-mainly, the seasonal migration of families, but also that girls reside in hostels outside the study blocks/district, and even deliberate withholding of information by parents about girls who have been withdrawn from school.

We made special efforts to minimise loss to follow up by tracking all the girls who had participated in the baseline survey, during the period between the baseline and endline surveys. In June 2014, three research assistants, who were part of the baseline survey team, visited all the households from which baseline respondents had been drawn, and recorded whether they were attending school at the time of the tracking exercise and, if yes, the name of the school in which they were studying. If they were found to have migrated from the village, their address was sought and recorded. In this way, we successfully obtained new addresses for the majority of girls who had moved out of their village.

We conducted the endline assessment, comprising a household census and a follow-up survey of girls who participated in the baseline survey, one to two months after concluding our pilot intervention. We note that the intervention activities were spread across two academic years: intervention activities were rolled out in the fourth month of the academic year 2013-14 and completed in the sixth month of the academic year 2014-15. The field team enumerated all the households in the study villages and collected details, identical to those gathered at baseline of girls aged 10 to 18 years residing in the household, from an adult member of the household. A total of 26,868 households were enumerated. We used data, thus obtained, to calculate the transition rates to Class 9 and Class 10 at endline, and cross-checked them against the records maintained in the primary and secondary schools located within the study villages.

The endline survey of girls who participated in the baseline survey and who consented to be re-interviewed was conducted between December 2014 and March 2015 which corresponded with the sixth to ninth month of the academic year 2014-15. During the endline survey, research assistants visited each household containing a baseline respondent, using addresses collected the time of the baseline survey and the tracking exercise. All efforts were made to interview baseline respondents irrespective of whether they were living within the project site or elsewhere, including outside the study district. 
Statistical analyses of the intervention effect were performed using Stata 11. Effect estimates were computed as the difference in cluster-level proportions or means, as appropriate. Analysis was by intention to treat. We compared unadjusted cluster-level summary measures across arms using an unpaired t-test for the main outcomes. For outcomes that showed evidence of an intervention effect, we applied a t-test with unequal variances to check whether precision had improved (see Chapter 6 for more details).

\section{Study instruments}

Three instruments were developed-a household listing form, a questionnaire to collect the socioeconomic characteristics of the households of eligible girls who were interviewed, and a girl's questionnaire to elicit information from these girls. Responses to the household listing form were gathered from a responsible adult member of each households enumerated in the study villages. Responses to the household questionnaire were obtained from a responsible adult member of the household to which the eligible girl belonged to collect information about the basic sociodemographic characteristics of the household and access to various amenities.

At baseline, the girl's questionnaire sought information on her educational aspirations and expectations; her agency, gender role attitudes and time use; her experiences at school, including attendance, as also her perceptions about teacher attitudes, practices and attendance; facilities and environment in the school; her awareness and utilisation of entitlements obtainable from the school; her access to safe transportation to commute to school; her perceptions of her parents' aspirations about and support for her secondary schooling; and her perceptions of community engagement in the secondary education of girls. The questionnaires were translated into Gujarati, pretested and revised in light of the insights obtained during pretesting.

At endline, we used an identical questionnaire, except for an additional module to capture the girls' exposure to the intervention activities. The module contained questions on the girls' experiences and perceptions about the acceptability and quality of the activities of Project Sankalp, and the extent, if any, to which their participation in these activities had influenced their educational aspirations and experiences at school.

We also administered competency tests in the English and Gujarati languages, and in Mathematics, to assess the academic performance of the girls. Identical tests were administered at baseline and endline.

\section{Recruitment, training and fieldwork}

A total of 22 young women and men underwent training for undertaking the household census and 29 young women for administering the survey instrument to the girls at baseline and, from the same pool, seven young women for the household census and 14 for the follow-up survey of girls at endline. These research assistants are graduates in the science or social science streams, are proficient in Gujarati and have three to four years of experience in conducting field-based studies. The training team monitored each trainee's progress on a regular basis and selected as interviewers only those trainees who demonstrated a full understanding of the questionnaire as well as the ability to ask questions appropriately and record responses accurately. Thus, of those trained, 18 young women and men were selected for the household census and 12 young women for the girls' survey at baseline, and seven young women for the household census and 11 for the follow-up survey of girls at endline.

The training of interviewers for both baseline and endline fieldwork was conducted by Population Council staff in partnership with CHETNA staff. The training duration for the household census and the girls' survey was two days and one week, respectively, both at baseline and endline. Moreover, to ensure data quality and adherence to ethical principles, Population Council staff provided ongoing supervision and support to the interviewers.

\section{Response rates}

As many as 99 percent of the total of 1,568 girls who were identified at baseline were successfully interviewed (see Figure 1.2). The remaining girls could not be interviewed as they were not available in the village even after making three visits. We note that the number of girls studying in Class 8 and Class 9 in each cluster varied in both arms, ranging from 39 to 150 girls, at baseline. 
Figure 1.2: Flow diagram showing the number of girls interviewed, number of girls assigned to treatment arms and number of girls lost to follow up

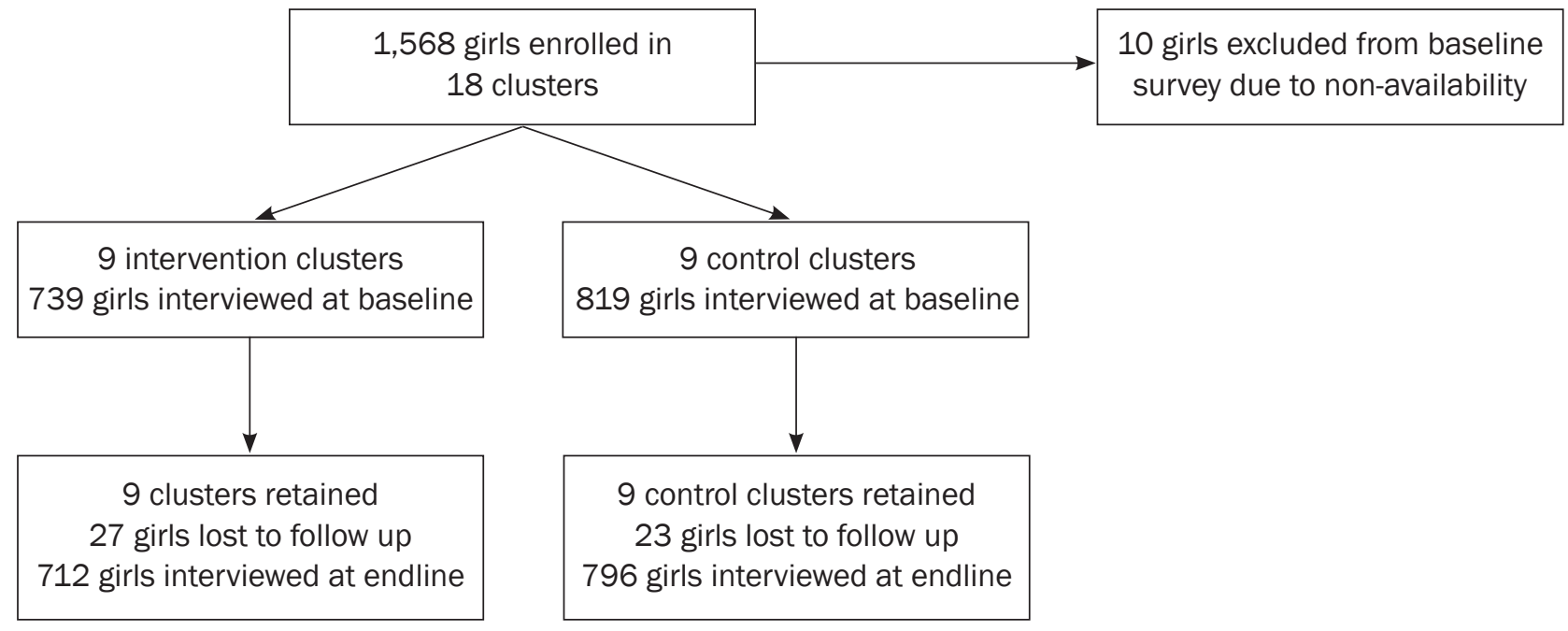

At endline, 97 percent of the girls interviewed at baseline were successfully re-interviewed. The loss to follow up was due to non-availability of the baseline respondent at home or in the hostel even after making three visits, refusal by the baseline respondent or her parents or hostel warden (in case of girls who were staying in hostels at the time of the endline survey), or her non-availability due to family migration outside the study district or state (Table 1.2)

Table 1.2: Follow-up rate of study participants and reasons for loss to follow up at endline by treatment arms

\begin{tabular}{lrr}
\hline Follow-up rate and reasons for loss to follow up at endline & $\begin{array}{c}\text { Intervention } \\
\text { Arm }\end{array}$ & $\begin{array}{c}\text { Control } \\
\text { Arm }\end{array}$ \\
\hline Girls interviewed at baseline & 739 \\
Girls interviewed at endline & 712 \\
Follow-up rate at endline (\%) & 96.3 \\
Reasons for loss to follow-up & 519 \\
Girl not at home/hostel & 2 \\
Girl refused to be interviewed & 2 \\
Girl's parents refused to let her be interviewed & 2 \\
Warden of the hostel in which the girl was staying at the time of the endline survey & 4 \\
refused to let her be interviewed & 0 \\
Family migrated outside the study district/state & 17 \\
Incapacitated & 1 \\
Number of girls lost to follow-up & $\mathbf{2}$ \\
\hline
\end{tabular}

\section{Structure of the report}

This report is divided into seven chapters, including this introductory chapter. Chapter 2 describes the school experiences of the surveyed adolescent girls at baseline, including their transition to secondary school, attendance at school and academic performance at baseline. It also presents baseline information about their educational aspirations and agency; awareness and utilisation of the entitlements obtainable from school and time use patterns related to schooling; as well as the extent to which the school, family and community environment has been supportive of their secondary schooling. Chapter 3 briefly describes the objectives and the design of Project Sankalp, 
its key components, the extent of participation of various stakeholders in intervention activities, and the challenges faced in implementing the project. Drawing on endline survey data, Chapter 4 discusses girls' awareness and experiences of the intervention activities as well as their perceptions of changes, if any, in their parents and teachers during the inter-survey period. Chapter 5 presents the findings of the effect of the intervention in improving girls' aspirations and agency in matters related to their secondary schooling, and in creating an enabling environment at the school, family and community levels for girls to pursue secondary education. Chapter 6 describes the effect of the intervention on the school experiences of the girls, namely, their transition to secondary education, school attendance and academic competency. The final chapter summarises the main findings of the study and highlights lessons learnt for planning and implementing future programme and research initiatives. 


\section{Chapter 2 \\ Profile of girls' school experiences at baseline}

This chapter briefly profiles and compares the schooling experiences of adolescent girls of Class 8 and Class 9 enrolled in the intervention and control arms, before initiating Project Sankalp. We begin with the background characteristics of these girls, obtained from a baseline survey, and the transition rates from Class 8 to Class 9 and Class 9 to Class 10 at the village level, obtained from a household census. Our survey of schooling experiences also includes data on the girls' school attendance, academic performance, future aspirations about their education, agency in matters related to schooling, awareness and utilisation of the entitlements available from their school, and time devoted to school activities. Finally, we describe the girls' perceptions of teacher, parental and community support for their education.

\section{Background characteristics of girls and their parents}

Table 2.1 presents baseline data on selected background characteristics of the surveyed girls and their parents by treatment arms. Findings show that the girls enrolled in the intervention and control arms had similar characteristics, with the exception of a moderate difference in the proportion of Muslim girls.

Table 2.1: Selected background characteristics of girls who participated in the baseline survey by treatment arms, 2013

\begin{tabular}{lcc}
\hline Characteristics & $\begin{array}{c}\text { Intervention } \\
\text { Arm }\end{array}$ & $\begin{array}{c}\text { Control } \\
\text { Arm }\end{array}$ \\
\hline Age (years) & 12.8 & 12.8 \\
Mean age & & 97.3 \\
Religion (\%) & 91.9 & 2.7 \\
Hindu & 8.1 & 18.1 \\
Muslim & & 66.4 \\
Caste (\%) & 20.1 & 15.5 \\
Scheduled castes or tribes & 63.1 & \\
Other backward castes & 16.8 & 31.9 \\
General castes ${ }^{1}$ & & \\
Engagement in economic activities (\%) & 30.4 & 24.2 \\
Engaged in paid or unpaid work in the week prior to the interview & & 18.1 \\
Household standard of living & 23.5 & 47.6 \\
Mean score, household wealth index (range 0-52) & & 6.1 \\
Parents' educational level & & 3.2 \\
\% of girls whose father had never attended school & 20.2 & $\mathbf{8 1 9}$ \\
\% of girls whose mother had never attended school & 51.7 & \\
Mean years of schooling completed by fathers & 6.1 & $\mathbf{3}$ \\
Mean years of schooling completed by mothers & 3.0 & $\mathbf{7 3 9}$ \\
Number of girls & & \\
\hline
\end{tabular}

Note: ${ }^{1}$ Includes those who do not belong to scheduled castes, scheduled tribes or other backward castes. 
Girls were aged, on average, 13 years, suggesting that most girls had enrolled in school at the right age and had not repeated any class. Over 90 percent of the girls were Hindus; a slightly larger proportion of girls in the intervention arm were Muslims, compared to their counterparts in the control arm (8\% versus 3\%). Distribution by caste shows that the majority of girls (63-66\%) were from other backward castes. Participation in economic activities, paid or unpaid, was quite common; some 30-32 percent of the girls had been engaged in either paid or unpaid work in the week prior to the interview.

The economic status of the household was measured using an index composed of household asset data on ownership of selected durable goods, including means of transportation as well as access to a number of amenities. The wealth index was constructed by allocating scores to a household's reported assets or amenities, with a possible minimum value of zero and a maximum value of 52 (for details of the scores, see Appendix 2). The majority of the surveyed girls came from households with a low or average economic status (mean score of 24 on an index ranging in value from 0 to 52). The educational level of their parents shows that fathers were better educated than mothers (six years of schooling among fathers versus three years among mothers, on average). Moreover, about one-fifth and one-half of the girls reported that their father and mother, respectively, had never attended school.

\section{School experiences of girls}

The main outcomes that this pilot intervention sought to influence were the percentage of girls in the community making the transition to secondary education, their school attendance rates and academic performance as measured by various test scores. Findings related to these main outcomes at baseline, described in the sub-sections below, suggest that the girls' school experiences were compromised in many ways. Findings also show that these experiences were similar between the intervention and control arms, suggesting that the randomisation scheme was able to achieve a good balance between the treatment arms.

\section{Transition rates}

We measured transition to secondary education by transition rates of Class 8 and Class 9 girls to Class 9 and Class 10, respectively, drawing on data from the household census that we carried out in the intervention and control villages. Specifically, we defined the transition rate to Class 9 in terms of the number of girls enrolled in Class 9 in the academic year in which the baseline survey was conducted, expressed as a percentage of the number of girls enrolled in Class 8 in the previous academic year. The transition rate to Class 10 was similarly defined. Figure 2.1, which presents these transition rates at baseline, by treatment arms, shows that a sizeable proportion of girls had discontinued schooling after completing primary education; just two-thirds of Class 8 girls had transitioned to Class 9 (65-67\%). Findings also show that once enrolled for secondary education, a large proportion of girls continue to study; for example, the transition rate to Figure 2.1: Transition rates of girls to Class 9 and Class 10 by treatment arms, baseline survey, 2013

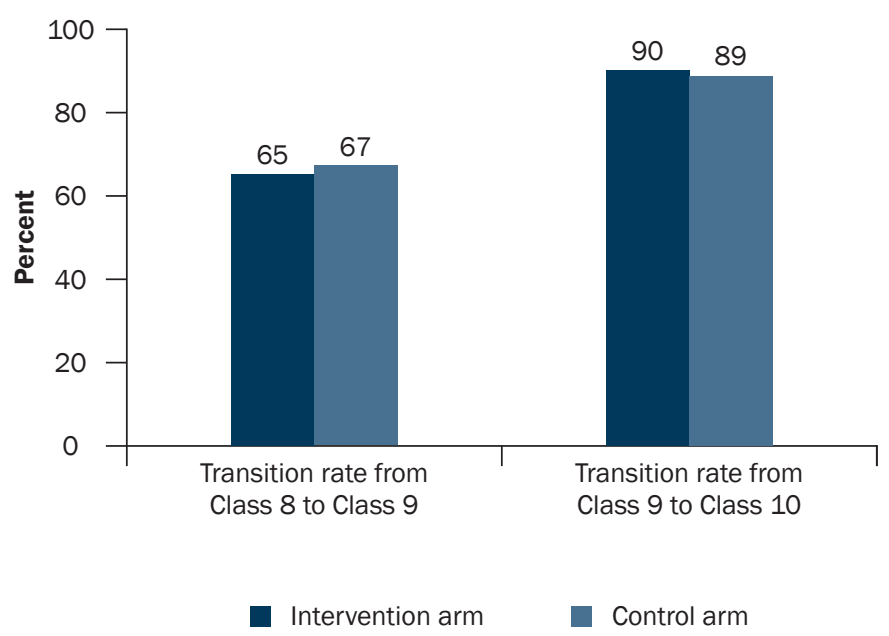

Class 10 was nearly 90 percent.

\section{School attendance}

We measured school attendance rates, as reported by the girls themselves, in two ways. First, we measured the percentage of girls who reported that they had attended school on all days during the week prior to the interview and second, we asked the girls whether they had missed attending school continuously for one week or more in the last academic year. Findings depicted in Figure 2.2 show that school attendance was far from regular for 
Figure 2.2: Percentage of girls reporting attendance at school by treatment arms, baseline survey, 2013

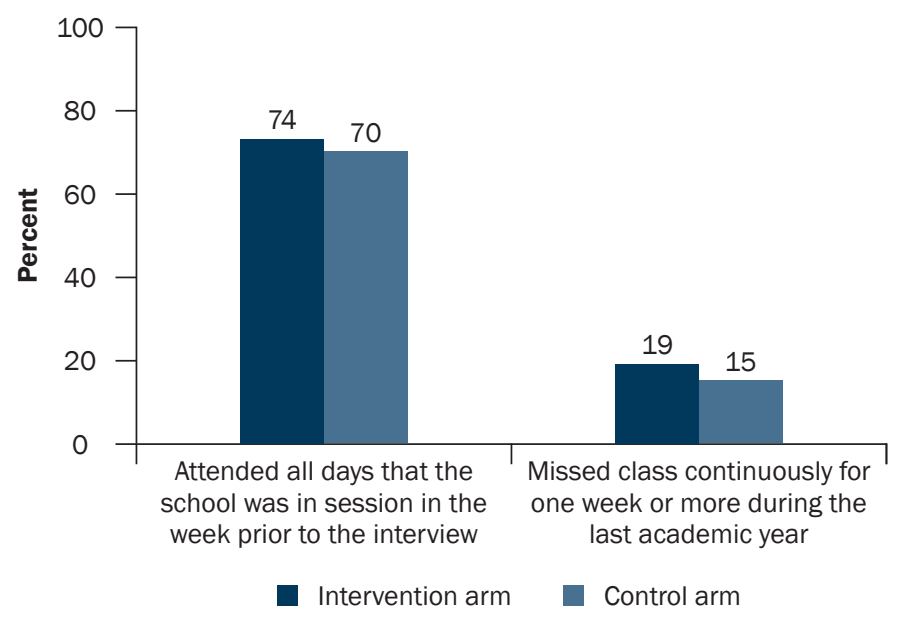

the Class 7 curriculum approved by the State Education Department, and were asked to answer five questions relating to each paragraph. Class 9 girls were given one additional paragraph each in both these languages, drawn from the Class 8 curriculum approved by the State Education Department, and were asked to answer five questions relating to each paragraph. The responses of the girls were assessed in terms of comprehension and sentence construction. They were given a score of 0 for no comprehension, 1 for partial comprehension and 2 for full comprehension; likewise, they were given a score of 0 for incorrect sentence construction, 1 for partially correct sentence construction and 2 for fully correct sentence construction. One summary index each for the English and Gujarati languages was constructed by adding the scores for comprehension and sentence construction. The value of the index ranged from 0 to 20 for Class 8 girls and 0 to 40 for Class 9 girls. In order to test Mathematics competency, Class 8 girls were asked to solve 14 problems drawn from the Class 7 curriculum, and Class 9 girls were asked to solve four additional problems drawn from the Class 8 curriculum. These questions ranged from simple addition, subtraction, multiplication and division to those related to algebra and geometry. The composite indicator of Mathematics competency comprised the number of problems correctly solved, and ranged from 0 to 14 for Class 8 girls and 0 to 18 for Class 9 girls. Given that the maximum scores that Class 8 and Class 9 girls could attain differed, the scores were standardised by converting them into percentage marks in relation to the maximum score.

Figure 2.3: Standardised scores obtained by girls in competency tests by treatment arms, baseline survey, 2013

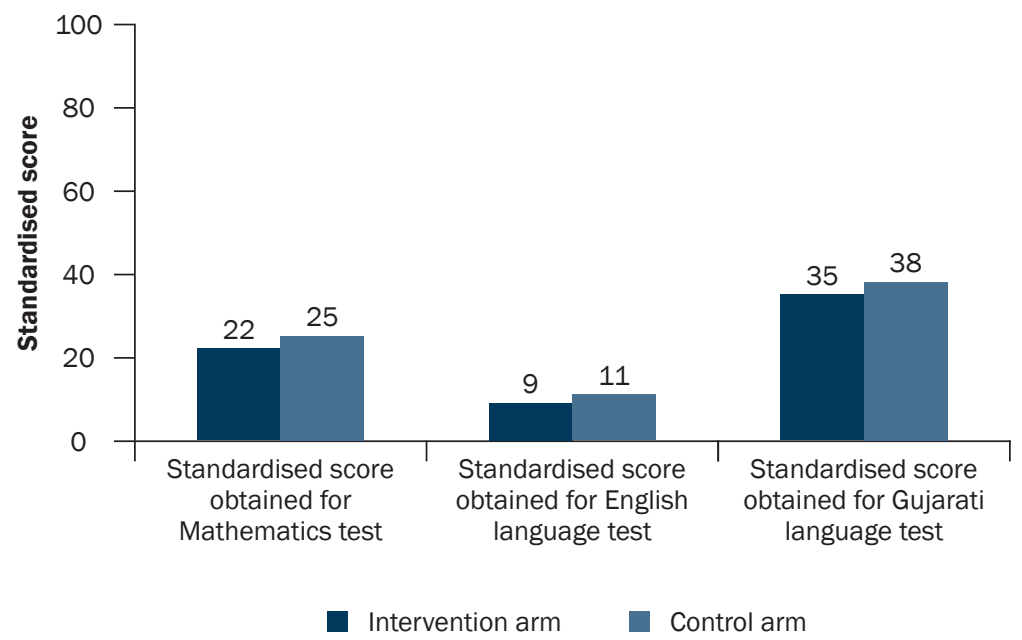

Figure 2.3 presents the baseline standardised scores obtained in the competency tests administered to the girls enrolled in the control and intervention arms. Findings underscore the extremely poor academic performance of the surveyed girls. Girls scored, on average, 22-26 percentage marks in solving Mathematics problems that they were expected to have learned to solve in previous classes. In English comprehension and sentence construction too, they performed very poorly; for example, they scored, on average, just 9-11 percentage marks. Finally, although they performed better in the Gujarati than in the English language competency test, their performance in Gujarati was also far from satisfactory; on average, girls scored 35-38 percentage marks. 


\section{Girls' future aspirations, agency, awareness and utilisation of entitlements, and time use in relation to studies}

We assessed the future aspirations of the surveyed girls with regard to their education, agency in matters related to schooling, awareness and utilisation of entitlements obtainable from school, and time devoted for school activities, in order to better understand their desire and ability to pursue their studies. Findings, described below, suggest that although most girls aspired to complete at least a secondary education, their agency to realise their educational aspirations was somewhat limited. Findings also indicate that there were no differences between girls enrolled in the intervention and control arms. Moreover, girls enrolled in both treatment arms had spent about the same amount of time on schoolwork and other school-linked activities.

\section{Girl's educational aspirations and agency}

We measured the educational aspirations of the surveyed girls by probing them about the extent to which they valued the successful completion of secondary education. In order to capture their agency in matters related to schooling, we used four indicators: (1) their confidence about their ability to attend school regularly and perform well, (2) their communication skills, (3) their ability to negotiate with parents on schooling, and (4) their decisionmaking say with regard to the level of schooling that the girl should have. We assessed girls' confidence about their ability to perform well in school from their responses to three questions. Specifically, they were asked whether they agreed or disagreed with three statements: "I will not be able to attend school regularly"; "The school lessons are difficult for me to learn" and "I will not be able to get good marks in my examinations". Girls who disagreed with all these three statements were considered to have a high level of confidence about their ability to attend school regularly and perform well. We measured their communication skills using their responses to three questions that assessed whether they found it difficult to express their opinion to elders in their family, to confront classmates who hurt their feelings, and whether they felt comfortable speaking in front of a group. Girls who replied that they never found it difficult to express their opinion to family elders or to confront classmates who hurt their feelings, or always felt comfortable speaking in front of a group were considered to have good communication skills. We captured girls' perceived negotiation skills by means of a question that assessed whether, if their parents' preferences about their education differed from their own, they would be able to convince their parents either on their own or with the help of others, or they would go against their parents' preference. Finally, we measured girls' decision-making ability from their response to a question on who would decide how much schooling they should have, and all those who responded that they would decide on their own or jointly with others were considered to have a decision-making say.

Figure 2.4 presents the percentage of girls surveyed at baseline, reporting their educational aspirations and agency regarding matters related to schooling, by treatment arms. According to the findings, the vast majority of girls aspired to complete at least a secondary education. When questioned about the value they attached to successfully completing a secondary education, most girls $(80 \%)$ responded that they valued it very much.

Findings underscore that some 67-71 percent of the surveyed girls were fully confident of their ability to attend classes and perform well, that is, they felt that they would be able to attend school regularly, that their lessons were easy to learn, and that they would be able to get good marks in their examinations. Some 57-59 percent of the girls displayed confidence in their ability to communicate their opinion without any discomfort, and 51-52 percent said that if their parents' opinion regarding their schooling differed from their own, they would convince their parents or go against their parents' wishes. Findings also show that the final decision about the girls' education rested with their parents; just 38-42 percent of the girls reported that they would have a say in decisions related to the level of schooling they should have.

\section{Awareness and utilisation of entitlements provided by schools}

Many schemes have been implemented in Gujarat to improve economic access to schooling; for example, the provision of scholarships and stipends, free uniforms and free textbooks. We assessed the efforts made by schools to make girls aware of and benefit from these entitlements by probing the girls participating in our study about their awareness and utilisation of these schemes.

Findings of the baseline survey, presented in Figure 2.5, suggest that although the majority of girls were aware of the entitlements obtainable from school, their in-depth awareness, as measured by being able to correctly state the 
Figure 2.4: Percentage of girls reporting their educational aspirations and agency in matters related to their schooling by treatment arms, baseline survey, 2013

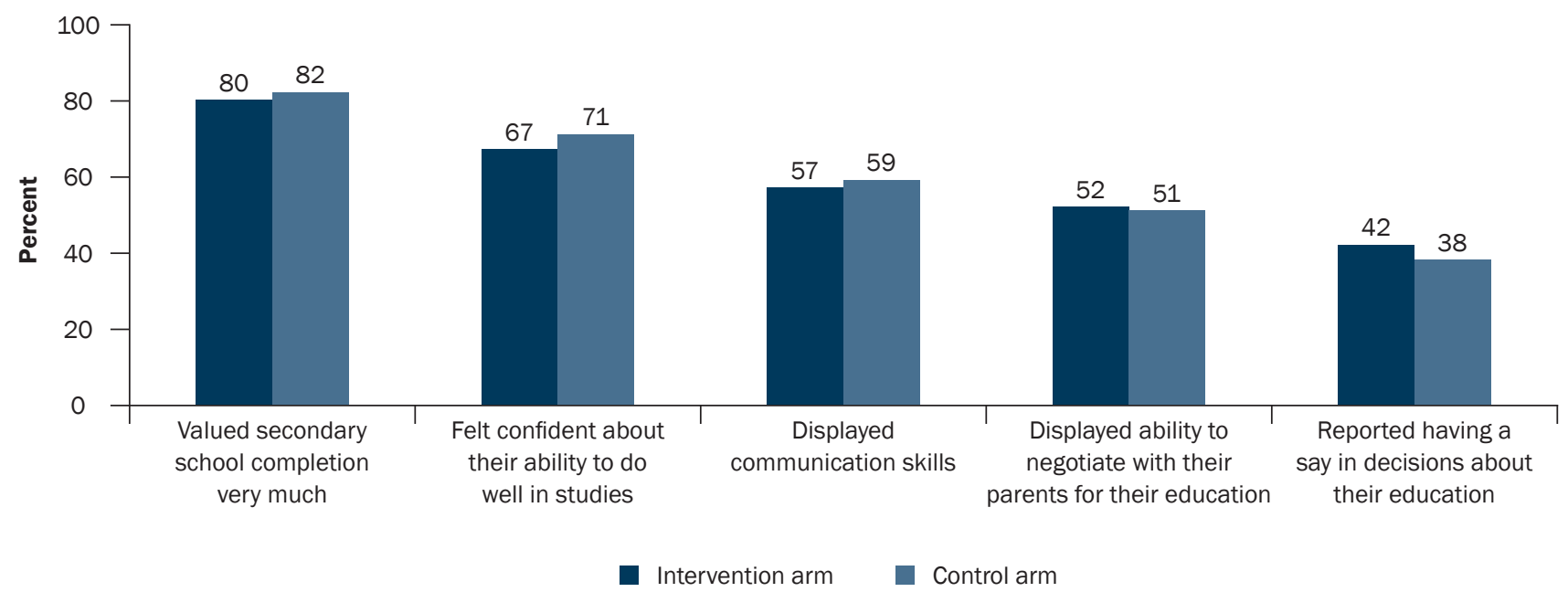

eligibility criteria and the amount of money awarded for at least one scholarship, and utilisation of entitlements was limited. While almost all the girls reported awareness of such entitlements as scholarships, in-depth awareness was limited in that just one-fifth of the girls were able to correctly state the eligibility criteria and the amount of money granted for at least one scholarship. Besides, findings also confirm low utilisation-very few girls had benefitted from a scholarship; just four to six percent of the girls had obtained a scholarship during the current academic year. ${ }^{7}$

Time devoted for school-related activities Figure 2.5: Percentage of girls reporting in-depth awareness and We measured time devoted for school activities by collecting time use data from all the girls utilisation of scholarships from school by treatment arms, baseline who took the survey, asking them to recall their activities in half-hour increments for the 24-hour period of the last school day they attended; assuming at least four hours of sleep, they were asked to record activities for a total of 20 hours. The interviewer recorded their responses according to appropriate categories. Time devoted to school activities included time spent in school, in doing homework and commuting between school and home.

Baseline findings of the average number of hours spent by girls on school-related activities on the last school day, by treatment arms, are illustrated in Figure 2.6. Findings show that on the last school day, the girls spent, on average, 7.6-7.8 hours, most of which included time spent in school. Time devoted for homework and commuting between school and home was limited. survey, 2013

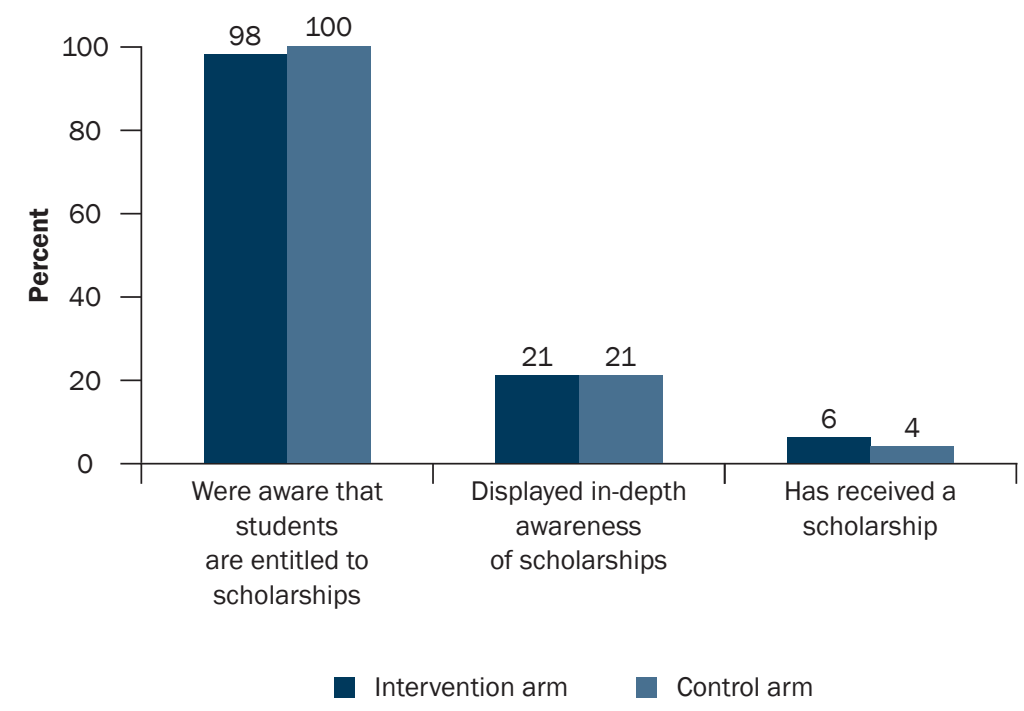

\footnotetext{
7 We note that eligibility criteria for various scholarships differed and that we did not collect the details of the scholarship, including the eligibility criteria from girls who had received a scholarship; as such, therefore, we are not able to specify whether or not all girls who were eligible had received a scholarship.
} 


\section{School environment}

We also assessed the extent to which the school environment was conducive for girls to pursue their education and perform well in their studies. Specifically, we assessed teachers' attendance in class and classroom dynamics as reported by the surveyed girls. To measure teacher attendance, we probed the girls about their teachers' presence on each of the six days when the school was in session in the week preceding the day of the interview.

Figure 2.6: Average number of hours spent on school-related activities on the last school day by treatment arms, baseline survey, 2013

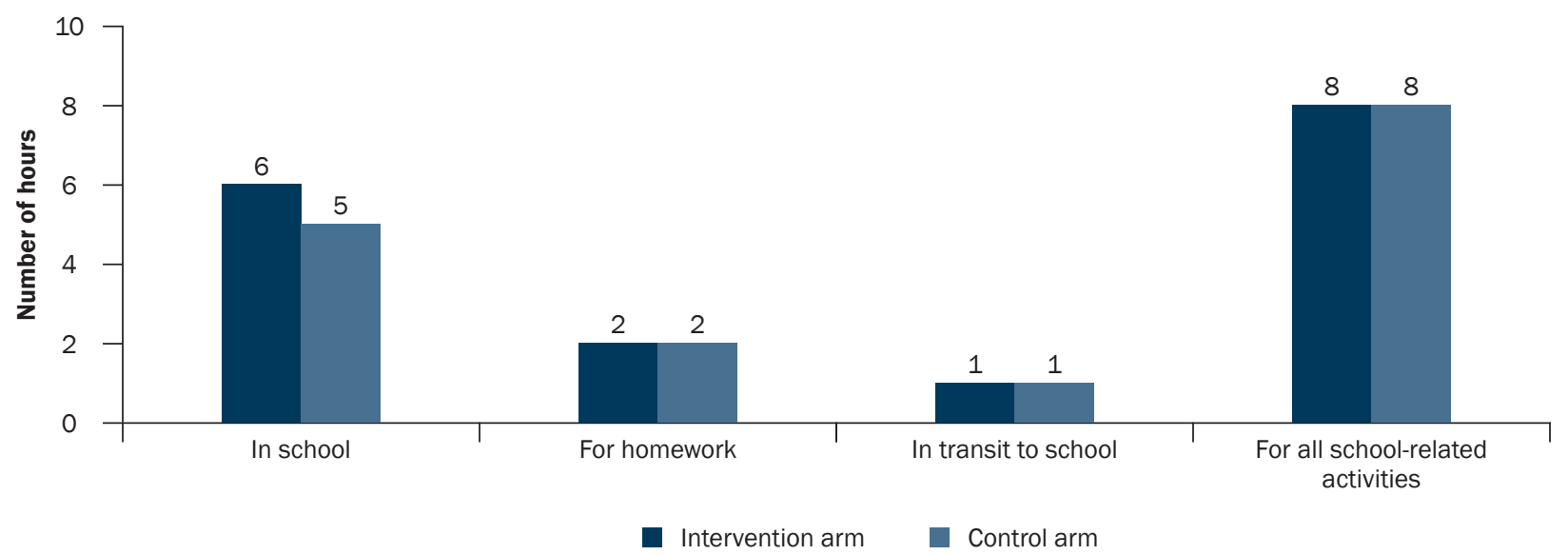

Several dimensions of classroom dynamics were also assessed. Three indicators were based on the responses of the surveyed girls that reflected the extent to which the teachers displayed positive, respectful, non-discriminatory and gender egalitarian attitudes and practices in the classroom toward students, in general, in the week prior to the interview. The first indicator assessed whether the teachers provided positive feedback to students in general, that is, whether they had praised students who had done well in class in the pre-interview week. The second indicator measured whether the teachers had conveyed egalitarian gender role attitudes to the students in the week before the interview, by probing the girls about whether any teacher had ever made any comment that implied that boys should concentrate on their studies as they would have to take care of family responsibilities or that girls should be helping their mothers instead of wasting their time at school. Girls who reported that their teachers had never made either of these comments were considered to have teachers who displayed egalitarian gender role attitudes. The third indicator captured the surveyed girls' own experience of corporal punishment, and verbal and sexual harassment perpetrated by their teachers. Girls were probed about whether, during the pre-interview week, any of their teachers had sent them out of class, made them stand for prolonged periods of time in the classroom, made them stand in the courtyard or playground, hit them, beat them, teased or mocked them about their appearance, scolded them when they did not understand their lessons, called them "stupid", or looked at them or touched them in a 'bad' way, that is, in a sexual way. Girls who reported that they had experienced any of these acts in the week prior to the interview were considered to have experienced corporal punishment or harassment perpetrated by their teachers.

Figure 2.7 illustrates the percentage of girls surveyed at baseline, reporting teacher attendance and indicators of classroom dynamics during the pre-interview week, by treatment arms. Findings show considerable absenteeism among teachers and mixed classroom dynamics; however, there were no differences between the intervention and control arms. For example, 37-40 percent of girls reported that at least one of their teachers had been absent on at least one day in the week prior to the interview.

Large proportions of the surveyed girls $(77-80 \%)$ reported that their teachers had provided positive feedback to students, that is, praised students when they did well in class in the week prior to the interview; likewise, the majority of girls (75-76\%) reported that their teachers had conveyed egalitarian gender role attitudes. At the same time, almost one-fifth of the girls had experienced corporal punishment, or sexual or verbal harassment at the hands of their teachers during that same week. 
Figure 2.7: Percentage of girls reporting teacher attendance, attitudes and practices during the week preceding the interview by treatment arms, baseline survey, 2013

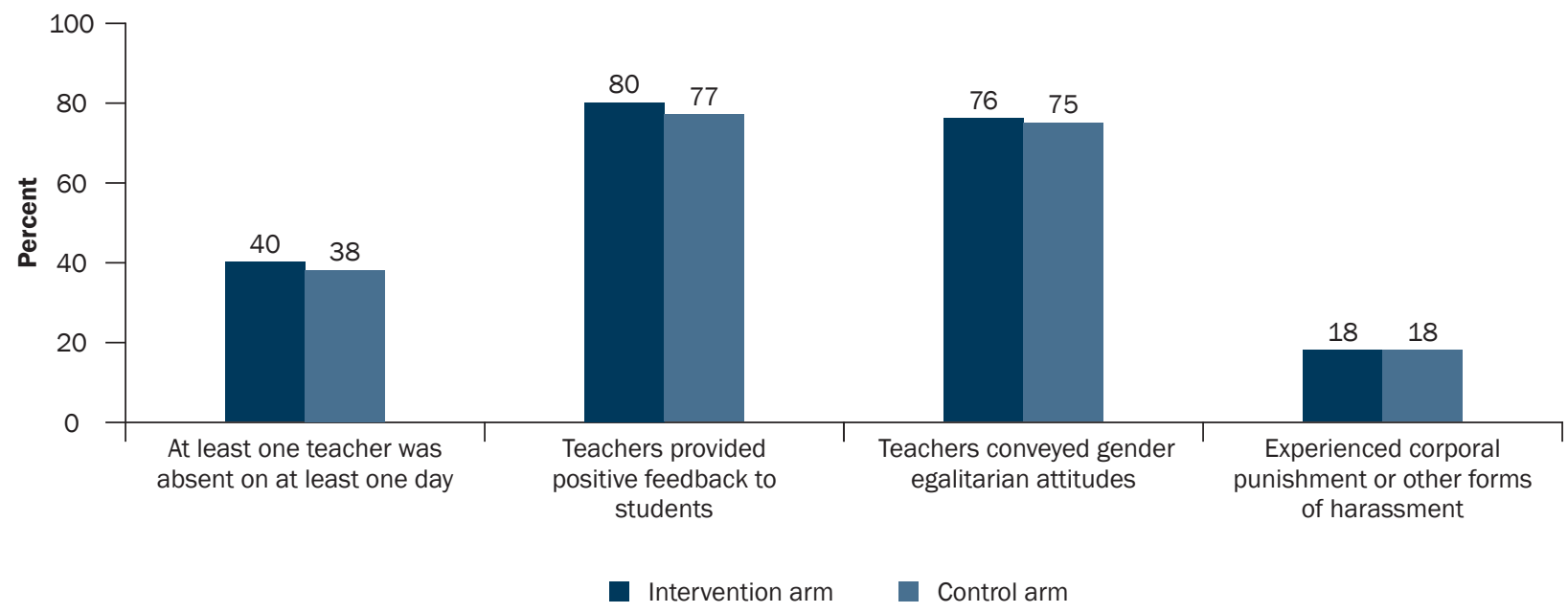

\section{Parental engagement in their daughter's education}

Given that the focus of the study was on engaging parents to promote their daughters' secondary education, we sought the perspectives of the surveyed girls on the encouragement they received from their parents for their studies. Specifically, we probed their perceptions of the extent to which their parents valued their completing secondary education, as also parental discussion about and engagement in their studies, and parental interaction with their school authorities, in the week prior to the interview.

\section{Parental aspirations for their daughter's education}

In order to assess parental aspirations for the education of their daughters, we probed the girls about the extent to which they thought their parents considered it important for them to complete Class 10 . Figure 2.8 depicts the aspirations of parents for their daughter's educational attainment as reported by the girls surveyed at baseline, by treatment arms. It shows that the majority of girls (76-77\%) perceived that their parents considered it very important for them to complete Class 10.

\section{Parental discussion with daughters about their studies}

We posed a series of questions to the girls who participated in the survey to capture the extent of communication between them and their parents about their education. We asked them whether their mother and father had talked to them in the week prior to the interview about such topics as homework, performance in class, study materials, their teachers and their teachers' behaviour toward them, and facilities in their school.

Figure 2.8 also illustrates parental involvement in their daughter's education during the pre-interview week, in terms of parent-daughter discussion about her studies, as reported by the girls surveyed at baseline, by treatment arms. As evident from the findings, an equal proportion of girls from both treatment arms (56\%) reported that their mother had discussed their studies with them in the week prior to the interview; fathers of fewer girls had engaged in such discussions with their daughters, the corresponding percentages being 46 and 43 in the intervention and control arms, respectively.

\section{Time spent by parents in supporting their daughter's education}

Several indicators were used to measure the time spent by parents in encouraging their daughters' educational pursuits. The girls who participated in our baseline survey were asked: (1) how often their parents had spent time with them on their studies in the week prior to the interview, that is, in helping them with their studies, giving them 
Figure 2.8: Percentage of girls reporting parental aspirations for their secondary education, and discussion with and time spent by parents in supporting their education during the week preceding the interview, by treatment arms, baseline survey, 2013

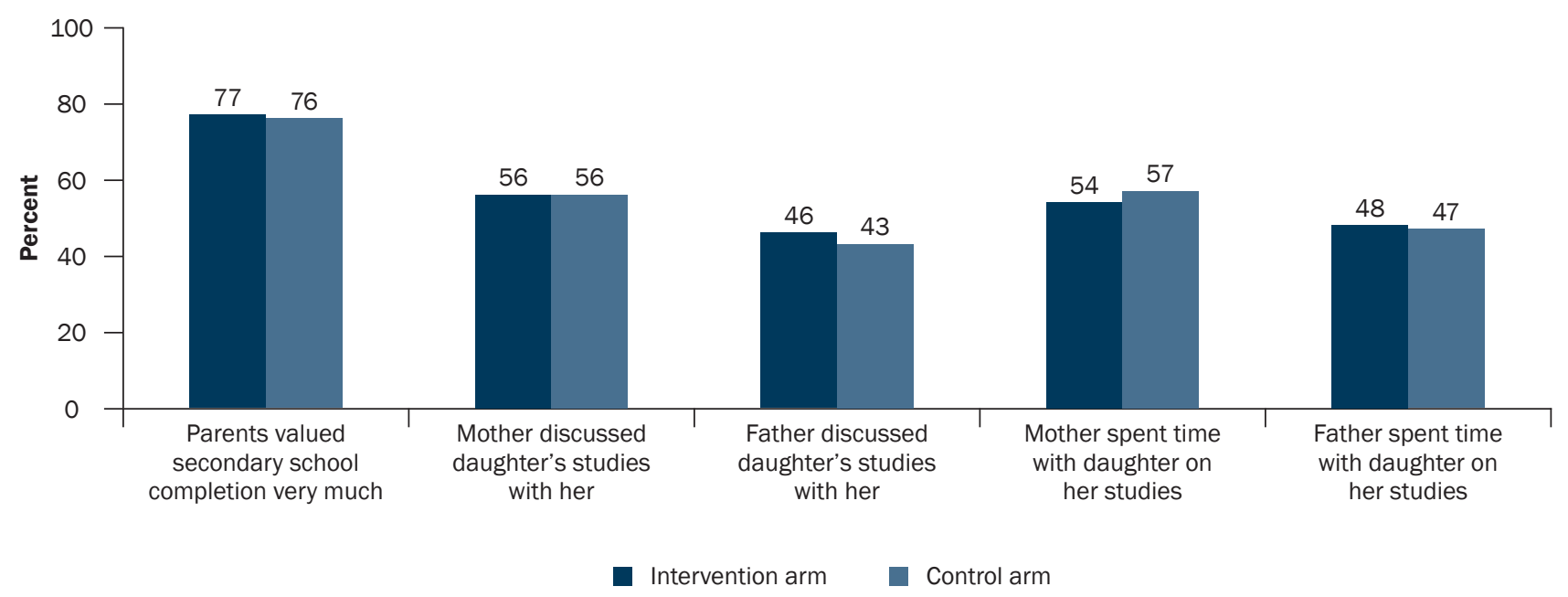

company when they did their homework, or escorting them to school; and (2) the amount of time their parents had spent in providing such support. These findings, also shown in Figure 2.8, suggest that in the week preceding the interview, mothers of 54-57 percent of the girls and fathers of fewer girls (47-48\%) had spent time to encourage them with their studies. As regards the amount of time spent by parents on these supportive activities during that week, girls reported that while their mothers had spent, on average, 1.6-1.9 hours; much more time had been so spent by their fathers-three hours (not shown in the figure).

\section{Parental interaction with school authorities}

The study also assessed the interaction of parents with the authorities of their daughter's school by probing the girls who participated in the survey about whether, to their knowledge, their parents had visited their school, their parents had attended parent-teacher meetings and their parents had discussed their performance at school with their teachers in the month preceding the interview.

Figure 2.9 illustrates the percentage of girls surveyed at baseline, reporting parental interaction with their school authorities in the month preceding the interview, by treatment arms. Figure 2.9 shows that parents of 34-40 percent of the surveyed girls had visited their daughter's school during that month. Girls also reported that parent-teacher meetings were rarely organised in their school (86\% and $92 \%$ of the girls in the intervention and control arms, respectively, reported that such meetings were not organised in their school; not shown in the figure). Just 6-11 percent of the girls reported that their parents had attended a parent-teacher meeting during the pre-interview month, and several more (30-31\%) said that their parents had discussed their performance with their teachers.
Figure 2.9: Percentage of girls reporting parental interaction with school authorities in the month preceding the interview by treatment arms, baseline survey, 2013

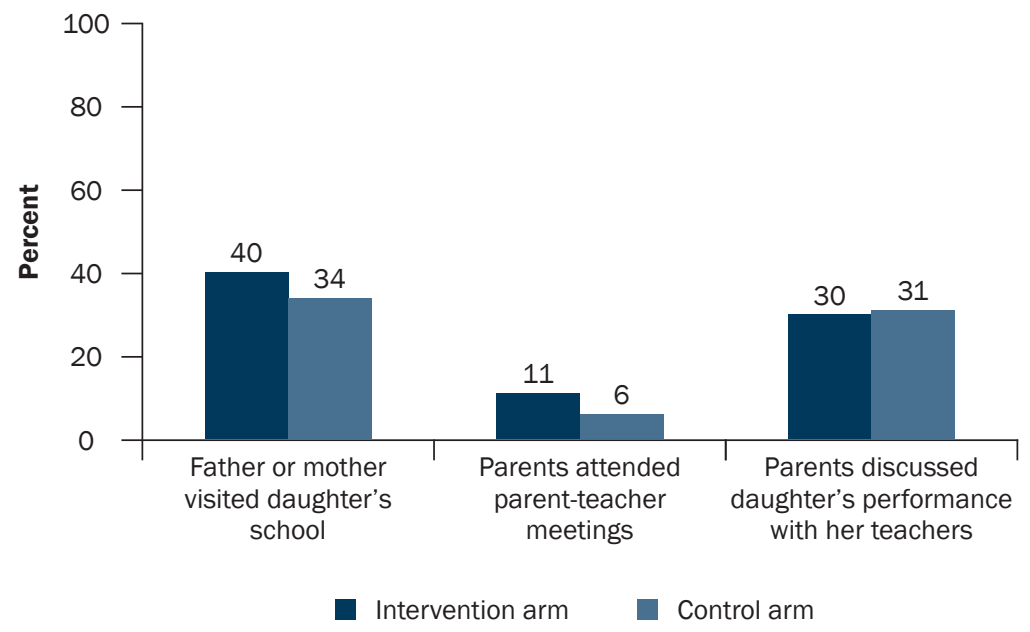




\section{Girls' awareness of School Management Committees and perceptions about the engagement of Panchayat members in girls' education}

Figure 2.10 illustrates the percentage of girls surveyed at baseline, reporting awareness of SMCs and perceptions about the engagement of Panchayat members in girls' education, by treatment arms. Findings suggest that community engagement in support of girls' education was limited or unknown to girls. Although SMCs, statutory bodies established by the government to promote enrollment, retention and achievement of children in primary schools and to make schools effective, are mandatory under the Right to Education Act, just 11-14 percent of girls reported awareness of such committees.

Girls' perceptions about the engagement of their village Panchayat in girls' education was elicited by probing whether Panchayat members in their village took any initiative in promoting girls' education; for example, talking to parents if their daughters discontinue schooling, and negotiating with schools if facilities are lacking and teachers remain absent. As shown in Figure 2.10, only a small proportion of girls reported the engagement of Panchayat members in these tasks. Specifically, just 14-16 percent of the surveyed girls believed that Panchayat members talked to parents if their daughter had discontinued schooling. Likewise, just 10-11 percent of the girls thought that Panchayat members would negotiate with the school if their teachers were absent, and a slightly larger proportion reported that Panchayat members would negotiate with schools which lacked facilities (30-31\%).

Figure 2.10: Percentage of girls reporting awareness of SMCs and perceptions about engagement of Panchayat members in promoting girls' education by treatment arms, baseline survey, 2013

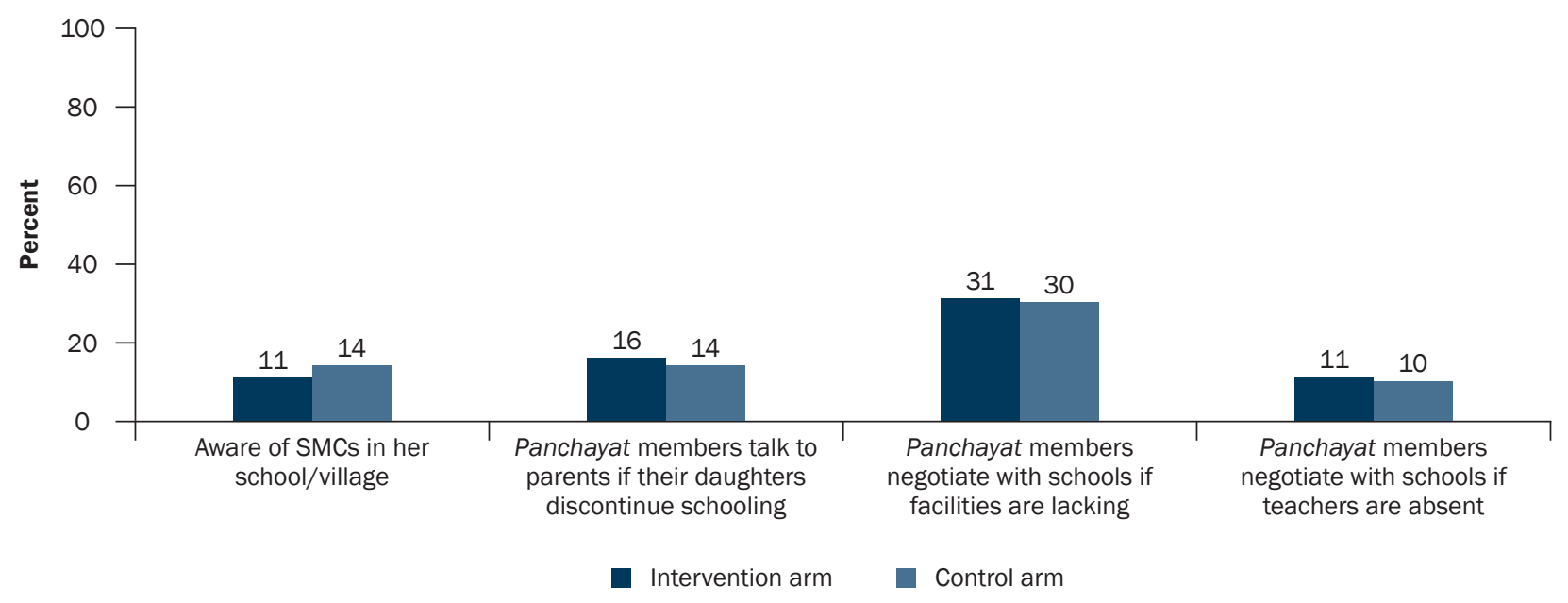

\section{Summary}

Our study findings underscore substantial discontinuation of schooling following primary education, irregular attendance, poor performance and limited agency in matters related to their education among girls studying in Class 8 and Class 9. They also highlight the limited support that girls receive from their parents, their teachers and their communities in overcoming obstacles to schooling as well as learning. Overall, these findings clearly support a focus on enhancing parental and community engagement in girls' secondary schooling, and a need to strengthen ways through which parents and communities may hold school systems and teachers accountable for ensuring more regular teacher and student attendance at school, adequate infrastructure, as well as better quality teaching and improved learning outcomes.

The findings presented in this chapter also show that the intervention and control arms were well balanced in terms of the background characteristics of the girls enrolled in the study as well as in terms of the main and intermediate outcomes that the intervention sought to influence. 


\section{Chapter 3 Project Sankalp}

Recognising the need for identifying feasible and effective intervention strategies to engage parents and communities to promote secondary education for girls, the Population Council, in partnership with CHETNA, MV Foundation, Awaaz.De and Navjeevan Trust, implemented a pilot intervention, Project Sankalp, in rural areas of Surendranagar district in Gujarat. The Population Council was responsible for designing, monitoring and evaluating the pilot intervention, while CHETNA and the Navjeevan Trust were responsible for implementing the intervention strategies. MV Foundation and Awaaz.De provided technical support for community mobilisation activities, and for developing and running the IVRS, respectively.

In this chapter, we first describe the design and objectives of Project Sankalp as originally conceived. Drawing on project monitoring data, we then discuss its implementation, including the challenges we faced in adhering to the full multifaceted design in intervention clusters. We conclude with insights gained in the field and implications for future intervention designs.

\section{Objectives and design of Project Sankalp}

The goal of Project Sankalp was to improve adolescent girls' transition to and retention in secondary school as well as their learning outcomes by building parental and community engagement in and accountability for secondary education. Specifically, the objectives of the project were:

- to raise awareness among adolescent girls, their parents and other community members about the economic and social returns to investments in secondary education for girls and strengthen parental commitment to the secondary education of their daughters;

- to provide parents with information and support in overcoming bureaucratic and logistical barriers that prevent many girls from pursuing secondary education; and

- to enhance communication and interaction between girls, their parents and their teachers to enable more accountability for girls' education.

Project Sankalp focused on several categories of stakeholders in the study villages of Surendranagar district. Given that the steepest decline in school completion occurs between the last year of primary school (Class 8) and the first year of secondary school (Class 9), and that our pilot intervention sought to engage parents and communities to promote girls' secondary education, it primarily targeted girls attending these classes, their parents, members of SMCs and community members, in general. It also targeted, albeit in a limited way, teachers of primary and secondary schools in the study villages.

The intervention activities of the project were launched in October 2013 (the fourth month of the academic year 2013-14) and completed in December 2015 (the sixth month of the academic year 2014-15).

A number of strategies were originally proposed to reach out to the target groups, as summarised in Table 3.1 and described below.

One of the major mechanisms through which Project Sankalp sought to engage parents and communities was by strengthening the capacity of SMC members and supporting them to reach out to parents, teachers, other influential adults and adolescent girls in their village. As mentioned in Chapter 2, the SMCs ${ }^{8}$ are statutory bodies established by the government to promote enrollment, retention and achievement of children in primary schools ${ }^{9}$ and to make schools effective. The activities proposed for strengthening the capacity of SMC members included: (1) meeting SMC members personally and sharing information about the goal, objectives and activities of Project Sankalp;

\footnotetext{
${ }^{8}$ The SMC typically consists of 12 members, of whom nine members are expected to be parents of the children attending that school.

${ }^{9}$ Although SMCs are proposed to be constituted in secondary schools under the Rashtriya Madhyamik Shiksha Abhiyan, such committees had not been established in secondary schools during the project period.
} 
(2) organising training workshops to orient SMC members about their roles and responsibilities as members of SMCs, the educational situation of girls in their communities and factors that inhibit girls from continuing schooling, the importance of motivating parents to support their daughters' secondary education and the approaches that they could use to do so, as well as to develop action plans for the SMCs; and (3) meeting SMC members once a month to motivate them to carry out activities to promote girls' secondary education in their respective villages. We note that the project proposed to train five members from each of the SMCs in its intervention villages. The SMC members, thus oriented, were expected to conduct regular meetings of their SMC and reach out to parents, teachers, other influential adults and adolescent girls in their village by meeting them individually as and when opportunities arose, and organising villagewide campaigns, including public pledges, to support girls' education, generally, as well as to promote the completion of and achievement in secondary education among adolescent girls, in particular.

A second channel through which Project Sankalp sought to raise awareness about the importance of girls' secondary education was through the formation of AGGs in the intervention villages, and supporting them to act as change agents to promote secondary education for girls in their villages. The members of AGGs were girls residing in the intervention villages and attending Class 7, Class 8 and Class 9 at the time of rolling out the activities of the project. The activities planned by the project to help AGG members to advocate girls' secondary education included organising a one-day training workshop for members and meeting them once or twice a month to support them to undertake a range of promotional activities at the village level. The training workshop sought to orient AGG members about the current educational scenario, the social factors affecting the education of adolescent girls, the provisions of the Right to Education Act, and the entitlements that they could access from their school to facilitate their schooling. It also sought to help them to develop such life skills as communication skills, negotiation skills and decision-making skills, as also to work out individual action plans to realise their educational aspirations. Girls who had completed Class 10 were invited to these workshops to share their experiences with AGG members. The AGG members, thus enrolled and oriented, were expected to hold group meetings once a month as well as undertake such activities to promote girls' secondary education as girl-to-girl campaigns, meetings with parents of other adolescent girls and SMC members, villagewide campaigns, including cycle rallies and street dramas, and the distribution of informational materials.

Establishing an easy-to-use IVRS to improve channels of communication between adolescent girls and their parents on the one hand, and their schools on the other, was yet another key project initiative. The IVRS was designed to: (1) relay generic messages to all parents on the economic and social returns to investments in girls' secondary education, primary to secondary school transfer procedures, entitlements available to girls from their school and the schedule of examinations; (2) receive voice messages about girls' schooling from parents, SMC members and teachers; and (3) relay feedback messages in response to messages received from parents, SMC members and teachers to the concerned stakeholders, as appropriate.

Another channel through which the project sought to inform communities about girls' educational entitlements and to raise their awareness about the importance of secondary education for girls was (1) by preparing and distributing a booklet on the schemes sponsored by the Education Department and other departments of the Gujarat government that are intended to facilitate girls' enrollment and continuation in school, and (2) developing and disseminating twelve key messages on girls' secondary education through the IVRS and wall posters. The booklet on schemes contained, for each scheme, detailed information about the eligibility criteria, the monetary and non-monetary benefits offered and the documents that the girl and her family need to furnish in order to avail of the benefits of the scheme. The twelve messages sought to impress upon parents the social and economic returns to investing in the secondary education of their daughters; the importance of sending their daughters to school on time and regularly; parental roles and responsibilities in enabling their daughters to realise their aspirations, including educational aspirations; the importance of completing secondary or higher education before getting their daughters married; the importance of parent-child communication and parent-teacher interaction, and so on.

Apart from the above-mentioned activities, field-level project staff were required to interact with adolescent girls, their parents, SMC members and teachers either individually or in groups and through villagewide campaigns.

\section{Preparatory activities}

Prior to the initiation of Project Sankalp, the Population Council undertook preparatory activities in Surendranagar, the study district, to understand the realities on the ground. Specifically, the Council mapped all government-run or government-aided primary and secondary schools in the blocks of Surendranagar district, and collected information 


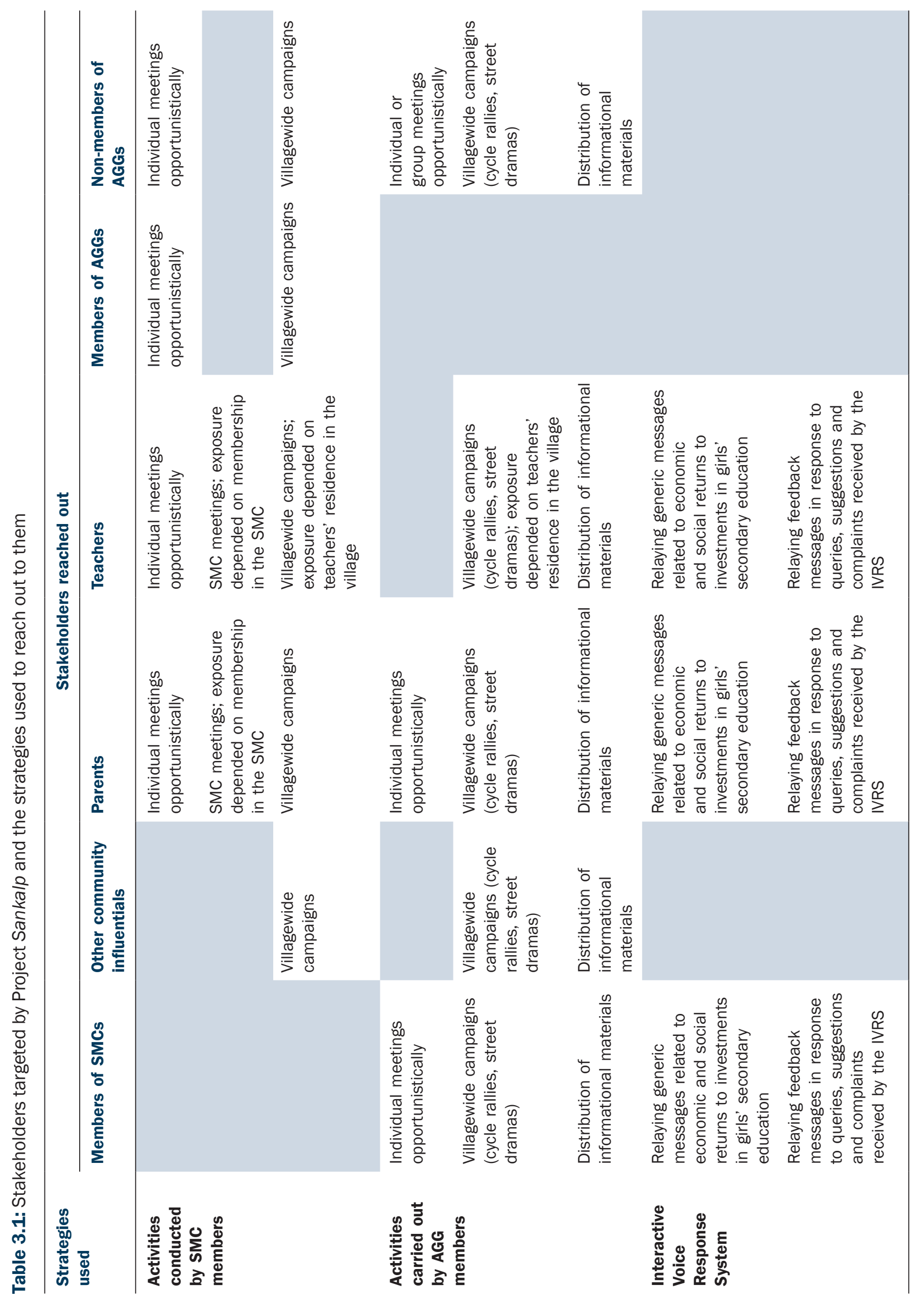




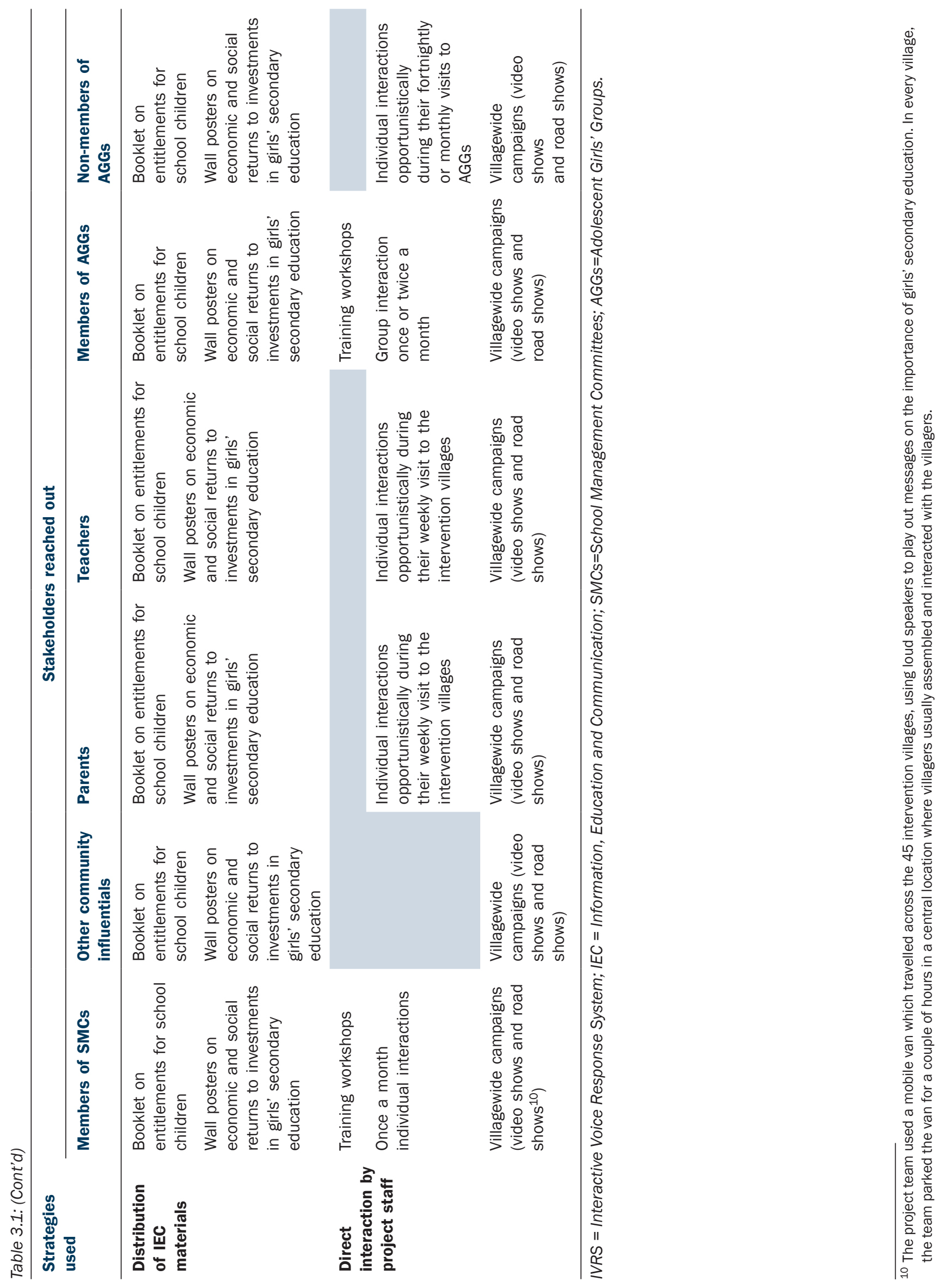


about these schools and the villages located close to these schools. A total of 159 villages, 201 primary schools and 41 secondary schools were mapped. The Population Council also conducted focus group discussions with the parents of girls studying in primary and secondary schools to understand the obstacles faced by parents in supporting their daughters to progress to secondary school, and to explore appropriate communications platforms to promote communication between girls, parents, communities and schools. A total of 11 focus group discussions were conducted with parents; insights from these focus group discussions were used to inform the baseline instruments and the intervention design, including the randomisation of clusters into intervention and control arms.

CHETNA undertook several preparatory activities to build community and government acceptance of Project Sankalp. CHETNA staff held several meetings with district and state officials of the Departments of Primary and Secondary Education to seek their permission for implementing the project. They also collated information about girls' education schemes run by various state government departments, including the Education, Social Welfare and Local Selfgovernment Departments, and prepared a booklet on the entitlements provided by schools to promote girls' education. Similarly, CHETNA and Navjeevan Trust staff visited primary and secondary schools to better understand the status of SMCs, and prepared a list of primary and secondary schools along with the phone numbers of the school, and its principal and SMC members. They met the SMC members individually and informed them about the project. They also made individual household visits to inform parents and girls about project activities, and prepared a list of girls attending Class 7 to Class 9 and the phone numbers of their parents or guardians. Finally, a bilingual brochure in Gujarati and English was developed jointly by the Population Council and CHETNA that sought to introduce Project Sankalp to the intervention communities, including key stakeholders in the State Education Department.

During the preparatory phase, considerable efforts were made by CHETNA and Navjeevan Trust to identify educated and articulate young women and men residing in the intervention district who could be recruited as project staff, and to build staff capacity. An initial three-day training programme focused on orienting newly-recruited project staff about the goal and various components of the project, their roles and responsibilities and the monthly monitoring formats, as well as on building their skills with a focus on communication and negotiation skills and skills for mobilising parents and communities. During the course of the project, staff from CHETNA and the Population Council made several monitoring visits, interacted with field staff and gave them useful tips for improving project implementation. Likewise, Awaaz.De helped CHETNA staff to set up the IVRS and oriented them in operating the system.

The Population Council staff prepared formats for monitoring the implementation of project activities on a monthly basis, and oriented project staff from both CHETNA and Navjeevan Trust in filling up the formats.

\section{Implementation of Project Sankalp}

Drawing on project monitoring data, we describe the implementation of Project Sankalp in the sub-sections below.

\section{Capacity building of SMCs and activities carried out by SMC members}

Although all primary schools ${ }^{11}$ in the intervention villages had constituted SMCs, many SMCs fell short of their stipulated strength of 12 members. Therefore, at the start of Project Sankalp, project staff established contacts with some 456 members from 53 SMCs across the 45 intervention villages; this worked out to 72 percent of the stipulated number of SMC members as per government guidelines. As seen in Table 3.2, which summarises monitoring data on the activities of both project staff and SMC members, this percentage varied across clusters, ranging from 51 percent to 95 percent of the stipulated number of SMC members. We note that several of these members were, in fact, not even aware that they had been nominated as SMC members until project staff so informed them. A few months into the project, several of these members were replaced by new members and, as a result, project staff established contacts with an additional 315 members. Over the course of the project, therefore, project staff had interacted with a total of 771 SMC members.

Capacity building of SMC members was achieved through a total of 20 training workshops organised during the first, second and fourth quarters of the project. A total of 343 SMC members, which translated into 44 percent of SMC members with whom project staff had established contact, participated in these workshops. The percentage of SMC members who participated in workshops held during the initial months of the project, varied across clusters, ranging from 17 percent to 61 percent of the stipulated number of SMC members. Of the 343 SMC participants, 91 percent

\footnotetext{
${ }^{11}$ In two primary schools in the intervention villages, SMCs were constituted following the intervention of project staff.
} 
had attended a training workshop once and the remaining nine percent had attended it twice. We note that this was the first time that several SMC members had attended any training workshop, and they assessed them quite positively, as evident from the excerpt below:

My husband initially refused to let me attend the training workshop. He was concerned about losing the Rs. 200 that I would earn, had I gone for work instead of attending the training workshop. I convinced him to allow me to attend the workshop by saying that I will get Rs. 200 from my parents' house and give him. He finally allowed me to attend the workshop. I am now (after attending the workshop) going to tell him that we lost Rs. 200, but I learnt things worth Rs. 1000 in the workshop. [A parent representative of the SMC, project monitoring data]

Following the training workshops, project staff met, on average, three or more SMC members at least once every month in every intervention village.

Project monitoring data on the activities carried out by the SMC members to reach out to parents, teachers, other influential adults and adolescent girls in their village are also summarised in Table 3.2. Findings show that in the nine intervention clusters, SMC meetings were held almost every month (i.e., for 10-11 of the 11 months for which monitoring data were available) in two clusters, following their revitalisation by project staff, and less often (i.e., for 7-9 months) in the remaining clusters. Variation across clusters was observed in the extent to which SMC members carried out such activities as interacting with adolescent girls, their parents, teachers and others in the State Education Department, and organising public campaigns in their villages: thus, available project monitoring data show that SMC members had conducted at least one of these activities almost every month (i.e., for 10 months) in five clusters and less often (i.e., for 7-9 months) in the remaining four clusters. Moreover, the regularity with which

Table 3.2: Activities carried out by project staff for capacity building of SMCs and by SMC members to reach out to selected target groups, project monitoring data

\begin{tabular}{|c|c|c|c|c|c|c|c|c|c|}
\hline \multirow[t]{2}{*}{ Activities } & \multicolumn{9}{|c|}{ Clusters } \\
\hline & C.1 & C. 2 & C.3 & C. 4 & C.5 & C. 6 & C. 7 & C. 8 & C.9 \\
\hline \multicolumn{10}{|l|}{ Activities conducted by project staff } \\
\hline $\begin{array}{l}\text { Establishing contact with SMC members in } \\
\text { the initial months of the project-\% contacts } \\
\text { made of stipulated number of members }\end{array}$ & 51.4 & 85.0 & 95.0 & 86.7 & 58.3 & 51.4 & 52.8 & 86.7 & 76.4 \\
\hline $\begin{array}{l}\text { Capacity building workshops for SMC } \\
\text { members held in the initial months of the } \\
\text { project-\% trained of stipulated number of } \\
\text { members }^{1,2}\end{array}$ & 61.1 & 38.3 & 46.7 & 46.7 & 33.3 & 33.3 & 16.7 & 46.7 & 36.1 \\
\hline
\end{tabular}

Activities conducted by SMC members

\begin{tabular}{|c|c|c|c|c|c|c|c|c|c|}
\hline & \multicolumn{9}{|c|}{ Total number of months ${ }^{3}$ in which the activity was carried out in } \\
\hline & C.1 & C.2 & C.3 & C.4 & C.5 & C. 6 & C.7 & C.8 & C.9 \\
\hline Meetings of SMC members & 9 & 7 & 8 & 8 & 10 & 7 & 8 & 11 & 8 \\
\hline Interaction with adolescent girls & 10 & 9 & 10 & 10 & 9 & 8 & 8 & 9 & 6 \\
\hline Interaction with parents of adolescent girls & 9 & 9 & 9 & 10 & 8 & 7 & 8 & 10 & 6 \\
\hline $\begin{array}{l}\text { Interaction with teachers and officials of the } \\
\text { State Education Department }\end{array}$ & 8 & 8 & 9 & 8 & 8 & 4 & 7 & 8 & 5 \\
\hline Public campaigns, including public pledges & 2 & 0 & 4 & 2 & 1 & 3 & 3 & 4 & 1 \\
\hline At least one village-level activity ${ }^{4}$ & 10 & 9 & 10 & 10 & 10 & 8 & 9 & 10 & 7 \\
\hline
\end{tabular}

Note: ${ }^{1}$ The denominator used for calculating the percentage is the total number of members of the SMCs, based on the stipulated number of 12 members per SMC; ${ }^{2}$ The SMC members with whom project staff established contact and who were trained in the latter part of the project are not shown in the table; ${ }^{3}$ Of the 11 months for which project monitoring data were available; ${ }^{4}$ Activities included are interactions with adolescent girls, their parents and teachers, and officials of the State Education Department, and public campaigns. 
these activities had been undertaken over the course of the project varied by the type of activity in that interactions with adolescent girls, their parents and their teachers had been carried out with greater regularity than villagewide campaigns. For example, interaction with adolescent girls was reported consistently throughout the course of the project, i.e., for 10 months, in three clusters, for eight to nine months in five clusters and for six to seven months in the remaining cluster. Likewise, interaction with the parents of these girls had taken place almost every month (i.e., for 10 months) in two clusters, for eight to nine months in five clusters and for six to seven months in the remaining two clusters, while interaction with teachers was reported for eight to nine months in six clusters and four to seven months in the remaining clusters. In comparison, villagewide campaigns had been organised less frequently-for 3-4 months in four clusters and 1-2 months or not at all in five clusters, for example.

\section{Formation and activities of Adolescent Girls' Groups (AGGs)}

A total of 454 adolescent girls who resided in the intervention villages, and were primarily attending Class 7 and Class 8 , were organised into 45 AGGs, with each group containing a minimum of five girls. We note that a few members were attending Class 9 and Class 10. Prior to organising them into groups, the project staff met the girls and their parents individually, and oriented them about the project and the role expected of them as members of the AGG.

Nine training workshops were organised in which 428 or 94 percent of the AGG members participated. As shown in Table 3.3, which summarises project monitoring data on the activities undertaken by the AGGs to reach out to parents, teachers, other influential adults and adolescent girls in their village, the percentage of AGG members who participated in the workshops varied across clusters, ranging from 28 percent to 53 percent. At these training workshops, all the girls took an oath that they would complete at least their secondary education, and motivate and convince their parents to enable them to do so. Most workshops were organised on weekends and public holidays to ensure maximum participation, without the girls having to miss their regular classes. Several girls found their participation in the training workshop an enriching experience, as the excerpts below show:

Till now, no one in our family has ever asked us what our dreams are or what we want to be in future. Family members have never shown interest in our education. Even we had not thought about how much education we should have or what we should become in the future. Because of the training, we have started thinking for ourselves. [Adolescent girl attending Class 8, project monitoring data]

I am studying in Class 7. I never wanted to study after Class 7 before I attended the AGG's training workshop. When the Didi (meaning 'elder sister' a courteous way of addressing the facilitator) asked about my dream during the training workshop, I thought I should become a teacher. I drew a picture of a teacher. I pasted my drawing on the wall of my house. When my father saw the drawing, he was surprised and asked me whether I really wanted to be a teacher. On that day, my father promised me that he would provide me all the support to make my dream come true. [Adolescent girl attending Class 7, project monitoring data]

Following the training workshops, project staff met with AGG members once a month in each village in the initial months of the project and twice a month thereafter. On average, they met and interacted with five AGG members in a month in each village and supported them to develop action plans, including following up adolescent girls who were irregular at school or did not attend school, interacting with other adolescent girls who were not members of the AGG, supporting adolescent girls who were weak in their studies to the extent possible, and so on.

Project monitoring data on activities carried out by AGG members to reach out to adolescent girls who were not members of the AGG, parents of adolescent girls, SMC members and others in the village are summarised in Table 3.3. Findings suggest that group meetings of AGG members were held almost once a month throughout the project period in eight of the nine clusters.

AGG members also carried out village-level activities almost every month (i.e., for 10-11 months) in just two clusters, for eight to nine months in six clusters and for five months in the remaining cluster (Table 3.3). The most frequent activity was interacting with parents and SMC members; with AGG members reporting interaction with parents of at least some adolescent girls and SMC members for eight to nine months in eight of the nine clusters. Surprisingly, girl-to-girl campaigns were less frequently reported; the AGGs had organised such events consistently for eight or more months in just three clusters. Villagewide campaigns, including cycle rallies and street dramas, had been 
Table 3.3: Activities carried out by project staff for capacity building of AGGs and by AGG members to reach out to selected target groups, project monitoring data

\begin{tabular}{|c|c|c|c|c|c|c|c|c|c|}
\hline \multirow[t]{2}{*}{ Activity } & \multicolumn{9}{|c|}{ Cluster } \\
\hline & C.1 & C.2 & C.3 & C.4 & C.5 & C.6 & C.7 & C.8 & C.9 \\
\hline \multicolumn{10}{|l|}{ Activities conducted by project staff } \\
\hline $\begin{array}{l}\text { AGG members who participated in training } \\
\text { workshops }(\%)^{1}\end{array}$ & 41.3 & 44.0 & 52.5 & 34.2 & 30.9 & 38.5 & 35.7 & 36.4 & 27.6 \\
\hline \multicolumn{10}{|l|}{ Activities conducted by AGG members } \\
\hline & \multicolumn{9}{|c|}{ Total number of months ${ }^{2}$ in which the activity was carried out in } \\
\hline & C.1 & C.2 & C.3 & C.4 & C.5 & C. 6 & C. 7 & C.8 & C.9 \\
\hline Monthly meetings of the AGG & 11 & 11 & 11 & 11 & 11 & 8 & 10 & 11 & 10 \\
\hline Girl-to-girl campaigns & 10 & 3 & 8 & 8 & 0 & 4 & 6 & 1 & 1 \\
\hline $\begin{array}{l}\text { Interaction with parents of adolescent girls or } \\
\text { SMC members }\end{array}$ & 8 & 9 & 9 & 9 & 9 & 8 & 8 & 8 & 4 \\
\hline $\begin{array}{l}\text { Public campaigns, including cycle rallies, } \\
\text { street dramas }\end{array}$ & 1 & 1 & 1 & 2 & 1 & 1 & 1 & 1 & 1 \\
\hline At least one village-level activity ${ }^{3}$ & 10 & 9 & 10 & 9 & 9 & 8 & 8 & 8 & 5 \\
\hline
\end{tabular}

Note: ${ }^{1}$ The denominator used for calculating the percentage is the total number of girls attending Class 7, Class 8 and Class 9 at the time of the baseline household census; ${ }^{2}$ Of the 11 months for which project monitoring data were available; ${ }^{3} \mathrm{Activities}$ included are girl-to-girl campaigns, interaction with parents of adolescent girls and SMC members, and public campaigns.

conducted once or twice in all the clusters. Additionally, AGG members reported distributing informational materials on girls' secondary education to parents and others in the village, and helping project staff in displaying these materials across the village as also in orienting parents in the use of the IVRS.

\section{Operationalisation of the Interactive Voice Response System (IVRS)}

The Population Council worked with Awaaz.De in managing the technical aspects of running the IVRS; with CHETNA, in hosting the channel to promote interaction between parents and teachers; and with CHETNA and Navjeevan Trust, in orienting parents and other stakeholders about the IVRS and motivating them to use it to address their concerns and seek information on girls' secondary education. Staff from Awaaz. De oriented the CHETNA team on the use of the IVRS, helped them develop common prompts which were needed for running the system, and supported the team in installing the software and fine-tuning the messages. A unique phone number was assigned for the IVRS through which messages were relayed and received. The IVRS stored the telephone numbers of the parents of girls studying in Class 7, Class 8 and Class 9, SMC members, teachers and schools in the intervention villages. The system was administered by a dedicated staff member of the project, housed in CHETNA.

In order to receive the message, the recipient of the call was required to pick up her/his phone and listen to the message; she/he was prompted to press a number to indicate whether she/he had listened to the message fully. An additional two calls were made for each message relayed (in case the recipient had not picked up the phone at the first attempt). In order to send a voice message to the system, the caller had to give a missed call to the system number following which, the system would call her/him back and prompt her/him about how to record her/his message on to the system. This procedure had been devised to enable parents, SMC members and teachers to send messages to the system free of cost. Once a message was received, the system administrator at CHETNA prepared an appropriate response message in consultation with other project staff and relayed a feedback message to all or selected stakeholders, as appropriate. The system administrator ensured that no breach of confidentiality of the information relayed through the system took place. The cost of calling in to send messages via the IVRS and relaying messages was borne by the project. 
Prior to making the system operational, project staff personally met the parents, AGG members, SMC members, principals, and primary and secondary school teachers in all the intervention villages and oriented them on the use of the IVRS. An information brochure on the IVRS, depicting pictorially how to access the messages relayed through it and the unique phone number through which parents and other stakeholders could use the system to voice their concerns, was developed and widely distributed. Stickers and labels advertising the IVRS phone number were also designed and posted across the village to allow ready access to the system to all the members of the village.

The CHETNA team worked with the Population Council to develop generic messages to be relayed through the IVRS. These audio-messages were recorded by a group of professionals and, as mentioned earlier, conveyed the social and economic returns to investments in the secondary education of girls, the importance of sending girls to school on time and regularly, parental roles and responsibilities in enabling their daughters to realise their educational aspirations, the importance of completing secondary or higher education before getting the girl married, the importance of parent-child communication and parent-teacher interaction, and so on.

The IVRS became operational in March 2014 that is, by the end of the second quarter of Project Sankalp. Between March 2014 and December 2014, a total of 64,581 calls were made to parents, teachers, SMC members and others. Figure 3.1, which illustrates the percent distribution of calls generated by the IVRS by the type of call made, shows that almost all of these calls (94\%) had been initiated by the system to relay generic messages on girls' secondary education. Calls that were made to receive messages from parents, SMC members, teachers and others, and to relay feedback messages in response to them were few; just one percent and five percent of all calls, respectively, fell into these categories.

Table 3.4 presents the percent distribution of calls made to relay generic messages by recipient status and the audibility of the message received. Findings show that of the total 60,387 calls made to relay generic messages, 75 percent had been sent to parents, 17 percent to SMC members and seven percent to teachers. Findings further suggest that of the calls received by parents, 20 percent had been fully heard, 32 percent had been partially heard, 11 percent had been unattended or disconnected immediately on receiving, and the remaining 36 percent had not been delivered to them because their cell phone was switched off or outside the network coverage area, or the number registered with the system was incorrect or had changed. The percentage of calls that had been fully heard did not differ by the category of the recipient, although somewhat fewer calls to teachers had been fully heard compared to calls to parents or SMC members (15\% versus $20-22 \%$ ).

Figure 3.1: Percent distribution of calls generated by the IVRS by the type of call, project monitoring data

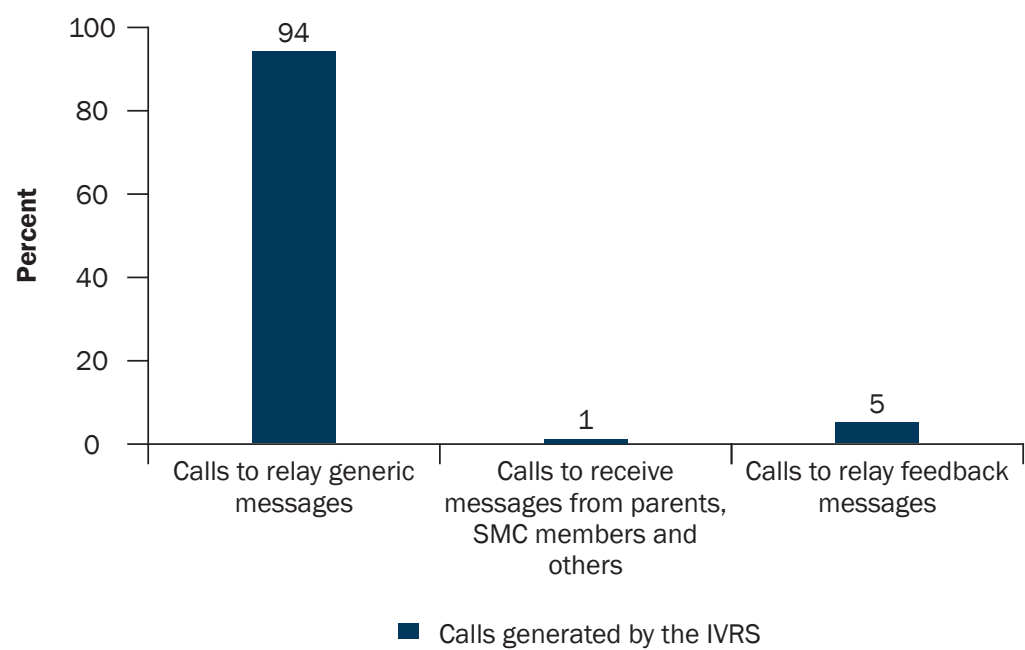

Note: IVRS data pertain to 10 months of the project period.
The percent distribution of calls received by the IVRS host system by the caller's status and the action taken by the caller are given in Table 3.5. Findings show that a total of 684 calls had been received, of which 30 percent had been made by parents, six percent by SMC members and three percent by teachers. Indeed, more than one-half of the calls had been made from phone numbers that were unregistered with the system. Moreover, a message had been recorded in just 29 percent of such calls; instead, in more than one-half of such calls, the caller had just listened to the generic messages stored in the system and in almost one-fifth of such calls, the caller had done nothing whatsoever. The responses/ queries received by the system were related to concerns about safe transportation for girls, the quality of schooling, opportunities available for further education, schemes supported by the government and so on. 
Table 3.4: Percent distribution of calls made to relay generic messages by the status of the recipient and the audibility of the message received, project monitoring data

\begin{tabular}{|c|c|c|c|c|c|c|}
\hline \multirow[t]{2}{*}{ Status of the recipient } & \multirow{2}{*}{$\begin{array}{l}\text { Percentage of } \\
\text { all calls made }\end{array}$} & \multicolumn{4}{|c|}{ Percentage of calls heard ${ }^{4}$} & \multirow[t]{2}{*}{ Number of calls } \\
\hline & & Fully & Partially & Not at all & $\begin{array}{c}\text { Not } \\
\text { delivered }\end{array}$ & \\
\hline Parent $^{1}$ & 75.3 & 20.3 & 32.3 & 11.4 & 36.0 & 45,466 \\
\hline SMC member ${ }^{2}$ & 17.3 & 21.5 & 30.4 & 17.7 & 30.4 & 10,448 \\
\hline Teacher & 6.5 & 14.8 & 27.6 & 12.5 & 45.2 & 3,906 \\
\hline Field-based project staff & 0.5 & 36.8 & 24.6 & 2.5 & 36.1 & 280 \\
\hline Not known & 0.5 & 14.3 & 26.8 & 17.7 & 41.8 & 287 \\
\hline Total calls & 60,387 & 12,205 & 19,083 & 7,555 & 21,544 & 60,387 \\
\hline
\end{tabular}

Note: IVRS data pertain to 10 months of the project period; ${ }^{1}$ Includes 3,003 calls to 95 parents who received the same message more than once due to their additional capacity as a SMC member or a teacher; ${ }^{2}$ Includes 1,154 calls to 63 SMC members who received the same message more than once due to their additional capacity as a teacher; ${ }^{3}$ Percentages shown are column-based; ${ }^{4}$ Percentages shown are row-based.

As evident from Table 3.6 which presents the percent distribution of calls made to relay feedback messages by recipient status and audibility of the feedback message, a total of 3,510 feedback messages had been relayed in response to calls received by the system. Of these calls, the large majority had been made to parents (65\%), followed by SMC members (16\%) and teachers (11\%). Only 25-26 percent of feedback voice messages had been fully heard by the recipient. Again, calls to teachers were less likely than calls to parents and SMC members to have been fully heard (12\% versus $25-26 \%)$.

Table 3.7 summarises the percentage of calls received and sent by the main stakeholders targeted by the IVRS. Findings show that almost all parents, SMC members and teachers received at least one generic message on girls' secondary education. Parents were almost twice as likely as SMC members and three times as likely as teachers to have been reached out to with generic messages; on average, these messages had been sent out to parents 23 times over the course of the project; corresponding averages among SMC members and teachers were 14 and seven, respectively. Findings also suggest very low levels of message audibility; the mean number of times that recipients had fully heard the generic messages ranged from seven times among parents to five times among SMC members and two times among teachers.

Efforts on the part of parents, SMC members and teachers to voice their concerns through the IVRS were also negligible; just 3-5 percent of them had ever sent a voice message to the system. As such, fewer parents, SMC members and teachers had received at least one feedback message from the system in response to queries and concerns about girls' secondary education-77, 50 and 55 percent, respectively. The number of times that these stakeholders had received such messages, on average, was also few-a maximum of two times by parents.

Table 3.5: Percent distribution of calls received by the IVRS host system by the status of the caller and the action taken by the caller, project monitoring data

\begin{tabular}{lccccc}
\hline Status of the caller & $\begin{array}{c}\text { Percentage } \\
\text { of calls }^{\mathbf{1}}\end{array}$ & \multicolumn{3}{c}{ Percent of callers who $\mathbf{~}^{\mathbf{2}}$} & $\begin{array}{c}\text { Number } \\
\text { of calls }\end{array}$ \\
\cline { 3 - 5 } & & $\begin{array}{c}\text { Recorded a } \\
\text { message }\end{array}$ & $\begin{array}{c}\text { Listened to stored } \\
\text { generic messages }\end{array}$ & Did nothing & \\
\hline Parent & 29.7 & 37.4 & 39.4 & 23.3 & 203 \\
SMC member & 6.3 & 41.9 & 39.5 & 18.6 & 43 \\
Teacher & 2.8 & $*$ & - & $*$ & 19 \\
Field-based project staff & 4.8 & 39.4 & 51.5 & 9.1 & 33 \\
Not known & 56.4 & 19.4 & 63.2 & 17.4 & 386 \\
Total calls & $\mathbf{6 8 4}$ & $\mathbf{1 9 9}$ & $\mathbf{3 5 8}$ & $\mathbf{1 2 7}$ & $\mathbf{6 8 4}$ \\
\hline
\end{tabular}

Note: IVRS data pertain to 10 months of the project period; ${ }^{*}$ Percentages based on just 19 cases; ${ }^{1}$ Percentages shown are columnbased; ${ }^{2}$ Percentages shown are row-based. 
Table 3.6: Percent distribution of calls made to relay feedback messages by the status of the recipient and the audibility of the message received, project monitoring data

\begin{tabular}{|c|c|c|c|c|c|c|}
\hline \multirow[t]{2}{*}{ Status of the recipient } & \multirow{2}{*}{$\begin{array}{l}\text { Percentage of } \\
\text { calls made }^{3}\end{array}$} & \multicolumn{4}{|c|}{ Percentage of calls heard 4} & \multirow{2}{*}{$\begin{array}{l}\text { Number of } \\
\text { calls }\end{array}$} \\
\hline & & Fully & Partially & Not at all & Not delivered & \\
\hline Parent ${ }^{1}$ & 64.7 & 26.0 & 29.0 & 27.2 & 17.8 & 2,271 \\
\hline SMC member ${ }^{2}$ & 16.3 & 25.4 & 29.2 & 19.3 & 26.1 & 571 \\
\hline Teacher & 10.9 & 12.3 & 27.0 & 25.7 & 34.9 & 381 \\
\hline Field-based project staff & 1.4 & 30.6 & 28.6 & 28.6 & 12.2 & 49 \\
\hline Not known & 6.8 & 50.4 & 19.3 & 16.4 & 13.9 & 238 \\
\hline Total calls & 3,510 & 917 & 988 & 879 & 726 & 3,510 \\
\hline
\end{tabular}

Note: IVRS data pertain to 10 months of the project period; ${ }^{1}$ Includes 3,003 calls to 95 parents who received the same message more than once due to their additional capacity as a SMC member or a teacher; ${ }^{2}$ Includes 1,154 calls to 63 SMC members who received the same message more than once due to their additional capacity as a teacher; ${ }^{3}$ Percentages shown are column-based; ${ }^{4}$ Percentages shown are row-based.

\section{Development and dissemination of IEC materials}

The booklet on the entitlements provided to girls by their school, prepared by the project, was distributed to adolescent girls, their parents, SMC members, teachers and other key stakeholders in the intervention villages. Additionally, the twelve key messages to promote girls' secondary education prepared by the project team were disseminated through the IVRS as well as through wall posters posted across the intervention villages.

\section{Direct interaction of project staff with adolescent girls and their parents, SMC members and teachers}

Project monitoring data show that once a month, in every intervention village, field staff met an average of five AGG members, 14 adolescent girls who were not members of an AGG, 18 parents of adolescent girls, three SMC members and four teachers. Over the course of the project, they also organised two villagewide campaigns-a video show and a road show-across all the intervention villages.

Table 3.7: Percentage of parents, SMC members and teachers who were reached through the IVRS, project monitoring data

\begin{tabular}{lccc}
\hline Type of voice message & Parents & SMC members & Teachers \\
\hline Generic messages received & & & \\
Received at least one generic message (\%) & 99.8 & 99.4 & 98.6 \\
Mean number of times generic messages were received & 22.7 & 14.4 & 7.1 \\
Mean number of times generic messages were fully heard & 7.2 & 4.5 & 1.9 \\
Messages sent & & & \\
Sent at least one message to the system (\%) & 4.5 & 3.3 & 4.3 \\
Mean number of times messages were sent to the system & 0.1 & 0.4 & 6.4 \\
Feedback messages received & & & 54.5 \\
Received at least one feedback message (\%) & 77.3 & 50.1 & 0.8 \\
Mean number of times feedback messages were received & 1.5 & 0.8 & 0.2 \\
Mean number of times feedback messages were fully heard & 0.5 & 0.3 & $\mathbf{3 0 3}$ \\
Number of recipients of IVRS messages & $\mathbf{1 , 2 8 0}$ & $\mathbf{5 0 5}$ & \\
\hline
\end{tabular}

Note: IVRS data pertain to 10 months of the project period. 


\section{Challenges faced in conducting intervention activities}

We acknowledge several challenges that the project team faced in carrying out intervention activities.

First, empowering the SMCs to act as pressure groups that could help parents overcome bureaucratic and logistical barriers to getting their daughters to finish at least a secondary education, was challenging. We note that several of the SMC members were not, in fact, aware that they had been nominated as SMC members until project staff so informed them, and several had never attended any training workshops before they attended those organised as part of Project Sankalp. Moreover, several SMC members, especially female members, were not proficient in reading and writing and, as such, quite a few expressed inhibitions in actively participating in the training workshops. Besides, the project was not able to ensure that all the SMC members in the intervention villages participated in these workshops. Finally, although the field workers made considerable efforts to actively engage SMC members in promoting girls' secondary education in their communities, several members did not display enthusiasm in doing so.

Second, enabling girls in the AGGs to internalise the messages conveyed through project activities was equally challenging. During the early days of the project, there was limited interaction (once a month) between the field staff and AGG members. Besides, the field staff lacked clarity on how to encourage AGG members to act as change agents. In order to address these challenges, the Project increased the interaction between field staff and AGG members to at least twice a month and, in addition to field workers, Project Coordinators also interacted with AGG members and supported them to develop action plans using participatory learning approaches. Even so, we note that the organisation of girl-to-girl campaigns by AGG members was limited.

Table 3.8: Average number of adolescent girls, their parents, SMC members and teachers with whom project staff interacted in a month, project monitoring data

\begin{tabular}{lc}
\hline Target group & Number of interactions \\
\hline Members of AGGs & 14 \\
Non-members of AGGs & 18 \\
Parents of adolescent girls & 3 \\
SMC members & 4 \\
Teachers & 5 \\
\hline
\end{tabular}

Note: Project monitoring data were available for 11 months only.

Third, we note that individual interactions between field staff and parents were constrained to a certain extent by the non-availability of parents, either because they were away working in the field during the day time, or because of livelihood-related seasonal migration of families. Indeed, seasonal migration of the entire household was common in several intervention villages and posed a huge challenge in reaching the targeted beneficiaries of the project.

Fourth, activities targeting teachers of primary and secondary schools were more limited and opportunistic compared to activities for girls, their parents and SMC members. Moreover, although the project team sought to organise sensitisation workshops for teachers to emphasise the importance of promoting positive classroom dynamics and paying attention to the quality of teaching, we were not able to do so, as the State Education Department did not grant the necessary permission. Similarly, although the project team had tried to identify and train a designated teacher in each primary and secondary school who would be responsible for sending voice messages to the IVRS, the school authorities did not show any interest in it.

Fifth, as noted earlier, in the study villages, utilisation of the IVRS by parents, other community members and teachers to voice their concerns was limited. Likewise, the IVRS was not perceived as a channel to promote parentteacher interaction. 


\section{Summary}

In summary, the activities of Project Sankalp mainly targeted adolescent girls, particularly those studying in Class 8 and Class 9, their parents and SMC members, and in a limited way, teachers of primary and secondary schools. The main channels through which the project sought to engage parents and communities in promoting girls' secondary education comprised revitalising and supporting SMCs to take up villagewide campaigns; forming AGGs and encouraging them to undertake girl-to-girl, girl-to-parents and villagewide campaigns and disseminating informational materials on girls' secondary education; and launching an IVRS for relaying messages on the importance of secondary education for girls as well as for providing a platform to parents, other community members and teachers to voice their concerns on the subject. In addition, project staff also made efforts to reach out to the target groups through opportunistic individual interactions and two villagewide campaigns organised over the course of the project.

Project monitoring data suggest that project activities had succeeded in revitalising the SMCs to a certain extent, making SMC meetings regular at least in some clusters, and promoting interaction between SMC members, on the one hand, and adolescent girls and their parents, on the other. Likewise, the project was successful in creating a cadre of adolescent girls who showed considerable commitment in undertaking activities to promote girls' secondary education. Similarly, through the SMCs, AGGs, IVRS, informational materials and direct interaction with project staff, sizeable proportions of parents of adolescent girls were reached with messages emphasising the importance of girls' secondary education. However, the reach of the project among teachers was limited; this was not surprising as teachers were only a secondary target group of the project. Finally, the IVRS launched by the project did not make the anticipated inroads into the intervention communities. 


\section{Chapter 4 \\ Girls' awareness and experiences of Project Sankalp}

Drawing on data collected from adolescent girls who participated in the endline survey, this chapter describes their awareness and experiences of Project Sankalp. It also presents data on the girls' perceptions of the changes that they observed in their parents and teachers in the period between the baseline and endline surveys.

\section{Girls' awareness of Project Sankalp}

We probed all the adolescent girls, enrolled in both the intervention and control arms, at endline, to assess their awareness of Project Sankalp. Findings indicate that almost all the girls (97\%) in the intervention arm were aware of the project. We note that just two percent of the girls in the control arm also reported that they had heard about the project.

\section{Awareness of and experiences with AGGs}

As described in Chapter 3, one of the major strategies used in Project Sankalp was the formation of AGGs and training the members of these groups to advocate girls' secondary education. In the endline survey, we included a number of questions to capture the survey participants' awareness of and experiences with AGGs. Table 4.1, which summarises these findings, shows that 80 percent of the girls in the intervention arm had heard about the formation of AGGs as part of Project Sankalp. We note that one percent of girls in the control arm also reported so (not shown in the table).

In addition, almost one-half of the surveyed girls (47\%) in the intervention arm reported membership of an AGG when they were attending Class 8 or Class 9. Of those who reported AGG membership, over four-fifths had participated in the training workshop organised by CHETNA for AGG members (Table 4.1), and 81 percent of these participants described it as very useful; the remaining termed it as somewhat useful (not shown in the table). Further, at the time of the endline survey, nearly two-fifths of the girls were still AGG members.

We also probed girls who were not part of an AGG, about their interactions with AGG members. Findings suggest notable interaction between AGG members and non-members (more than that indicated by project monitoring data in Table 3.3). Three-fifths of the girls who had not joined an AGG reported that AGG members had discussed AGG activities with them and/or told them about the discussions that had taken place in their group; one-fourth stated that AGG members had interacted with their parents in the last one year (Table 4.1).

Table 4.1: Percentage of girls reporting awareness of and participation in AGG activities, intervention arm, endline survey, 2014-15

\begin{tabular}{lc}
\hline Participation in AGGs & Percentage \\
\hline Has heard about AGGs formed as part of Project Sankalp & 80.3 \\
Is an AGG member & 47.1 \\
Number of girls in the intervention arm & $\mathbf{7 1 2}$ \\
Has attended a training workshop conducted for AGG members & 84.7 \\
Continued to be an AGG member at the time of the endline survey & 38.4 \\
Number of girls who were AGG members & $\mathbf{3 2 8}$ \\
Perceptions of non-members of AGGs about the activities of AGG members & 61.6 \\
AGG members discussed activities/discussions that had taken place in the AGG with them & 23.4 \\
AGG members had interacted with their parents in the last one year & $\mathbf{2 4 5}$ \\
Number of girls who were not AGG members & \\
\hline
\end{tabular}




\section{Awareness of and experiences with the IVRS}

We further probed the girls enrolled in the intervention arm about their awareness of and experiences, including their perceptions of the experiences of their parents and other family members', with the IVRS run by the project. Table 4.2 presents the percentage of girls in the intervention arm, surveyed at endline, by their awareness of and experiences with the IVRS. Findings indicate that more than four-fifths of the girls (and one percent of girls in the control arm) were aware of the IVRS. However, only six percent of them were able to recall correctly the toll-free number of the IVRS. Two-thirds of all surveyed girls also reported that they had received an orientation, including a demonstration about the use of the IVRS, and as many as three-fifths (60\%) reported that they had encouraged their family members and others to use the system.

Findings about the use of the IVRS show that the parents or other family members of three-fifths of the girls had received at least one voice message from the system (Table 4.2). On average, their parents had received five voice messages in the six months preceding the interview, and 91 percent recalled spontaneously that the messages largely emphasised the importance of secondary education for girls. Another 42 percent of the girls reported that the messages exhorted parents to pay equal attention to educating their sons and daughters. However, not more than seven percent of the girls recalled their parents having received any message concerning the entitlements that they could get from school, their performance or attendance at school, or other day-to-day matters about their schooling.

Table 4.2 also suggests that one-sixth of the surveyed girls in the intervention arm (more than that indicated by project monitoring data in Table 3.7) reported that their parents or other family members had contacted the IVRS to enquire about matters related to girls' secondary education. We note that several messages received by the system were from unregistered telephone numbers (see Table 3.5), and it is possible that some of these messages were from the parents or other family members of the surveyed girls. Girls who reported that their parents had contacted the IVRS indicated that, on average, their parents or others in their family had sent 2.7 voice messages to the system, and spontaneously recalled that these messages were queries about quality schools in which to enrol girls for secondary education and beyond, residential schools for girls, and the level of schooling that girls should attain for realising their career aspirations. Finally, 45 percent of all surveyed girls in the intervention arm reported that they found the system very useful.

\section{Awareness of and participation in girl-to-girl, girl-to-parents and villagewide campaigns}

As described in Chapter 3, girls enrolled in the intervention arm, particularly those who were AGG members, were encouraged to undertake a number of activities to promote girls' secondary education, such as girl-to-girl campaigns, girl-to-parents campaigns and villagewide campaigns, including posting wall posters, and participating in cycle rallies, street dramas and so on. At endline, we probed these girls about their participation in these activities. The findings are summarised in Table 4.3.

Findings show that a notable proportion of these girls had participated in such girl-to-girl and girl-to-parents campaigns to motivate their classmates to pursue their studies or to help them with their studies, as also to identify girls who had dropped out or were irregular at school and to convince their parents to help their daughters to complete secondary school. Specifically, one-third of the girls reported that they had motivated their classmates to continue studies or helped them in their studies, two-fifths had identified girls who had discontinued schooling or had irregular attendance at school, and one-third had talked to parents of such girls (Table 4.3).

Likewise, substantial proportions of the girls in the intervention arm reported awareness of and participation in villagewide campaigns (Table 4.3). For example, 70 percent of the girls reported that public meetings to promote girls' secondary education had taken place in their village in the year preceding the interview. However, somewhat fewer reported that they or their parents had attended such meetings ( $46 \%$ and $28 \%$, respectively). Similarly, onehalf of the girls reported awareness of the public pledging events held in their village in the year preceding their interview, and one-fifth reported that at such meetings, their parents had pledged that they would educate them at least till Class 10.

Girls also reported participation in such activities as posting wall posters on girls' secondary education; shala pravotsava, the enrollment drive promoted by the State Education Department; and street dramas, road shows and cycle rallies. Table 4.3 suggests that between one-sixth and more than one-half of girls had participated in these activities. Finally, about one-tenth of the girls reported that they had voiced their concerns to members of their SMCs. 
Table 4.2: Percentage of girls reporting awareness of and experiences with the IVRS, intervention arm, endline survey, 2014-15

\begin{tabular}{|c|c|}
\hline Awareness of and experiences with the IVRS & Percentage \\
\hline Has heard about the IVRS & 82.5 \\
\hline Is able to recall the toll-free number to contact the IVRS & 5.5 \\
\hline Has received orientation about how the IVRS functions & 65.2 \\
\hline Has encouraged family members and others to use the IVRS & 59.8 \\
\hline Parents or other family members had received any voice message through the IVRS & 62.0 \\
\hline Parents or other family members had sent any voice message to the IVRS & 15.8 \\
\hline Has used the IVRS, through her parents or other family members, to report a problem & 12.9 \\
\hline Reported that the IVRS was very useful & 45.0 \\
\hline Number of girls in the intervention arm & 712 \\
\hline Mean number of voice messages received in the six months preceding the interview ${ }^{1}$ & 4.5 \\
\hline \multicolumn{2}{|l|}{ Content of the voice message received, as recalled spontaneously by girls } \\
\hline Importance of secondary education for girls & 90.9 \\
\hline Paying equal importance to education of sons and daughters & 41.9 \\
\hline Entitlements from school & 6.9 \\
\hline Special events in school, including parent-teacher meetings & 6.8 \\
\hline Information about quality schools and residential schools & 2.6 \\
\hline School examination schedules & 1.2 \\
\hline Information about school transfer procedures & 0.9 \\
\hline Girls' performance and attendance at school & 2.9 \\
\hline Information about safe transportation & 0.4 \\
\hline Don't know & 3.6 \\
\hline $\begin{array}{l}\text { Number of girls whose parents or other family members had received any voice message through } \\
\text { the IVRS }\end{array}$ & 433 \\
\hline $\begin{array}{l}\text { Mean number of voice messages sent by parents or others in the family in the six months preceding } \\
\text { the interview }\end{array}$ & 2.7 \\
\hline \multicolumn{2}{|l|}{ Content of the voice message sent, as recalled spontaneously by girls } \\
\hline $\begin{array}{l}\text { Information about residential schools and quality schools to enrol girls for secondary education and } \\
\text { beyond }\end{array}$ & 43.4 \\
\hline Information about the level of schooling to be completed for realising career aspirations & 13.2 \\
\hline Queries about procuring entitlements or complaints about not having received entitlements & 9.1 \\
\hline Queries about enrolling girls in secondary schools & 7.9 \\
\hline Queries on how to counsel girls who show lack of interest in studies & 6.0 \\
\hline Concerns about lack of transportation facilities & 5.0 \\
\hline Concerns about teachers' practices, school infrastructure & 3.6 \\
\hline Concerns about lack of community support for girls' education & 1.4 \\
\hline Query about the school examination schedule & 1.2 \\
\hline Complaints about the IVRS (i.e., not being able to talk to someone directly) & 20.1 \\
\hline Number of girls whose parents or other family members had sent any voice message to the IVRS & 117 \\
\hline
\end{tabular}

Note: ${ }^{199}$ girls reported that they did not know the number of voice messages received by their parents or others in the family.

\section{Interaction with project staff}

In the endline survey, we asked the adolescent girls in the intervention arm about their interaction as well as their parents' interactions with the staff of Project Sankalp. Findings, summarised in Table 4.4, show that in the year preceding the interview, over four-fifths of the girls had met project staff at least once, and, on average, girls who 
Table 4.3: Percentage of girls reporting awareness of and participation in project activities to promote girls' secondary education, intervention arm, endline survey, 2014-15

\begin{tabular}{lc}
\hline Awareness of and participation in AGG activities & Percentage \\
\hline Has motivated fellow classmates to continue studies or helped with their studies & 32.2 \\
Has identified girls who had discontinued schooling or were irregular at school & 38.8 \\
Has talked to the parents of girls who had discontinued schooling or were irregular at school & 34.3 \\
Is aware of public meetings to promote girls' secondary education held in their village in the year \\
preceding the interview \\
Has attended public meetings to promote girls' secondary education in her village in the year preceding \\
the interview \\
Is aware that her parents attended public meetings to promote girls' secondary education in her village \\
in the year preceding the interview \\
Is aware of public pledging events in her village in which parents promised to educate their daughters \\
Is aware that her parents took a public pledge to educate her at least up to Class 10 \\
Has posted wall posters on girls' secondary education \\
Has participated in the shala pravotsava (enrollment drive promoted by the State Education \\
Department) \\
Has participated in street dramas to promote girls' secondary education \\
Has supported road shows to promote girls' secondary education \\
Has participated in cycle rallies to promote girls' secondary education \\
Has voiced her concerns to SMC members \\
Number of girls
\end{tabular}

had so interacted, had met them four times during the pre-interview year. Fewer girls (64\%) reported an interaction between their parents and project staff in the year preceding the interview; girls whose parents had so interacted had, on average, done so three times in the year preceding the interview.

\section{Girls' perceptions of changes experienced during the inter-survey period}

We posed a few questions to the girls in both the intervention and control arms about any changes that they may have observed in their parents' and teachers' practiceduring the inter-survey period. Findings, presented in Table 4.5, show that girls in the intervention arm were consistently more likely than those in the control arm to report positive changes in their teachers' practices. Specifically, a larger proportion of girls in the intervention than in the control arm reported that compared to the class in which they were attending at the time of baseline survey, the teachers of the class which they were attending at the time of endline survey were more regular (76\% versus $64 \%$ ), taught better (79\% versus $69 \%)$, treated students in a nicer way $(71 \%$ versus $60 \%)$ and were readier to help students with any difficulties encountered in class ( $71 \%$ versus $61 \%)$. We caution that some of these effect may be the result of their shift to a new class; nevertheless, the differences between the intervention and control arms were notable.

Table 4.4: Percentage of girls reporting their own and their parents' interactions with Project Sankalp staff in the year preceding the interview, intervention arm, endline survey, 2014-15

\begin{tabular}{lc}
\hline Interaction with project staff & Percentage \\
\hline Reported an interaction with project staff & 82.3 \\
Reported an interaction between their parents and project staff & 63.8 \\
Number of girls in the intervention arm & $\mathbf{7 1 2}$ \\
Mean number of times project staff interacted with girls & 3.9 \\
Number of girls who reported an interaction with project staff & $\mathbf{5 8 0}$ \\
Mean number of times project staff interacted with parents of girls & 2.7 \\
Number of girls who reported an interaction between their parents and project staff & $\mathbf{4 4 0}$ \\
\hline
\end{tabular}


With regard to changes in their parents' practices vis-a-vis their schooling too, the girls in the intervention arm were somewhat more likely than those in the control arm to report at endline, that compared to the time around the baseline survey, their parents were more attentive to their schoolwork (77\% versus $74 \%$ ) and more committed to helping them complete their schooling (65\% versus 59\%).

Table 4.5: Percentage of girls reporting changes perceived in teachers' and parents' practices with regard to their schooling during the inter-survey period, by treatment arms, endline survey, 2014-15

\begin{tabular}{llc}
\hline $\begin{array}{l}\text { Changes observed during the inter-survey period: compared to baseline, } \\
\text { at endline }\end{array}$ & Intervention Arm & Control Arm \\
\hline Teachers come more regularly & 75.7 & 63.7 \\
Teachers teach better in class & 79.0 & 69.4 \\
Teachers treat students in a nicer way & 70.8 & 60.0 \\
Teachers are readier to help students with difficulties & 76.7 & 61.3 \\
Parents are more attentive to their school work & 64.6 & 73.6 \\
Parents are more committed to helping them complete their schooling & $\mathbf{5 1 3}$ & 58.5 \\
Number of girls who were attending school at the time of the endline survey & $\mathbf{5 9 4}$ \\
\hline
\end{tabular}

\section{Summary}

The endline survey findings presented in this chapter indicate that adolescent girls enrolled in the intervention arm were well aware of project activities: almost all of them had heard about the project in general, four-fifths had heard about AGGs and the IVRS, and two-thirds had heard about villagewide campaigns to promote girls' secondary education.

Girls' participation in project activities was also notable. About one-half of the girls were members of an AGG and of them, almost two-fifths were continuing members at the time of the endline survey. Three-fifths had encouraged their parents and others to use the IVRS and one-eighth had used the IVRS, through their parents or other family members, to report a problem. Additionally, between one-third and two-fifths of the girls had participated in girl-togirl campaigns and girl-to-parents campaigns, and no less than one-half of them had participated in a villagewide campaign to promote girls' secondary education. A majority of the girls also recalled their own as well as their parents' interactions with project staff.

Finally, more girls in the intervention than control arm reported positive changes in their parents' and teachers' practices during the inter-survey period vis-a-vis their schooling. 


\section{Chapter 5}

\section{Effect of Project Sankalp on creating an enabling environment for girls to pursue secondary education}

The theory of change underpinning Project Sankalp emphasises that an enabling environment at the community, family and school levels as well as enhanced aspirations and agency among girls can improve their transition to secondary education, their attendance at school and their learning outcomes. As such, the strategies adopted in Project Sankalp primarily sought to improve community and parental engagement in girl's secondary education and, in a limited way, the school environment. They also sought to influence girls' aspirations and agency in matters related to their schooling. This chapter describes the effect of the project on these intermediate outcomes.

We used cluster summary measures to estimate the effect of Project Sankalp on its intermediate outcomes. To address the potential for detecting an effect that is not present when making multiple comparisons on one dataset (Schochet, 2008), we present descriptive proportions of intermediate outcomes and results of t-tests where the observed difference between intervention and control arms seemed large, that is, 10 percentage points or more.

\section{Effect on girls' aspirations, agency, awareness and utilisation of entitlements, and time use in school-related matters}

As described in the theory of change underpinning Project Sankalp, project strategies were expected to improve girls' educational aspirations, their agency in matters related to their schooling, their awareness and utilisation of the entitlements obtainable from school, and the time they devoted to school-related activities. Findings presented in this section suggest that, for the most part, the activities of our project did not contribute to a significant improvement in these intermediate outcomes.

Figure 5.1 portrays the percentage of girls surveyed at endline, reporting their educational aspirations and agency in school-related matters, by treatment arms. It is evident from the figure that of the five indicators that we used to measure girls' aspirations and agency, only one indicator, namely, their educational aspirations, showed a positive

Figure 5.1: Percentage of girls reporting their educational aspirations and agency in matters related to their schooling by treatment arms, endline survey, 2014-15

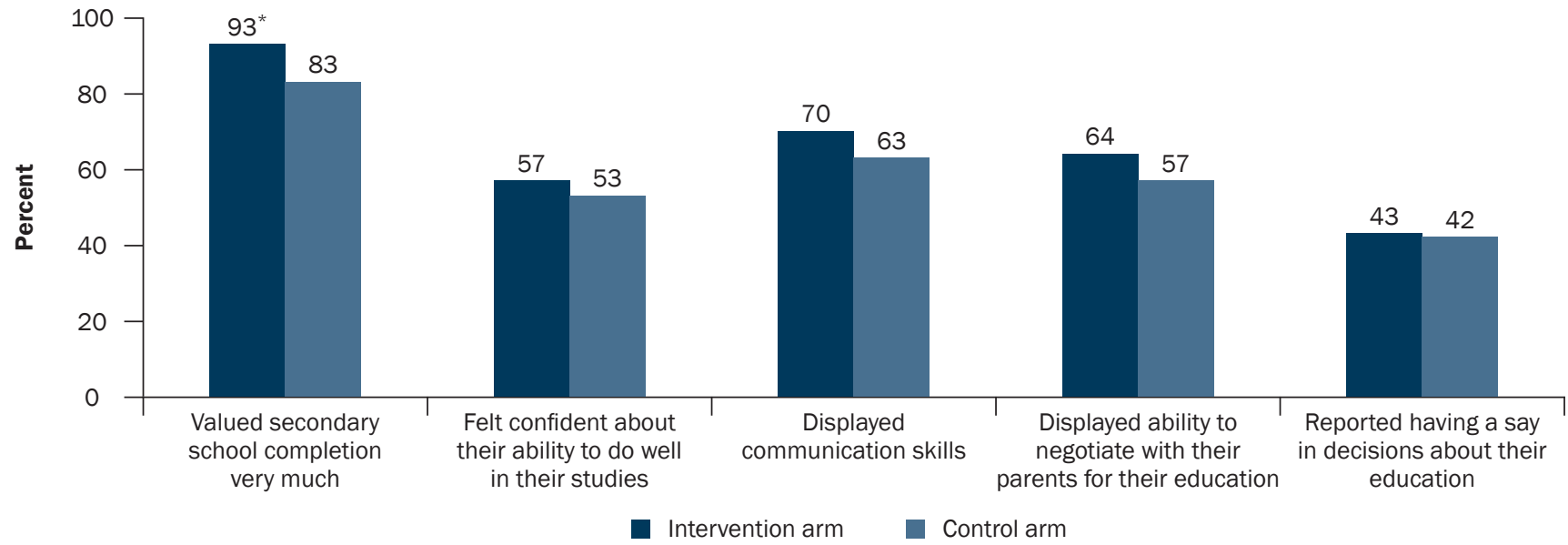

Note: ${ }^{*}$ indicates that the difference between the intervention and control arms was significant at $p<0.05$ in the unpaired t-test. 
and significant effect. At endline, a larger proportion of the girls in the intervention than in the control arm valued completing secondary education (estimated intervention effect of 11 percentage points). The other indicators-girls' confidence in their ability to do well in their studies, communication skills, ability to negotiate with their parents on matters related to their education, and their decision-making role in respect of their education-did not show an effect large enough to be attributable to the project.

Although the project made considerable effort to improve awareness among girls and their parents of the entitlements obtainable from school, including through the widespread distribution of its booklet on entitlements, and through the IVRS and wall posters, endline findings indicate that these activities did not have a significant effect in improving girls' in-depth awareness and utilisation of the entitlements. Figure 5.2 which presents the percentage of girls reporting in-depth awareness and utilisation of scholarship schemes at endline, suggests that although a larger proportion of girls in the intervention than control arm displayed such awareness, as measured by being able to correctly state the eligibility criteria and the amount of money awarded for at least one scholarship and having received a scholarship in the current academic year, these differences were not large enough to be attributable to the project.

Finally, as evident from Figure 5.3, the endline findings indicate that the project had no effect on the amount of time that the girls devoted to school-related activities in that girls in the intervention and control arms spent an equal amount of time on such activities on the last school day they attended prior to the interview (9.2 hours versus 9.0 hours).

Figure 5.3: Average number of hours spent on school-related activities by treatment arms, endline survey, 2014-15

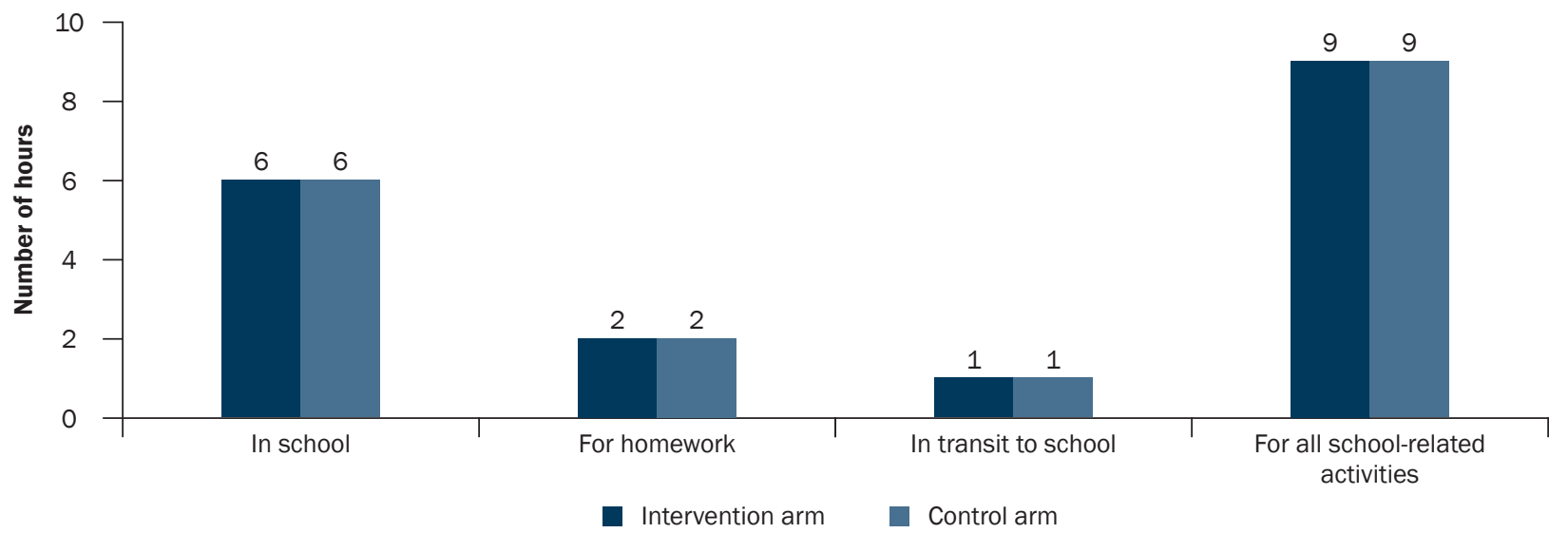

\section{Effect on the school environment}

As described in Chapter 3, the project sought to make the school environment more congenial to girls by working with the school authorities, albeit in a limited way. Moreover, as mentioned in our theory of change, we hypothesised that improvements in the engagement of parents and SMCs in girls' education can make the school environment more girl-friendly. We measured the effect of the project on the school environment in terms of teachers' attendance at school and classroom dynamics.

Figure 5.4 illustrates the percentage of girls surveyed at endline, reporting teacher attendance and classroom dynamics during the pre-interview week, by treatment arms. Findings show that the pilot intervention had no effect 
on improving the school environment of the girls. No difference between intervention and control arms was observed with regard to teacher absenteeism as defined by the absence of at least one teacher on at least one day in the week preceding the interview. Likewise, an equal proportion of girls in the intervention and control arms reported that their teachers provided positive feedback to students during that week. Moreover, although a larger proportion of girls in the intervention than in the control arm reported that their teachers displayed gender egalitarian attitudes in the classroom during the pre-interview week, the difference was not large enough to be attributable to the project. Finally, no difference was observed between the treatment arms in terms of the proportion of girls who experienced corporal punishment or harassment from their teachers in the week preceding the interview.

Figure 5.4: Percentage of girls reporting teacher attendance, and teachers' attitudes and practices in the week preceding the interview by treatment arms, endline survey, 2014-15

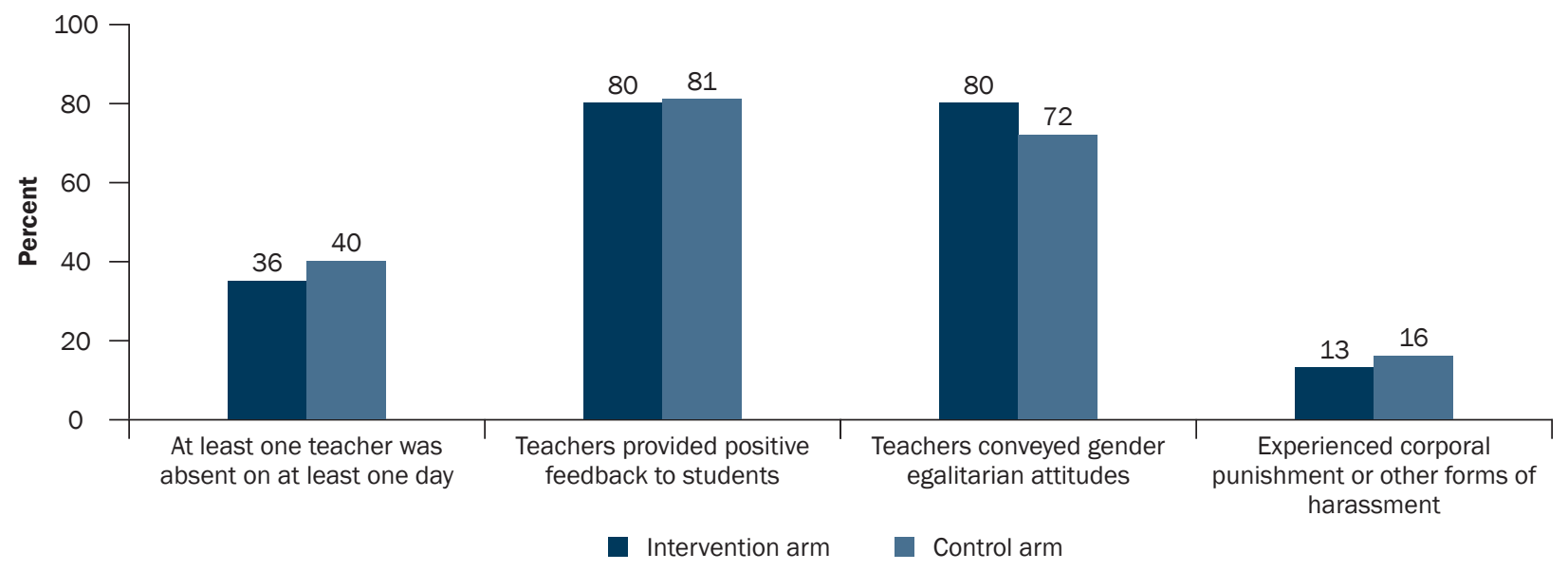

\section{Effect on parental engagement in their daughter's secondary education}

We used a number of indictors to measure the effect of the project on parental engagement in support of their daughter's secondary education, namely, parental appreciation of secondary school completion by daughters, parent-daughter discussion on her studies, parental support to their daughter's education in the form of time spent on her studies, and parental interaction with the authorities of their daughter's school.

Findings presented in Figure 5.5 on the percentage of girls reporting the encouragement received from their parents for their studies, suggest mixed effect of Project Sankalp on parental engagement in support of girls' secondary education. Specifically, the project contributed to improving communication between girls and their parents on their studies: girls in the intervention arm were significantly more likely than those in the control arm to report that their mother and father had talked to them about their studies in the week preceding the interview (estimated intervention effect of 14 percentage points with respect to communication with the mother and father, respectively). However, no effect was observed with regard to the extent to which parents appreciated secondary school completion by the surveyed girls and spent time with them on their studies in the week preceding the interview.

Figure 5.6 which presents indicators of parental interaction with their daughter's school authorities in the month preceding the interview, as reported by the girls at endline, suggests, by and large, a positive effect of Project Sankalp. For example, a larger proportion of girls in the intervention arm than in the control arm reported that their parents had attended a parent-teacher meeting in the month preceding the interview (estimated intervention effect of 10 percentage points). Likewise, girls in the intervention arm were more likely than those in the control arm to report that their parents had discussed their performance with their teachers in the pre-interview month (estimated effect of 10 percentage points).

\section{Effect on community engagement in support of girls' secondary education}

We measured the effect of Project Sankalp on community engagement in support of girls' secondary education from the responses of the surveyed girls to questions on their awareness of SMCs; the interactions of SMC members with the girls, their parents and their schools; the support provided by SMCs in resolving issues related to their secondary 
Figure 5.5: Percentage of girls reporting parental support for their studies in the week preceding the interview by treatment arms, endline survey, 2014-15

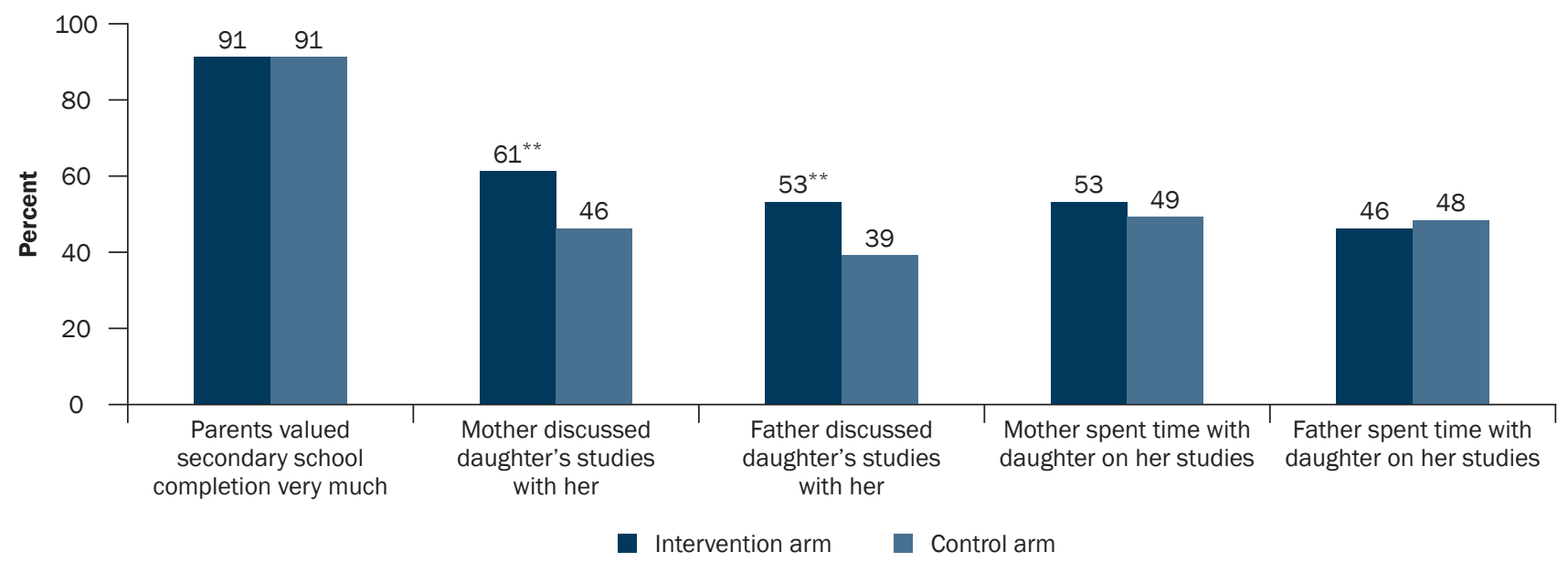

Note: ${ }^{* *}$ indicates that the difference between the intervention and control arms was significant at $p<0.01$ in the unpaired t-test.

education, including that of transportation between home and school, and their perceptions of the involvement of representatives of Panchayats (local administration) in issues concerning girls' secondary schooling.

Findings, presented in Figure 5.7, suggest that the project succeeded in raising girls' awareness of SMCs in that a larger proportion of girls in the intervention than in the control arm were aware of SMCs in their village/school, with an estimated intervention effect of 16 percentage points. Moreover, girls in the intervention arm were more likely than those in the control arm to report that in the six months preceding the interview, SMC members had interacted

Figure 5.6: Percentage of girls reporting parental interaction with school authorities in the month preceding the interview by treatment arms, endline survey, 2014-15

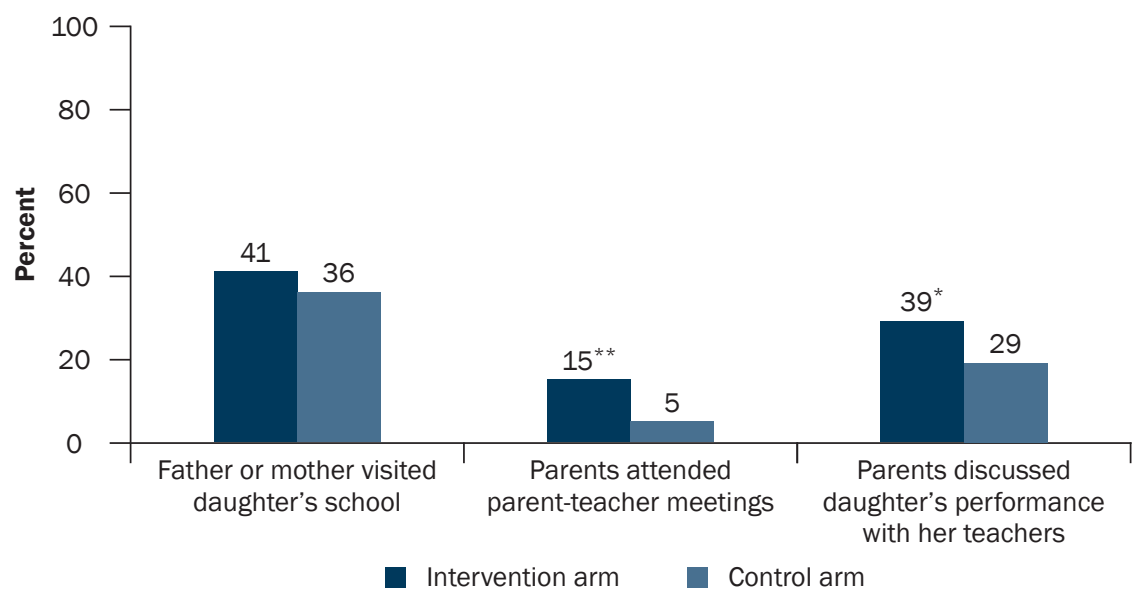

Note: *and ** indicates that the difference between the intervention and control arms was significant at $p<0.05$ and $p<0.01$ respectively, in the unpaired $t$-test. with them, visited their school, tried to resolve school-related problems and arranged transportation between home and school. However, the difference between the study arms was not large enough to attribute this increased support to the project, when the analysis was based on all girls whom we interviewed at endline, regardless of their schooling status at the time of the interview. We note that many of these indicators, for example, SMC members visiting the girls' school and making arrangements for transportation between home and school, showed a large and positive effect when we restricted the analysis to girls who were attending school at the time of the endline analysis (see Appendix 3). 
Figure 5.7: Percentage of girls reporting awareness and engagement of SMCs in their schooling by treatment arms, endline survey, 2014-15

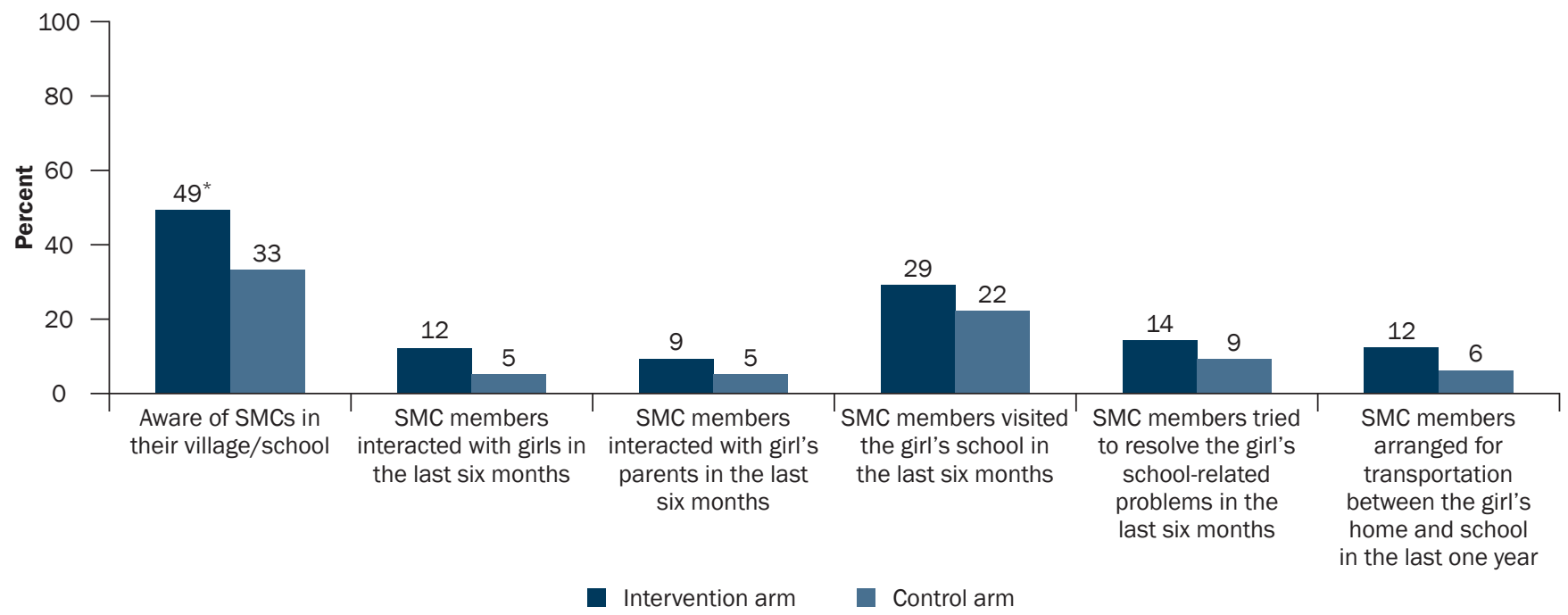

Note: ${ }^{*}$ indicates that the difference between the intervention and control arms was significant at $p<0.05$ in the unpaired t-test.

Figure 5.8: Percentage of girls reporting their perceptions about the involvement of Panchayat members in matters concerning girls' schooling by treatment arms, endline survey, 2014-15

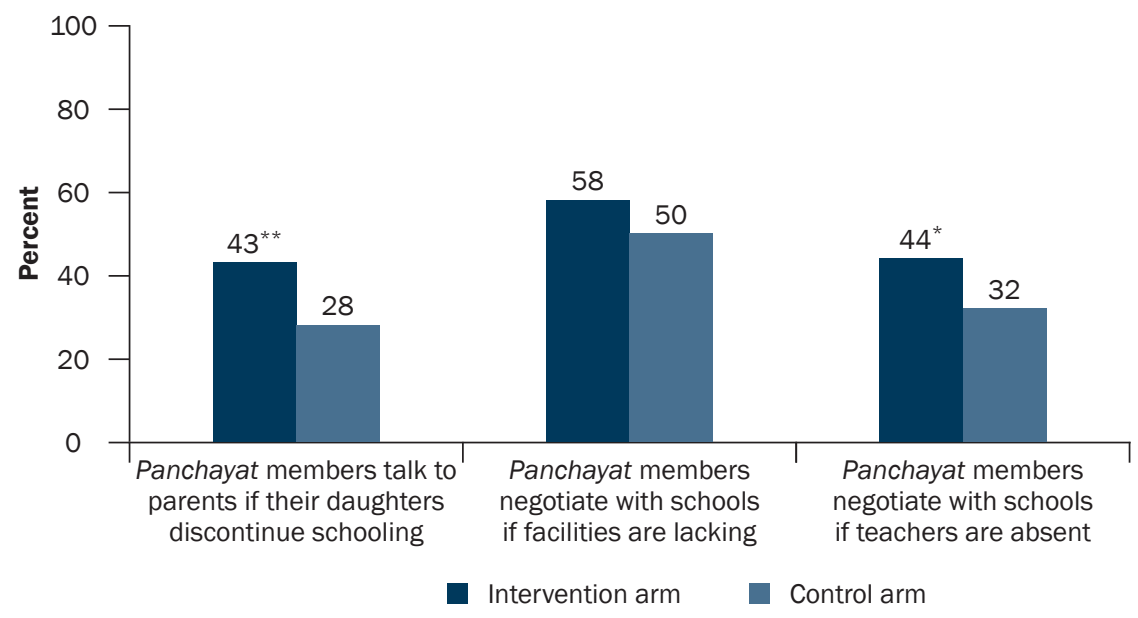

Note: *and ${ }^{* *}$ indicates that the difference between the intervention and control arms was significant at $p<0.05$ and $p<0.01$ respectively, in the unpaired t-test.
However, no intervention effect was observed with regard to interactions between SMC members and the parents of the surveyed girls.

Findings depicted in Figure 5.8 show that the girls' perceptions of the extent of involvement of Panchayat members in matters related to their schooling had increased following the implementation of the project. Girls in the intervention arm were consistently more likely than their counterparts in the control arm to report that Panchayat members talked to parents if their daughters discontinued schooling (estimated effect of 14 percentage points) and negotiated with schools if teachers were absent (estimated effect of 12 percentage points).

\section{Summary}

The findings presented in this chapter on the effect of the project on its intermediary outcomes are mixed. On the positive side, the project had succeeded in raising girls' educational aspirations; in improving parental support for their secondary education as measured by parental discussion with the daughter on her studies and parental interaction with her school authorities; and raising girls' awareness of SMCs. When we restricted the analysis to girls who were enrolled in school at the time of the endline survey, findings showed that the project was successful in increasing SMC members' interactions with school authorities and their involvement in resolving barriers to girls' secondary education; for example, those related to transportation. Girls' perceptions about the involvement of the Panchayat in matters concerning their education also improved. However, there was no evidence of an effect on their agency in matters related to their schooling, their awareness and utilisation of the entitlements obtainable from school, the time devoted by them to school-related activities, the time spent by parents in supporting their education, teacher absenteeism and classroom dynamics. 


\section{Chapter 6}

\section{Effect of Project Sankalp on girls' transition to secondary education, school attendance, and competency}

The main outcomes that Project Sankalp sought to influence were girls' transition to secondary education, their attendance at school and their learning outcomes in Mathematics, and the English and Gujarati languages. In this chapter, we present findings on the effect of the project on these outcomes. We begin with a discussion of the method used for analysing the effect on the main outcomes, followed by a description of the results of the effect analysis.

\section{Method used for effect analysis}

We used data from the girls' survey to analyse the effect of the intervention on such outcomes as girls' attendance at school in the week preceding the interview, their absence from school for one week or more continuously in the last academic year, and their competency in Mathematics, and the English and Gujarati languages. We used data from the household census to assess the effect on the transition to secondary education.

We note that, as described in Chapter 1, the background characteristics of the surveyed girls and the main outcomes among them were balanced between intervention and control arms at baseline, thereby, ruling out the need for adjusting for covariates. Using endline data, we first compared the cluster-level summary measures of the main outcomes and the overall measures of the main outcomes from all the individual values. Table 6.1 presents a comparison of point estimates using cluster summaries and individual values. The two approaches did not yield large differences in estimates, suggesting that cluster size was not associated with the outcomes. Thus, cluster summaries are presented in subsequent results. Moreover, with no reliable estimate of intra-cluster correlation, applying cluster weighting was not appropriate.

Effect estimates were computed as the difference in cluster-level proportions or means, as appropriate. We also examined the distribution of outcomes across 18 clusters for normality, and as outcomes were approximately normally distributed, with no marked skewness in cluster summaries, logarithmic transformation was not applied. With nine clusters in each treatment arm, analysis accounted for clustering through methods based on cluster-level summaries rather than individual-level regression methods (Hayes and Moulton, 2009). We further note that analysis was by intention to treat. We compared unadjusted cluster-level summary measures across arms using the unpaired $\mathrm{t}$-test for the main outcomes. For outcomes that showed evidence of an intervention effect, we applied the t-test with unequal variances to check whether precision had improved.

\section{Effect on transition rates}

Findings presented in Table 6.2 on transition rates from Class 8 to Class 9 and from Class 9 to Class 10, among girls at endline indicate that a substantial decline in school continuation occurred between Class 8 and Class 9 , and that girls were likely to continue to study once enrolled in a secondary school. Table 6.2 which also presents the effect of the project on transition rates, indicates that although the transition rate from Class 8 to Class 9 was slightly higher in the intervention than in the control arm, the difference was not statistically significant and could not be attributed to the project. Moreover, girls in Class 9 were equally likely to transition to Class 10 in both intervention and control arms.

\section{Effect on attendance at school}

Table 6.3 describes the effect of the project on girls' attendance at school. Of the girls who were attending school both at baseline and endline, a larger proportion who were enrolled in the intervention than in the control arm reported that they had attended school on all the days when it was in session in the week preceding the interview, 
Table 6.1: Comparison of cluster summaries with overall means for selected outcome indicators by treatment arms, endline survey, 2014-15

\begin{tabular}{|c|c|c|c|c|c|c|c|}
\hline Outcome indicators & & $\begin{array}{l}\text { Intervention } \\
\text { Arm }\end{array}$ & & & $\begin{array}{c}\text { Control } \\
\text { Arm }\end{array}$ & & $\begin{array}{c}\text { Effect } \\
\text { estimates } \\
\text { (difference } \\
\text { in means) }\end{array}$ \\
\hline Number of clusters & & 9 & & & 9 & & \\
\hline Girls enrolled in cohort & & 739 & & & 819 & & \\
\hline \multirow[t]{2}{*}{ Girls followed-up after 15 months } & & 712 & & & 796 & & \\
\hline & $\mathbf{N}$ & $\begin{array}{l}\text { Proportion/ } \\
\text { mean }\end{array}$ & SD & $\mathbf{N}$ & $\begin{array}{l}\text { Proportion/ } \\
\text { mean }\end{array}$ & (SD) & \\
\hline \multicolumn{8}{|l|}{$\begin{array}{l}\text { Attendance at school in the } \\
\text { week preceding the survey }(\%)\end{array}$} \\
\hline Mean of cluster proportions & & 85.0 & 5.7 & & 74.2 & 16.2 & 0.11 \\
\hline Overall mean proportion & 513 & 85.6 & 35.1 & 594 & 82.2 & 38.3 & 0.03 \\
\hline \multicolumn{8}{|l|}{$\begin{array}{l}\text { Absence from school for one } \\
\text { week or more in the last } \\
\text { academic year }(\%)\end{array}$} \\
\hline Mean of cluster proportions & & 4.9 & 1.3 & & 8.6 & 6.3 & -0.04 \\
\hline Overall mean proportion & 513 & 5.1 & 22.0 & 594 & 6.4 & 24.5 & -0.02 \\
\hline \multicolumn{8}{|l|}{ Mathematics competency ${ }^{* *}$} \\
\hline Mean of cluster summaries & & 29.1 & 7.0 & & 27.5 & 7.8 & 1.6 \\
\hline Overall mean score & 711 & 29.9 & 21.3 & 795 & 29.9 & 20.9 & -0.03 \\
\hline \multicolumn{8}{|l|}{ English language competency ${ }^{* *}$} \\
\hline Mean of cluster summaries & & 18.1 & 6.3 & & 20.0 & 5.9 & -1.82 \\
\hline Overall mean score & 711 & 19.1 & 20.4 & 795 & 22.0 & 21.5 & -2.95 \\
\hline \multicolumn{8}{|l|}{ Gujarati language competency ${ }^{* *}$} \\
\hline Mean of cluster summaries & & 61.9 & 8.1 & & 54.3 & 9.9 & 7.62 \\
\hline Overall mean score & 711 & 63.0 & 25.8 & 795 & 57.2 & 27.1 & 5.76 \\
\hline
\end{tabular}

Note: ${ }^{\star}$ Of girls enrolled in school at baseline and endline; ${ }^{* \star}$ Data on two girls were missing.

Table 6.2: Estimated intervention effect on transition rates, endline survey, 2014-15

\begin{tabular}{lccccc}
\hline Transition rate & Intervention & Control & \multicolumn{3}{c}{ Effect estimates } \\
\cline { 5 - 6 } & Arm & Arm & Mean difference & $\mathbf{9 5 \%}$ Cl & p value \\
\hline $\begin{array}{l}\text { From Class } 8 \text { to } \\
\text { Class } 9\end{array}$ & $\begin{array}{c}75.1 \\
(65.8,84.3)\end{array}$ & $\begin{array}{c}69.6 \\
(59.3,80.0)\end{array}$ & 5.4 & $(-7.3,18.2)$ & 0.38 \\
$\begin{array}{l}\text { From Class } 9 \text { to } \\
\text { Class10 }\end{array}$ & 89.9 & 86.3 & & & \\
\hline
\end{tabular}

Note: Values given in parentheses are 95\% confidence intervals (Cl).

with a mean difference of 11 percentage points; statistical analysis suggests that the intervention effect was mildly significant $(p=0.08)$. Findings also show that girls in the intervention arm were less likely to have missed school continuously for one week or more in the last academic year, although the intervention effect was mildly significant statistically $(p=0.10)$. 
Table 6.3: Estimated intervention effect on attendance at school, endline survey, 2014-15

\begin{tabular}{|c|c|c|c|c|c|}
\hline \multirow[t]{2}{*}{ School attendance } & \multirow{2}{*}{$\begin{array}{l}\text { Intervention } \\
\text { Arm }\end{array}$} & \multirow{2}{*}{$\begin{array}{l}\text { Control } \\
\text { Arm }\end{array}$} & \multicolumn{3}{|c|}{ Effect estimates } \\
\hline & & & Mean difference & $95 \% \mathrm{Cl}$ & p value \\
\hline $\begin{array}{l}\text { Attended all days that the } \\
\text { school was in session in the } \\
\text { week prior to the interview }{ }^{1}\end{array}$ & $\begin{array}{c}85.0 \\
(80.6,89.3)\end{array}$ & $\begin{array}{c}74.2 \\
(61.7,86.6)\end{array}$ & 10.8 & $(-1.3,22.9)$ & 0.08 \\
\hline $\begin{array}{l}\text { Missed school continuously for } \\
\text { one week or more in the last } \\
\text { academic year }{ }^{1}\end{array}$ & $\begin{array}{c}4.9 \\
(3.9,5.9)\end{array}$ & $\begin{array}{c}8.6 \\
(3.8,13.5)\end{array}$ & -3.7 & $(-7.8,2.3)$ & 0.10 \\
\hline
\end{tabular}

Note: Values given in parentheses are 95\% confidence intervals (Cl); ${ }^{1}$ Of girls enrolled in school at baseline and endline.

\section{Effect on learning outcomes}

Findings on learning outcomes in Mathematics, and the English and Gujarati languages, at endline, underscore the poor academic performance of girls in the project area. Findings presented in Table 6.4 which presents these findings, shows no effect of the project on Mathematics and English language competency; the average standardised scores obtained for tests in Mathematics and English were similar in the intervention and control arms. Girls in the intervention arm scored higher in the Gujarati test compared to those in the control arm, with a mean difference of 7.6; statistical analysis, however, suggests that the intervention effect was mildly significant $(p=0.09)$.

Table 6.4: Estimated intervention effect on learning outcomes, endline survey, 2014-15

\begin{tabular}{|c|c|c|c|c|c|}
\hline \multirow[t]{2}{*}{ Learning outcomes } & \multirow{2}{*}{$\begin{array}{l}\text { Intervention } \\
\text { Arm }\end{array}$} & \multirow{2}{*}{$\begin{array}{l}\text { Control } \\
\text { Arm }\end{array}$} & \multicolumn{3}{|c|}{ Effect estimates } \\
\hline & & & $\begin{array}{c}\text { Mean } \\
\text { difference }\end{array}$ & $95 \% \mathrm{CI}$ & p value \\
\hline $\begin{array}{l}\text { Standardised score obtained for } \\
\text { Mathematics competency test }\end{array}$ & $\begin{array}{c}29.08 \\
(23.7,34.5)\end{array}$ & $\begin{array}{c}27.48 \\
(21.5,33.5)\end{array}$ & 1.60 & $(-5.8,9.0)$ & 0.65 \\
\hline $\begin{array}{l}\text { Standardised score obtained for } \\
\text { English competency test }\end{array}$ & $\begin{array}{c}18.14 \\
(13.3,23.0)\end{array}$ & $\begin{array}{c}19.96 \\
(15.5,24.5)\end{array}$ & -1.82 & $(-7.9,4.2)$ & 0.54 \\
\hline $\begin{array}{l}\text { Standardised score obtained for } \\
\text { Gujarati competency test }\end{array}$ & $\begin{array}{c}61.87 \\
(55.6,68.1)\end{array}$ & $\begin{array}{c}54.25 \\
(46.6,61.9)\end{array}$ & 7.62 & $(1.4,16.7)$ & 0.09 \\
\hline
\end{tabular}

Note: Values given in parentheses are 95\% confidence intervals (Cl).

\section{Summary}

In summary, findings of the effect analyses show that Project Sankalp did not have any positive and significant effect on the transition of adolescent girls to secondary education and their learning outcomes in Mathematics and English. At the same time, there was evidence of some effect on improving girls' attendance at school and learning outcomes in Gujarati, although the effect was statistically mildly significant. 


\section{Chapter 7 \\ Summary and conclusions}

This chapter summarises the major findings of Project Sankalp with regard to its acceptability and effectiveness in creating an enabling environment for adolescent girls to pursue secondary education and in helping them transition to secondary education, attend school regularly and perform well in their studies. The chapter also highlights lessons learnt for planning and implementing future programme and research initiatives.

Project Sankalp was undertaken to assess the acceptability and feasibility of a pilot intervention to engage parents and communities to promote girls' secondary education and its effectiveness in improving girls' transition to secondary education, their attendance at school and learning outcomes in Mathematics, and the English and Gujarati languages. The project was implemented over a period of 15 months among adolescent girls attending Class 8 and Class 9, their parents, SMC members, and teachers of primary and secondary schools in 45 villages in rural Surendranagar district of Gujarat. The major strategies adopted by the project included revitalising SMCs and supporting them to take up villagewide campaigns advocating secondary education for girls; forming AGGs and supporting them to undertake girl-to-girl campaigns, girl-to-parents campaigns and villagewide campaigns on girls' secondary education; launching an IVRS for relaying messages on the importance of secondary education for girls as also for providing parents, other community members and teachers an opportunity to voice their concerns about the subject; and disseminating informational materials on girls' secondary education. In addition, project staff also made efforts to reach out to the target groups through opportunistic individual interactions throughout the project period, and villagewide campaigns organised twice over the course of the project.

We used a cluster randomised trial, with nine clusters each in the intervention and control arms to evaluate Project Sankalp. We conducted a baseline assessment, comprising a household census and a survey of all the girls attending Class 8 and Class 9 in the 90 villages comprising the 18 clusters. At the conclusion of our pilot intervention, we conducted an endline assessment, comprising a household census and a follow-up survey of the girls who had participated in the baseline survey. A total of 1,588 girls were interviewed at baseline; of these, 97 percent were successfully re-interviewed at endline. Effect estimates were computed as the difference in cluster-level proportions or means, as appropriate.

Project monitoring data and project experiences reported by the surveyed girls as well as their perceptions of the experiences of their parents and other family members, suggest that revitalising the SMCs, making SMCs hold meetings regularly, and promoting interaction between SMC members on the one hand, and adolescent girls and their parents, on the other, were acceptable and feasible to some extent. Likewise, our experience suggests that adolescent girls can be trained and supported to advocate for increased investments in girls' secondary education even in settings as conservative as the project area. Similarly, through the SMCs, AGGs, IVRS, informational materials and direct interaction with project staff, parents of adolescent girls could be encouraged to take more interest in their daughters' secondary education. At the same time, however, the IVRS launched by the project did not make the anticipated inroads in the intervention communities.

Findings on the effect of the project on its intermediary outcomes are mixed. On the positive side, the project had succeeded in raising girls' educational aspirations; in improving parental support for their secondary education as measured by parental discussion with the daughter on her studies and parental interaction with her school authorities; and raising girls' awareness of SMCs. When we restricted the analysis to girls who were enrolled in school at the time of the endline survey, findings showed that the project was successful in increasing SMC members' interactions with school authorities and their involvement in resolving barriers to girls' secondary education; for example, those related to transportation. Girls' perceptions about the involvement of the Panchayat in matters concerning their education also improved. However, there was no evidence of an effect on their agency in matters related to their schooling, their awareness and utilisation of the entitlements obtainable from school, the time devoted by them to school-related activities, the time spent by parents in supporting their education, teacher absenteeism and classroom dynamics. Findings also suggest some effect (though not statistically strong) on improving girls' attendance at school and their competency in Gujarati, but no effect on transition rates and competency in Mathematics and English. 
Some key lessons are evident. Findings that there was no evidence of any effect of the project on girls' agency in matters concerning their schooling, their awareness and utilisation of the benefits available from school, and the time committed to school-related activities as well as on the time spent by parents in supporting their daughter's education underscore the need for a longer term engagement with girls and their parents than was possible in Project Sankalp, or for more intensive efforts that will enable girls to make effective use of the knowledge and skills they gain through a pilot intervention such as Project Sankalp and, at the same time, give parents more time to translate the messages they receive from the project into real-life practices.

The absence of an effect on transition rates and learning outcomes in Mathematics and English (two of the three subjects tested), suggest that pursuing and successfully completing their secondary education with the basic competencies expected of a secondary school graduate, call for an enabling environment at the school level as well. Given that the project had no effect on teacher absenteeism and classroom dynamics, factors that are more likely to influence girls' transition to secondary education and learning outcomes, our findings further underscore the need for complementing a demand-side model like Sankalp with supply-side interventions that focus more directly on teachers and school infrastructure. 


\section{References}

ASER Centre. 2015. Annual Status of Education Report (Rural) 2014 (Provisional). New Delhi: ASER.

Banerjee, A.V., R. Banerji, E. Duflo et al. 2006. Can informational campaigns spark local participation and improve outcomes: A study of primary education in Uttar Pradesh, India. World Bank Policy Research Working Paper 3967.

Banerjee, A.V., R. Banerji, E. Duflo et al. 2010. "Pitfalls of participatory programs: Evidence from a randomized evaluation in education in India." American Economic Journal: Economic Policy, 2:1, 1-30.

Barrera-Osorio, F., T. Fasih, H.A. Patrinos et al. 2009. Decentralized Decision-making in Schools: The Theory and Evidence on School-based Management. Washington, D.C.: The World Bank.

Bruns, B., D. Filmer and H.A. Patrinos. 2011. Making Schools Work: New Evidence on Accountability Reforms. Washington, D.C.: The World Bank.

Connell, J.P. and A.M. Klem. 2000. "You can get there from here: Using a theory of change approach to plan urban education reform." Journal of Educational and Psychological Consultation, 11(1), 93-120.

Dhaliwal, I., E. Duflo, R. Glennerster et al. 2011. Comparative Cost-Effectiveness Analysis to Inform Policy in Developing Countries: A General Framework with Applications for Education. Accessed on 14 October, 2015 at http://www.povertyactionlab.org/ publication/cost-effectiveness.

Educational Initiatives. 2010. Student Learning Study: Status of Student Learning across 18 States of India in Urban and Rural Schools. Accessed on 14 February, 2016 at http://www.ei-india.com/student-learning-study-an-india-report/

Hayes, R.J. and L.H. Moulton. 2009. Cluster Randomised Trials. Boca Raton, FL: Chapman \& Hall/CRC.

Haynes, N.M., J.P. Comer and M. Hamilton-Lee. 1989a. "The effects of parental involvement on student performance." Educational and Psychological Research, 8(4): 291-299.

Haynes, N.M., J.P. Comer and M. Hamilton-Lee. 1989b. “School climate enhancement through parental involvement." Journal of School Psychology, 27: 87-90.

International Institute for Population Sciences (IIPS) and Population Council. 2010. Youth in India: Situation and Needs, 2006-2007. Mumbai: IIPS.

International Institute for Population Sciences (IIPS). 2010. District Level Household and Facility Survey (DLHS-3), 2007-08: India. Mumbai: IIPS.

Jensen, R. 2010. “The (perceived) returns to education and the demand for schooling." The Quarterly Journal of Economics, 125 (2): 515-48.

Lloyd, C. and J. Young. 2009. New Lessons-the Power of Educating Adolescent Girls: A Girls Count Report on Adolescent Girls. New York: Population Council.

Mehta, A. 2014. Elementary Education in India: Progress towards UEE. Analytical tables 2013-14. Accessed on 14 October, 2015 at http://www.dise.in/AR.htm.

Ministry of Human Resource Development (MOHRD). 2009. Framework for Implementation of Rashtriya Madhyamik Shiksha Abhiyan. New Delhi: MOHRD, Government of India. Accessed on 14 October, 2015 at http://mhrd.gov.in/sites/upload_files/ mhrd/files/upload_document/Framework_Final_RMSA_3.pdf.

Ministry of Human Resource Development (MOHRD). 2011. Working Group Report on Secondary and Vocational Education 12th Five Year Plan, 2012-2017. New Delhi: Department of School Education and Literacy, MOHRD, Government of India.

Ministry of Human Resource Development (MOHRD). 2013. India: Rashtriya Madhyamik Shiksha Abhiyan (RMSA). First Joint Review Mission, January 14-28, 2013. New Delhi: MOHRD, Government of India. Accessed on 14 February, 2016 at http:// rmsaindia.org/administrator/components/com_pdf/pdf/RMSA_1st_JRM_Aide_Memoire.pdf

Ministry of Human Resource Development (MOHRD). 2014. Statistics of School Education 2011-12. New Delhi: MOHRD, Government of India. Accessed on 14 February, 2016 at http://mhrd.gov.in/sites/upload_files/mhrd/files/statistics/ SSE1112.pdf. 
Ministry of Women and Child Development (MOWCD). 2015. Launch of Beti Bachao Beti Padhao Campaign. New Delhi: MOWCD, Government of India. Accessed on 14 October, 2015 at http://wcd.nic.in/BBBPscheme/launch/workshop/ SchemeDocument_2220Dec20201.pdf.

National Council of Educational Research and Training (NCERT). 2012. What Students of Class VIII know and can do: A Summary of India's National Achievement Survey, Class VIII, 2012. New Delhi: NCERT. Accessed on 15 March, 2016 at http://ssa.nic. in/NAS/national-achievement-survey-class-iv/11\%20March\%20National\%20Summary\%20Report\%20NAS\%20Class\%20VIII. pdf/at_download/file.

National University of Educational Planning and Administration, Ministry of Human Resource Development. Government of India. 2014. Education for All: Towards Quality with Equity: India. New Delhi: National University of Educational Planning and Administration.

Nguyen, T. 2008. “Information, Role Models and Perceived Returns to Education: Experimental Evidence from Madagascar.” Massachusetts Institute of Technology Working Paper, Cambridge, MA: MIT.

Office of the Registrar General and Census Commissioner, India. 2012. Houses, Household Amenities and Assets-Communication. New Delhi: Office of the Registrar General and Census Commissioner, India. Accessed on 14 October, 2015 at http://www. censusindia.gov.in/2011census/hlo/Data_sheet/India/Communication.pdf

Office of the Registrar General and Census Commissioner, India. 2013. Primary Census Abstract, Data Highlights, India, Series 1. New Delhi: Office of the Registrar General and Census Commissioner, India. Accessed on 14 October, 2015 at http://www. censusindia.gov.in/2011census/PCA/PCA_Highlights/pca_highlights_file/India/Chapter-3.pdf

Office of the Registrar General and Census Commissioner, India. 2014a. Profiles of Adolescents and Youth in India: Rural-Urban Distribution of Adolescents and Youth Population. New Delhi: Office of the Registrar General and Census Commissioner, India.

Office of the Registrar General and Census Commissioner, India. 2014b. Census of India 2011: A-5 State Primary Census Abstract-2011. New Delhi: Office of the Registrar General and Census Commissioner, India. Accessed on 14 October, 2015 at http://www.censusindia.gov.in/2011census/hlo/pca/pca_pdf/PCA-CRC-2400.pdf.

Office of the Registrar General and Census Commissioner, India. 2014c. Census of India 2011: Five Year Age Group Data-C14 Table. New Delhi: Office of the Registrar General and Census Commissioner, India. Accessed on 14 October, 2015 at http:// www.censusindia.gov.in/2011census/Age_level_Data/India/Age_data.xls.

Office of the Registrar General and Census Commissioner, India. 2015. C-8 Educational Level by Age and Sex for Population 7 and above-2011. New Delhi: Office of the Registrar General and Census Commissioner, India. Accessed at http://www. censusindia.gov.in/2011census/C-series/DDWCT-0000C-08A.xIsx on 14.02.2016.

Pandey, P., S. Goyal and V. Sundararaman. 2009. "Community participation in public schools: impact of information campaigns in three Indian states.” Education Economics, 17 (3): 355-75.

Planning Commission. 2013. Press Note on Poverty Estimates, 2011-12. Accessed on 14 October, 2015 at http:// planningcommission.nic.in/news/pre_pov2307.pdf.

Planning Commission. 2014. Data-book Compiled for Use of Planning Commission. Accessed on 8 May, 2015 at http:// planningcommission.nic.in/data/datatable/data_2312/comp_data2312.pdf

Santhya, K.G. and S.J. Jejeebhoy. 2012. Gender differences in educational attainment among youth in India: An exploratory study of parental aspirations about and investment in young people's schooling. New Delhi: Population Council (unpublished).

Schochet, P.Z. 2008. Guidelines for Multiple Testing in Impact Evaluations of Educational Interventions. Final Report. Mathematica Policy Research, Inc. 
Appendix 1: Selected characteristics of clusters in the intervention and control arms

\begin{tabular}{|c|c|c|c|c|c|c|}
\hline Cluster number & $\begin{array}{c}\text { Number } \\
\text { of } \\
\text { villages }\end{array}$ & $\begin{array}{l}\text { Number of } \\
\text { primary schools } \\
\text { in the cluster } \\
\text { (girls only or } \\
\text { co-educational) }\end{array}$ & $\begin{array}{l}\text { Number of } \\
\text { secondary } \\
\text { schools in the } \\
\text { cluster (girls } \\
\text { only or } \\
\text { co-educational) }\end{array}$ & $\begin{array}{l}\text { Mean distance } \\
\text { between the } \\
\text { primary and } \\
\text { secondary } \\
\text { school } \\
\text { (Kms) }\end{array}$ & $\begin{array}{l}\text { Percent of } \\
\text { households } \\
\text { with a } \\
\text { landline or } \\
\text { mobile phone } \\
\text { connection }\end{array}$ & $\begin{array}{c}\text { Percent of } \\
\text { households } \\
\text { with adolescent } \\
\text { first generation } \\
\text { learners }\end{array}$ \\
\hline 1 & 5 & 6 & 2 & 2.8 & 97.5 & 14.5 \\
\hline 2 & 5 & 5 & 2 & 4.8 & 94.0 & 5.8 \\
\hline 3 & 5 & 5 & 1 & 2.6 & 97.6 & 13.3 \\
\hline 4 & 5 & 5 & 1 & 4.6 & 97.6 & 31.7 \\
\hline 5 & 5 & 6 & 1 & 5.0 & 99.0 & 22.6 \\
\hline 6 & 5 & 7 & 1 & 2.8 & 94.2 & 28.9 \\
\hline 7 & 5 & 7 & 1 & 5.2 & 100.0 & 13.2 \\
\hline 8 & 5 & 5 & 1 & 3.6 & 93.9 & 11.4 \\
\hline 9 & 5 & 5 & 1 & 4.4 & 93.3 & 7.4 \\
\hline Cluster average & 5.0 & 5.7 & 1.2 & 4.0 & 96.3 & 16.5 \\
\hline 10 & 5 & 5 & 1 & 5.8 & 94.4 & 12.3 \\
\hline 11 & 5 & 5 & 1 & 4.4 & 91.3 & 16.3 \\
\hline 12 & 5 & 6 & 1 & 6.8 & 97.8 & 8.5 \\
\hline 13 & 5 & 6 & 1 & 4.0 & 99.1 & 9.5 \\
\hline 14 & 5 & 5 & 2 & 5.0 & 100.0 & 13.6 \\
\hline 15 & 5 & 7 & 1 & 5.2 & 96.5 & 15.7 \\
\hline 16 & 5 & 6 & 1 & 4.0 & 98.4 & 11.4 \\
\hline 17 & 5 & 4 & 1 & 3.2 & 84.9 & 24.3 \\
\hline 18 & 5 & 5 & 1 & 2.9 & 100.0 & 20.9 \\
\hline Cluster average & 5.0 & 5.4 & 1.1 & 4.6 & 95.8 & 14.7 \\
\hline
\end{tabular}


Appendix 2: Details of the household wealth index

Household economic status was measured using a wealth index composed of household asset data on ownership of selected durable goods, including means of transportation, as well as data on access to a number of amenities. The wealth index was constructed by allocating the following scores to a household's reported assets or amenities:

Type of house: 2 for pucca; 1 for semi-pucca; 0 for kachcha.

Agricultural land owned: 4 for more than 10 acres; 3 for 5.1-10.0 acres; 2 for 2.6-5.0 acres; 1 for less than 2.6 acres, or if the household owns some land but does not know how much; 0 for no land.

Irrigated land owned: 1 for any irrigated land; 0 for no land.

Access to a toilet facility: 4 for own toilet; 2 for shared toilet; 0 for no toilet facility.

Cooking fuel used: 2 for liquid petroleum gas, electricity or bio-gas; 1 for kerosene, wood, crop residue, dung cakes, coal or charcoal; 0 for other types of cooking fuel, for example, straw, shrubs or grass.

Access to a drinking water facility: 4 for own piped water, hand-pump or covered well; 3 for own open well; 2 for public or shared piped water, hand-pump or covered well; 1 for public or shared open well; 0 for other sources of drinking water, for example, surface water, tanker/truck or rainwater.

Access to electricity: 3 for electricity; 0 for no electricity.

Ownership of household assets: 4 for car, truck, thresher or tractor; 3 each for motorcycle or scooter, refrigerator, computer/laptop, telephone (landline or mobile), colour television; 2 each for bicycle, electric fan, radio or transistor, black and white television, sewing machine, water pump; 1 for watch or clock; 0 for each of the above items that the household does not possess.

The possible values of the wealth index, so constructed, ranged from 0 to 52. 
Appendix 3: Indicators of community engagement by treatment arms, endline survey, 2014-15

\begin{tabular}{|c|c|c|c|}
\hline Community engagement (\%) & Intervention Arm & Control Arm & Effect estimate \\
\hline $\begin{array}{l}\text { SMC member visited girl's school in the six months } \\
\text { preceding the interview }\end{array}$ & 41.5 & 31.3 & 10.2 \\
\hline $\begin{array}{l}\text { SMC member tried to resolve the girl's school-related } \\
\text { problem in the six months preceding the interview }\end{array}$ & 19.1 & 11.7 & 7.4 \\
\hline $\begin{array}{l}\text { SMC member made arrangements for transportation for } \\
\text { commuting between girl's home and school in the one } \\
\text { year preceding the interview }\end{array}$ & 17.6 & 8.6 & 9.0 \\
\hline
\end{tabular}




\section{Authors}

K G Santhya, Senior Associate, Population Council, New Delhi

A J Francis Zavier, Senior Programme Officer, Population Council, New Delhi

Pallavi Patel, Director, CHETNA, Ahmedabad

Neeta Shah, Programme Officer, CHETNA, Ahmedabad 


\section{List of Investigators}

\section{Household Listers}

Hetashree Brahmbhatt

Sejalben Chaudhari

Sangita Chavda

Vijay Dabhi

Sangita Gamit

Ganpat S Gohel

Sanjay Kumar

Rekha Parmar

Kalpesh Patel

Jinal Patel

Priti Patel

Ankitaben Patel

Megha Ramanuj

Hasmukh Raval

Prakash Raval

Prakash Kumar Raval

Suresh Revar

Kaushik Senma

Naresh Senma

Mukesh Thakor

Jai Shankar Tiwari

Kamla Ben Vasava

Saraswati Vasava

\section{Field Investigators}

Krishna Ben

Kumud K Bhabhor

Saraswati Chaudhari

Sunanda Chaudhari

Ramila Chaudhari

Sejalben Chaudhary

Hetal Chauhan

Komal Choudhary

Pinal Choudhary

Tasnim Faruque

Jyoti Gaur

Bhavna V Herbha

Padma Kamtilal
Nasim Kousar

Pravin Kumar

Pannakumari Lakum

Priti Patel

Sharmistha Patel

Nikita Patel

Dipti Patel

Nita Shankarbhai Patel

Preeti Patel

Rukshana Pathan

Ashwini Rana

Surekha Rathwa

Pathon Ruksana 
Printed at :

Systems Vision

Email:systemsvision@gmail.com 


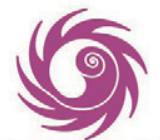

